\title{
WestVirginiaUniversity
}

THE RESEARCH REPOSITORY @ WVU

Graduate Theses, Dissertations, and Problem Reports

2014

\section{Cabaret: A lesson in recovery}

Jane Ryan

West Virginia University

Follow this and additional works at: https://researchrepository.wvu.edu/etd

\section{Recommended Citation}

Ryan, Jane, "Cabaret: A lesson in recovery" (2014). Graduate Theses, Dissertations, and Problem Reports. 507.

https://researchrepository.wvu.edu/etd/507

This Thesis is protected by copyright and/or related rights. It has been brought to you by the The Research Repository @ WVU with permission from the rights-holder(s). You are free to use this Thesis in any way that is permitted by the copyright and related rights legislation that applies to your use. For other uses you must obtain permission from the rights-holder(s) directly, unless additional rights are indicated by a Creative Commons license in the record and/ or on the work itself. This Thesis has been accepted for inclusion in WVU Graduate Theses, Dissertations, and Problem Reports collection by an authorized administrator of The Research Repository @ WVU. For more information, please contact researchrepository@mail.wvu.edu. 


\title{
Cabaret: A Lesson in Recovery
}

\author{
Jane Ryan
}

\author{
Thesis submitted \\ to the School of Theatre \& Dance \\ at West Virginia University
}

\section{In partial fulfillment of the requirement for the degree of Masters in Fine Arts in Scenic Design and Technology}

\author{
Robert Klingelhoefer, Chair \\ Steven Neuenschwander, M.F.A. \\ Lee Blair, M.F.A. \\ Mary McClung, M.F.A.
}

Morgantown, West Virginia

2014

Keywords: Cabaret, Kander and Ebb, Musical, Scenic design, Production process, Design process, Theatrical Budgeting

Copyright 2014 Jane Ryan 


\section{Abstract}

\section{Cabaret: A Lesson in Recovery \\ Jane Ryan}

This thesis chronicles the process of Scenic Designing and Paint Charging for West Virginia University School of Theatre and Dance's 2013 production of Cabaret. It details the entire process including research, design meetings, design and drafting process, construction and technical rehearsals. It discusses how the design changed due to issues such as over budgeting and time management. 


\section{Acknowledgements}

My Parents - Thank you for your undying support and constant encouragement. I would not be where I am today without you. You set the bar high and I hope that I have risen to the challenge. Thank you for exposing me to theater at an early age, fostering my love for history and design over the years, and wholeheartedly accepting my choice to make this my career.

Robert Klingelhoefer - I could not have asked for a better mentor through graduate school. You have truly been a source of inspiration. I feel that I have developed a better eye for design and a better understanding of the craft through your guidance. Thank you for always believing I could do better, push farther, and achieve more even when I didn't.

Steven Neuenschwander - From day one you laid down the gauntlet and I tried to rise to your expectations. Your constant challenging and insistence for perfection were never easy to live with, but I believe I am a better theater technician because of it. Thank you for never giving up on me.

Lee Blair \& Mary McClung - Thank you both for guiding and teaching me as I traveled through this experience.

Candice Day, Tim Thistleton, Joe Dots, \& Savannah Yost - Thank you all for your never ending patience and support through this show and helping me create a piece of art that I am truly proud of. 


\section{Table of Contents}

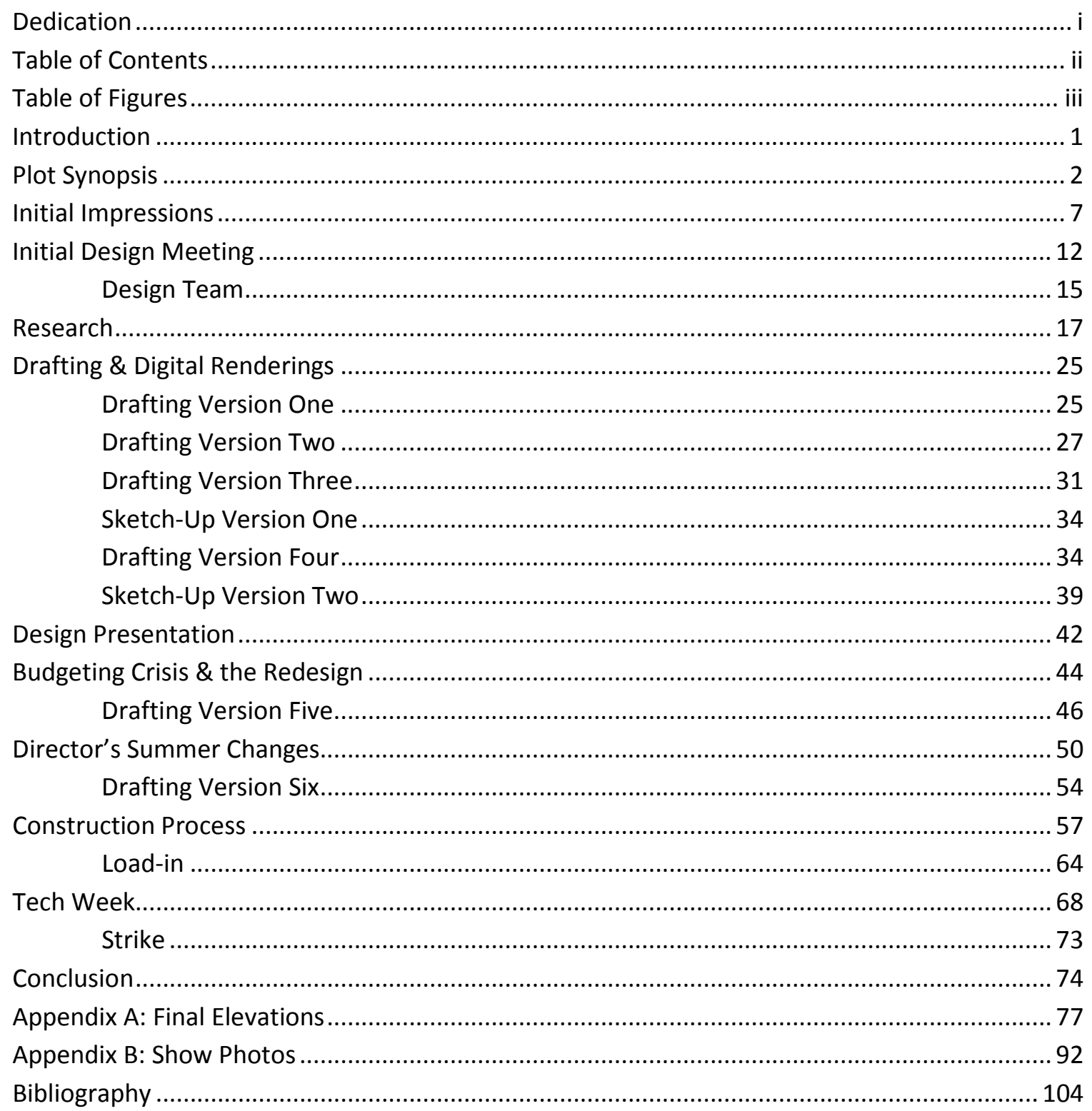




\section{Table of Figures}

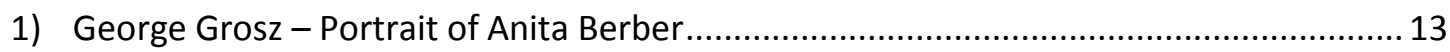

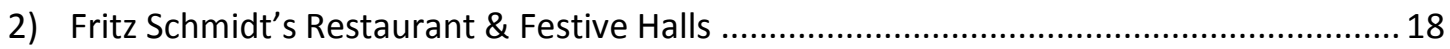

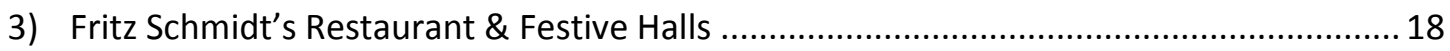

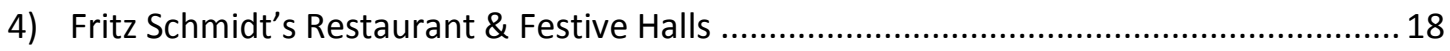

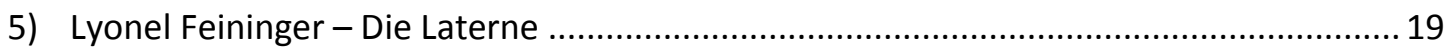

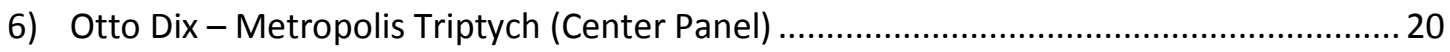

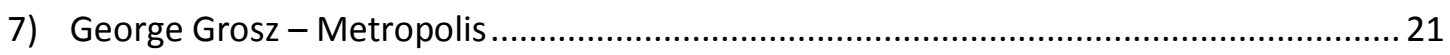

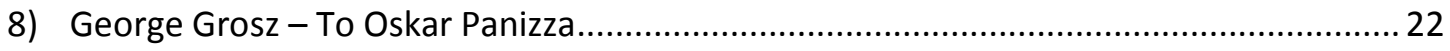

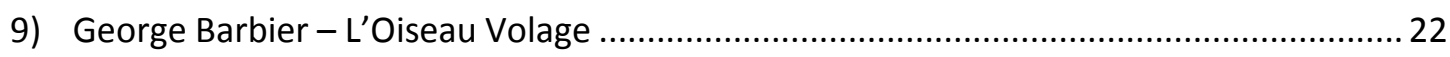

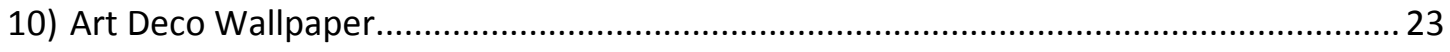

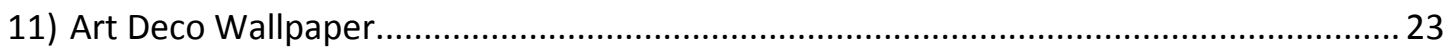

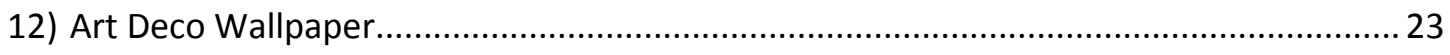

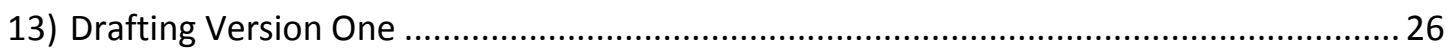

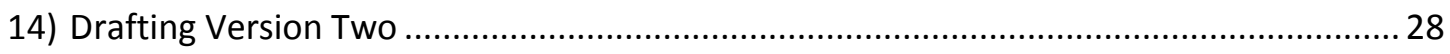

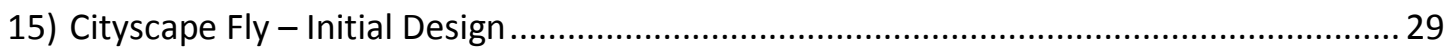

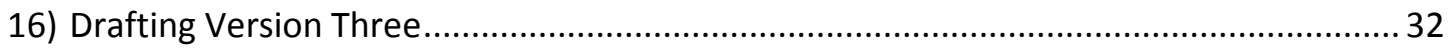

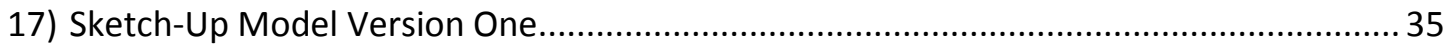

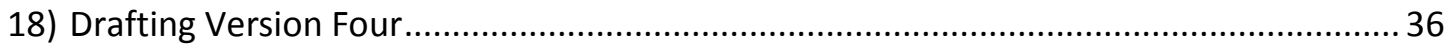

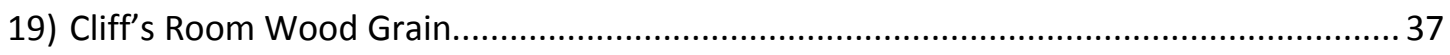

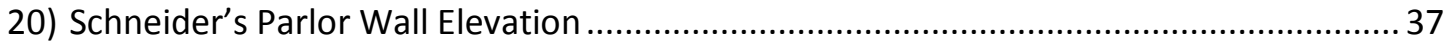

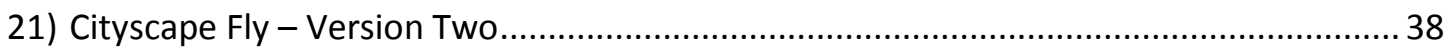

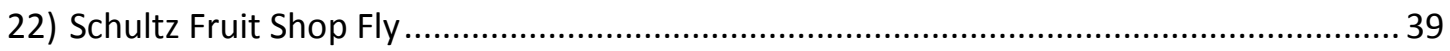

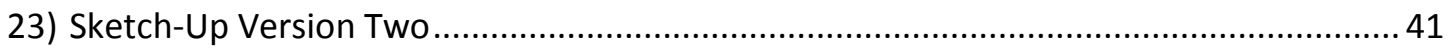

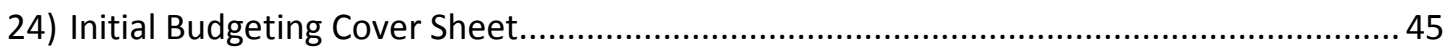

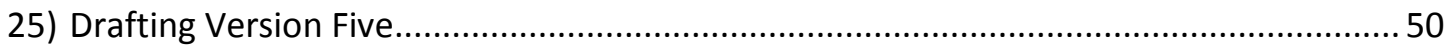

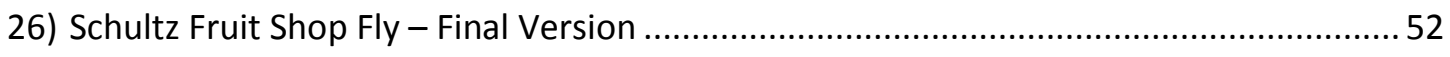

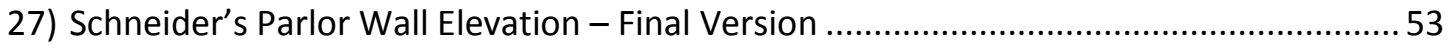

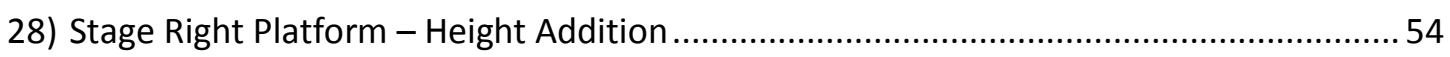

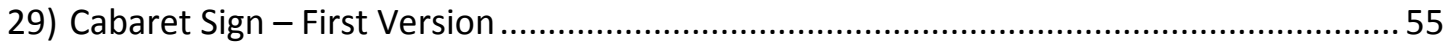

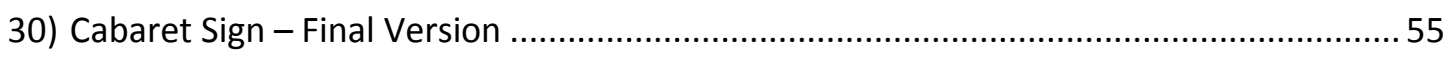

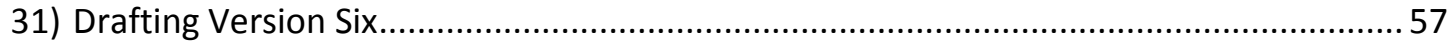

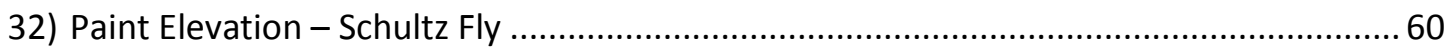

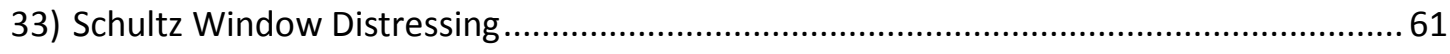

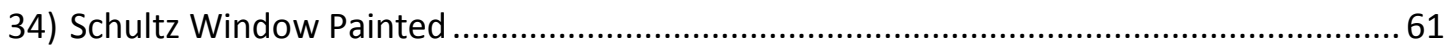

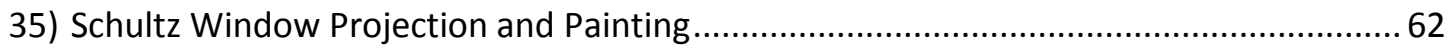

$(i i)$




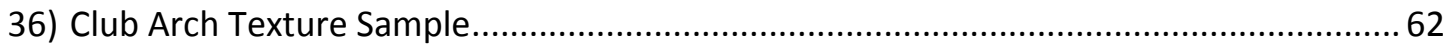

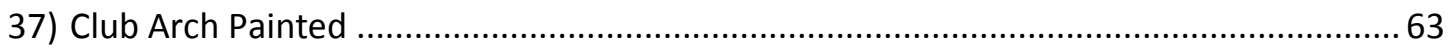

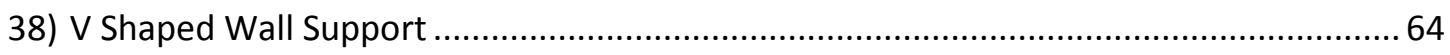

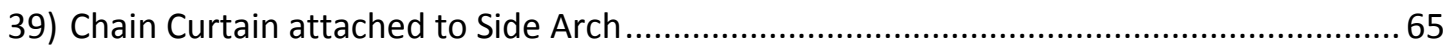

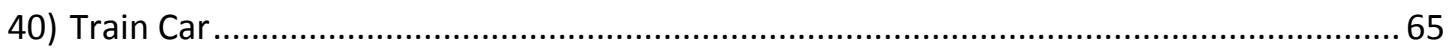

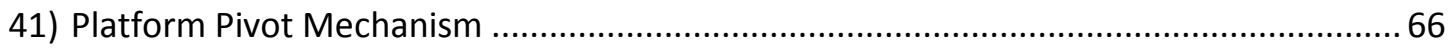

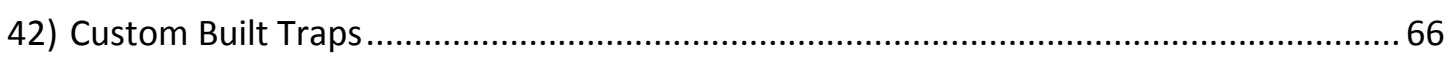

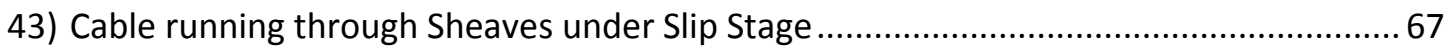

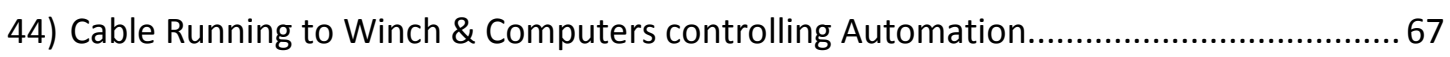

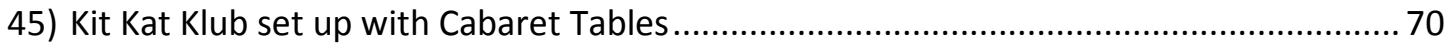

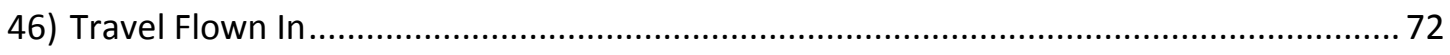

$($ iv $)$




\section{Introduction}

Cabaret, a musical by John Kander and Fred Ebb, was originally performed on Broadway in 1966. Since then there have been countless Broadway revivals, community theater, and high school productions. Most people have seen some version of the show, and The School of Theatre and Dance chose Cabaret for their main stage season in 2013. It was a huge challenge to be handed this musical as my thesis design for graduate school. This was my second design in the Lyle B. Clay Concert Theater, but my first musical and show of this budget and scale for West Virginia University. How was I going to take a musical that was so iconic and create something fresh? Audiences come to a show like Cabaret with preconceived notions and expectations about where the story will take them and the design. I wanted to design scenery that respected previous designs and supported the story, but also was inherently my own creation. I had approximately three months to complete the entire process from initial ideas to fully fleshed-out design.

In this paper I will discuss the process I went through to achieve that completed design. It began with research and meetings with the director to obtain the parameters of the design. I then spent a few weeks drafting and rendering my ideas, going through several versions. Also, I will discuss how I ran into a few obstacles that came up during the design process, and more importantly, recovered from them and kept the design process moving forward.

$\left(\begin{array}{ll}1 \\ 1\end{array}\right)$




\section{Plot Synopsis}

Cabaret is a story about two conflicting love stories and how they are challenged by the changing political situation in Berlin as the Nazi party came to power. These two love stories happen in two opposing worlds. First, there is the world of the Emcee: the seedy underbelly of Berlin. It is full of suspicious characters and daring artists, club owners and show girls, criminals, prostitutes, and drunks. There is magic in this world, not the kind of magic that saves the day or changes people into heroes. There are no dragons to be slain or adventures to experience. It is the kind of magic that can only be found at night, when the neon lights shine and the air has a cool bite. The kind of magic that allows you to meet people you never would have before and do things that you wouldn't do in the daylight. This magic often leads you into the kind of tales that are wonderful to retell later in life.

The play opens as the Emcee welcomes the audience to his world, the Kit Kat Klub, with the song 'Willkommen', gives them a taste of what his club has to offer and introduces the audience to the first love story. Cliff, an uninspired writer, and the romantic lead of the story, comes from the 'real' world. Real is a relative term, but it is used here to describe the world we are all familiar with; a world where there are bills each month, responsibilities to take care of, things are solid, dependable, and normal. Cliff seeks to leave the real world behind and find the inspiration he needs to write his next novel. Cliff arrives in Berlin by train and encounters his

first dodgy character, Ernst. What Ernst does for a living specifically is never spelled out, but

$\left(\begin{array}{l}2 \\ 2\end{array}\right)$


when we meet him he is smuggling items from Paris back into Germany. Cliff watches Ernst conceal his smuggled goods from the immigration officer at the German border and in turn for Cliff's silence Ernst helps him find a place to live in the city. At the recommendation of Ernst, Cliff seeks out the boarding house run by Fraulein Schneider, an elderly, single woman. They briefly haggle over the cost of the flat in the song 'So What', and Cliff is welcomed to Berlin. Seeking adventure and inspiration for his story, Cliff heads out on the town. At the Kit Kat Klub that night, Cliff is introduced to the Emcee and the lovely Sally Bowles. Sally, a young British woman working as a performer at the club, likes the looks of Cliff. She sings the cheeky dance hall number 'Don't Tell Mama', and catches his attention in return. Unfortunately, the man she's currently dating, Max, the club owner, is angered by her wandering eyes and ends their relationship. The next morning, Sally seeks refuge from destitution by calling at Cliff's room and talks him into letting her stay by singing 'Perfectly Marvelous'. The scene shifts back to the club where Emcee comments on their new living arrangement by singing 'Two Ladies', telling the audience he shares his lodging with more than one lover, demonstrating Berlin's acceptance of couples of all persuasions.

Next we are introduced to the second love story of Fraulein Schneider, the boarding house owner, and Herr Schultz, an elderly man residing there. When we meet the pair, there is an obvious flirtation between them. Schultz, who runs a fruit stand, brings Fraulein Schneider a pineapple as a gift and they sing about their growing affection for each other in "It Couldn't Please Me More". Another boarding house lodger, Fraulein Kost, a prostitute, enters the scene and she and Fraulein Schneider argue about whether or not Kost will be able to continue to bring customers back to the boarding house. Kost reveals that Schultz is a Jew and shows her

$-(2,2)$


allegiance to the up and coming Nazi party. The Emcee takes another opportunity to comment on the situation, and the men of the chorus sing 'Tomorrow Belongs to Me', a Nazi sympathizer tune. The Emcee seemingly indifferent to the growing Nazi influence skips offstage.

A few months pass, and we next see Sally and Cliff in the room they now share. Sally announces that it is time for her to move on and that she is pregnant. Cliff begs her not to leave, promises they will make it work, and professes his love for her in 'Don't Go'. Sally reluctantly agrees to stay and two realize they need to make some more money to support the child. Conveniently, Ernst arrives and offers Cliff a job smuggling goods from Paris back to Berlin. Cliff, desperate to make an extra buck and unaware of the ramifications, agrees wholeheartedly.

Next we see Fraulein Kost sneaking three customers out of the boardinghouse when she catches Schultz sneaking suspiciously out of Schneider's room. The pair has obviously been involved in a dalliance. When she confronts the pair, Schultz tells Kost that Schneider has agreed to be his wife and there was nothing indiscreet about their behavior. After Kost exits, Schneider and Schultz agree that they are both tired of living alone in the song 'Married' and she accepts his backwards proposal. Sally enters the scene, discovers their news and insists on throwing them an engagement party. The scene shifts into the engagement party held at Schultz's fruit shop. Everyone is in attendance and the party starts out as a merry one with gifts for the couple and everyone dancing. Ernst arrives at the party late, and in removing his jacket shows everyone his Nazi arm band. Kost, in an effort to stay on the good side of the up and coming political party, tells Ernst that Schultz is a Jew. Ernst insists on leaving the party and to

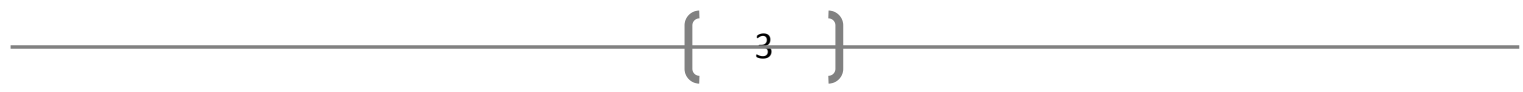


encourage him to stay Kost convinces the party to sing 'Tomorrow Belongs to Me'. Cliff arrives as this is transpiring, delivers the smuggled goods and realizes who his corrupt activities are supporting. The act ends with the party divided, half singing and half staring in trepidation. The Emcee appears out of the crowd, shrugs and exits; supposedly showing his indifference to the political situation.

Act Two begins with a kick-line number performed by the Kit Kat Klub girls dressed in full Nazi regalia demonstrating the growing political influence of the party. At the end the Emcee is revealed as one of the dancers in drag. The scene shifts to the fruit shop the morning after the engagement party, and we see Schultz sweeping up. Schneider arrives and expresses her apprehension to how the political situation will affect the upcoming marriage. Schultz sooths her with a reprise of 'Married' and nearly has her convinced when a group begins vandalizing the store front. They scream "Jew" and throw a brick through the window. Schneider is terrified and calls off the relationship for good.

Another of the Emcee's cabaret numbers begins and comments on the previous scene. In 'If You Could See Her' the Emcee introduces his "girlfriend" who is a gorilla. He sings of her beauty and that the audience simply doesn't see her as he does. At the end of the song he reveals that she is Jewish; making the point that this is how the Nazi party must view the Jewish community.

Back at Cliff's room, Cliff has decided that the political situation in Berlin is no longer safe and that he and Sally must travel to America to have the baby. Sally enters and protests leaving; her career is here and she has no intention of going. In the midst of their argument,

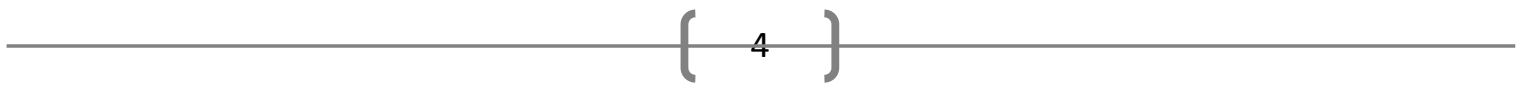


Schneider enters to return their wedding gift and informs them she has broken off her engagement to Herr Schultz. She explains her self-protecting actions in 'What Would You Do?' and wishes the young couple well. Sally and Cliff continue their argument, neither one agreeing with the other. Cliff, more determined after Schneider's song, leaves to go buy train tickets so the two can depart Berlin the next day. Sally departs directly after, presumably headed to the Kit Kat Klub to rehearse for that evening's performance, grabbing her fur coat on her way out the door.

The scene shifts to the cabaret where the Emcee sings the solo 'I Don't Care Much'. As he sings, Sally enters and surveys the club dressed and ready to perform. The club opens and quickly fills with patrons. Just before Sally's big number, Cliff arrives in a rage finding that Sally was not at home packing. The couple argues again about whether or not Sally should leave. Ernst enters at this moment and offers a very distraught Cliff another smuggling job. Cliff refuses on principle, the two men get into a fist fight, and Cliff is carried out of the club by Ernst's buddies. The Emcee announces Sally and she sings 'Cabaret'. As she sings, Sally resolves that she has made the right decision in staying and her last few lines are sung triumphantly.

The scene shifts back to Cliff's room the next morning. Cliff, bruised after last night's altercation, is packing up the last of his and Sally's belongings. Sally enters without her fur coat, and Cliff enquires after its whereabouts. Sally tells him she has left it at the doctor's office as payment for her abortion. He slaps her for this comment so shocked and devastated at the news. Sally once again finds herself in an abusive relationship and looks defeated. Cliff tries one last time to convince her to come away with him. She refuses, telling him "she's always hated

$-(55)$


Paris". As he exits, she asks him to dedicate his book to her. He is so changed by his experience in Berlin he leaves without a backward glance.

The train car to Paris arrives onstage and Cliff, on board, sings a reprise of 'Willkommen' as he begins to write the story of what he had just experienced. He has found his inspiration and is leaving the city. The cabaret performers and patrons continue the refrain as they mill around the club, echoing key phrases said earlier. Members in concentration camp outfits wander around amongst the patrons; a harbinger of what is to come. The Emcee ends the show by singing "...Auf Wiedersehen, A bientot..." and a cymbal crash ends the show.

$(5)$




\section{Initial Impressions}

My strongest initial impression of Cabaret was of the constant shifts between the real world and the magical. The scenes between Cliff and Sally, as well as Schultz and Schneider, paint a picture of the stark reality of Berlin on the brink of war. All four characters interact with members of the Nazi party and are forced to choose how they will react to the situation. Outside of this, the characters interact with the world of the Cabaret. This magical half of the world is directed by the Emcee; he breaks the fourth wall, shows up in scenes where he would/should not be and watches the action of the real scenes conspicuously from the side of the stage. The club and its patrons follow the Emcee's lead; the two worlds flow into each other with quick transitions, and often blur or overlap. In the scene where Cliff begins writing his novel, a girl at the Kit Kat Klub appears onstage and begins singing a song; the audience is asked to be in Cliff's apartment and the cabaret at the same time. I thought that these types of transitions in the script could lead to set pieces not looking completely finished, to be transparent or see through, and to move or transition in unusual ways. Things did not need to be all that they appeared or transition in expected ways.

My next impression was of the lively world of Berlin and that I needed to bring this exuberance to the stage. Berlin was humming in the thirties; there are characters flirting and fighting, going to parties and clubs, and bustling about their lives in a hectic city. Many past scenic designs of Cabaret, and also Chicago (another Kander \& Ebb musical), rely heavily on

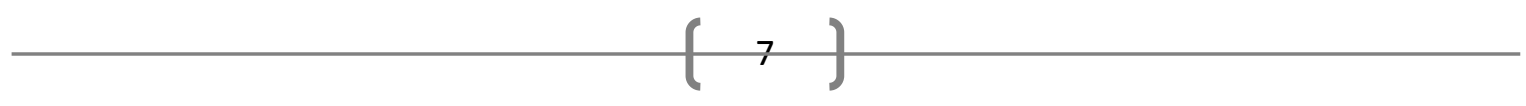


very limited color palette consisting of black, white, silver, and red. I knew from my initial readings that I wanted to stay away from this iconic, but overly used palette; I wanted to go in my own direction. There were too many strong personalities on stage, too much going on between all of the characters and in the city, to limit my color palette that closely. At the time, I did not know what colors I wanted to focus on, but I knew that it was crucial not to limit myself.

Another idea that occurred during my initial read through was to have a good sense of the number of locations and that the transitions were crucial in keeping up the show's momentum. The tempo of the piece could be easily ruined by slow transitions. Many of the musical numbers are fast-paced and upbeat and move into other enlivened numbers. Any sense of the transitions between 'real' and 'magical' could be killed by scenery changing too slowly.

Once I had established the locations and transitions, I needed to think very carefully about how each piece not only moved, but affected the other pieces of scenery. I had a good grasp on the five basic locations required by the script, and had an idea to create a sixth space that reinforced the 'magical'. The five basic locations consisted of the Kit Kat Klub, Schneider's parlor, Cliff's room, Schultz's fruit stand, and the train car. The Kit Kat Klub needed space for a bar and a band and to accommodate large numbers of chorus members dancing. This club seemed to me a seedy location, dirty, and run down. The shows performed here make little to no profit; the dancers dressing themselves in whatever was laying around. It is the kind of bar that you go to late at night already intoxicated, and you don't notice the dirt, grime, and sketchy characters sitting at the next table.

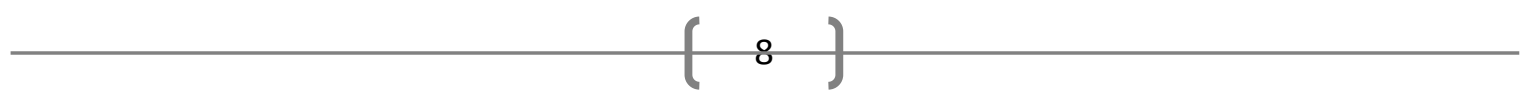


Next, there were the two spaces within the boarding house: Cliff's room, and Schneider's parlor. Cliff's room needed to be able to fit a single bed, dresser/armoire, and a table or desk. The room needed to be cramped, grungy, and not particularly inviting. It should seem as though Schneider was drastically overcharging Cliff by asking for one hundred marks in rent. It is sparsely decorated with an odd assortment of pieces that have been collected over the years. Everything is serviceable, but not particularly attractive. Schneider's parlor needed to have a few chairs, or a couch, and maybe a small table or two, but it was crucial to have the doors for Schneider and Fraulein Kost to enter and exit from. There are a few bits of physical comedy that involve the doors so they were imperative. The parlor has the same feeling as Cliff's room, run down and a bit neglected. Not because Schneider doesn't care, but because she is physically and financially unable to keep up with the decay. The furniture pieces are functional and mismatched. The fourth space was Schultz's fruit shop which required some fruit stands to establish the location as that type of business and a window that is broken in Act II. In the first scene, there is party furniture; tables decorated for guests and a bunch of mismatched chairs for people to congregate on. In the second act, the shop is restored to its usual manner. It is a clean, if worn, shop. Schultz is particularly proud of his wares and wants to show them off to their best advantage. The last required location in the script was the train car in which Cliff arrives and leaves Berlin. It needed seats, luggage racks, and a door for the Immigration Officer and Ernst to enter and exit from. There was no other information in the script as to style or decoration of the car. The last space, not specifically called for in the script and one I was hoping to create, was the space inhabited and used by the Emcee to create scenes that comment on the action of the play. The Emcee sings songs such as "Two Ladies" and "If You

$-\left(\begin{array}{l}0 \\ 0\end{array}\right)$


Could See Her" that follow a scene in which controversial interactions happen between characters. His songs poke fun or spoof the previous scene, commenting on them in a satirical manner. I came to refer to this sixth space as the "magical space". The magical space needed to be fluid, moving around the stage space and having different furniture at any moment as the Emcee required. Most musical numbers performed in this space required little scenery or furniture allowing the space to move wherever needed. I wanted to highlight these satirical scenes and allow them to live in their own location, outside the scenes of the play. The advice that I got from my mentor, Professor Klingelhoefer, was to concentrate on these transitions and how each space functioned first and worry about visual design later, "No one will care if a wall is beautifully painted if it takes forever to move, or doesn't function properly with the rest of the set" (Klingelhoefer).

I knew that I needed to find a way to communicate the hectic and often broken world of the play. Berlin at the time was a bustling industrial city, cranking out machines and soot and known worldwide for its rampant sex trade. I wanted this dirty, debauched air to permeate all the layers of the set. Even when indoors in a safe location like the boarding house, the characters could not escape the grime of the city. This was not a musical that could be set in Russia or Mexico. The action of the play could only take place in Berlin at this point in time. I knew that Berlin itself must be a silent character in the play and needed to be constantly present. I did not know the direction that incorporating this would lead, but I knew I wanted to use materials that reinforced the industrialization happening around the characters. I liked the textures of rusty steel, crumbling brick, peeling wallpaper, cracked and broken boards.

$(10)$


This show was scheduled to be performed in West Virginia University's Lyle B. Clay Concert Theater, a large proscenium road house with 1400 seats. As I read the play, I discovered that I would need to find some way to maintain the intimacy inherent in the script. There are many emotionally charged scenes between the characters, and to remove the audience would lessen their connection. An initial thought was to use the orchestra lift, not for the orchestra, but as a part of the stage space. The lift, lowered to the seating level would put the actors right at the feet of the first row, making the scenes played there unavoidable. The orchestra could instead be put where an orchestra in a traditional cabaret space would be: far up center stage. The orchestra could be back lit against a cyclorama creating a beautiful silhouette and be seen throughout the entire show.

I had the idea that Schneider's boarding house could create a third floor and wrap around the sides of the club space that would inhabited the main stage floor. I wanted all of the pieces of the space to flow evenly into one another, and this arrangement would reduce the scene changes to only the train car and Schultz's fruit shop and allow the other changes to be created with lighting. This configuration would allow actors to inhabit more than one of the locations at once and move easily between them with little alterations required. I felt sure that this arrangement of spaces would allow the transitions to flow freely and maintain the intimacy of the piece. Armed with all of these ideas I headed into our initial meeting with the director, Professor Lee Blair.

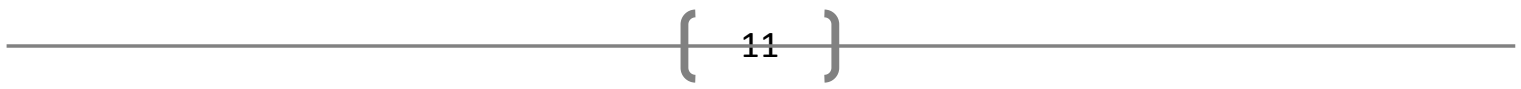




\section{Initial Design Meeting}

Our initial design meeting with Professor Blair focused on a few main avenues he wanted to explore in the design process as well as previously discussed ideas. His most prominent design idea for the show was to create a separation between what he saw were the two different worlds. The first world, much similar to my initial ideas, was that of the cabaret. He wanted it to feel run down, decayed, low budget, and chaotic. The second world was the 'real' world locations outside the cabaret. He wanted these scenes to feel homey, warm, and inviting in contrast. He talked to us about the socio-economic issues of the era, what people were doing, and how they lived. Berlin pre-WWII was suffering from massive inflation. The real financial worth of the German Reichsmark fluctuated daily and people were forced to spend hundreds or thousands of marks just to buy a loaf of bread. Anecdotes abound about people pushing wheelbarrows of cash to buy dinner for a family or using cash as a replacement for firewood or toilet paper as it was worth so little. He discussed the dichotomy of the social landscape. There were normal, working individuals living in the city right next to debauched, seedy characters that came out after dark. Prostitutes and housewives passed each other on street corners. Berlin was a mecca for artists, musicians, and dancers. He described the city as 'debauched', 'decadent', and 'avant garde'. The city at night had a dangerous feel; this danger he explained came from the excesses and decadence. "Everyone had a monkey and a monocle." Professor Blair wanted the two sides of the design to reflect the two opposing sides of Berlin in the nineteen thirties. He showed us images of certain pieces of art he liked. The

$-\left(\begin{array}{l}12 \\ \hline\end{array}\right)$


portrait of Anita Berber (Figure: 1) by George

Figure 1: George Grosz - Portrait of Anita Berber

Grosz was his main inspiration for Sally Bowles

and he wanted to use more of Grosz's work to

inspire the rest of the design.

The director did not get too specific about

the functionality of each space, and the specifics

he did mention were already ideas that I had

come up with as part of the design. He mentioned

that there needed to be a large dance area in the

Kit Kat Klub and that the club was "tired but it

aspired to glamour". Other requirements included

three or four doors for Schneider's parlor, and the

furniture that was required in Cliff's apartment.

He also wanted to make sure there was space to

denote the inside and outside of Schultz's fruit shop. He discussed with me wanting to always

see the cabaret, even if only slightly, on the fringes of every scene, which supported my

'magical realism' idea.

After this overview, the designers pitched ideas and asked questions about our initial impressions. First, I pitched the idea to the group of using the orchestra lift as a part of the stage space and to move the orchestra upstage. Professor Alan McEwen, the sound and lighting mentor, and Professor Steven Neuenschwander, the technical director, were very hesitant

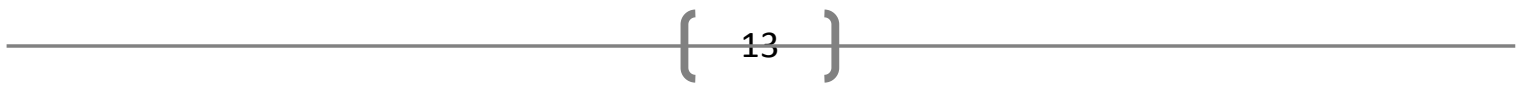


about the idea. The first and major issue being that the stage was not acoustically set up for a band. The theater did have an orchestra shell, but it is bright orange, and everyone agreed that it would not work with the set. The band could be mic'ed, but Professor McEwen felt that it would be too difficult to get the quality of sound that everyone would want from this piece. The sound system in the theater was already having issues, and Professor McEwen and Professor Neuenschwander were in discussions about renting a sound system for this show; moving the orchestra upstage would just create too many issues. The second issue was that the Clay Theater was not actually set up to light the apron level well, especially when it was lowered to the seating level. There were few good places to hang lights to properly cover the space and give the feel that everyone wanted. Professor Blair liked the idea of increasing the intimacy of the space, but agreed with Professor Neuenschwander and Professor McEwen that moving the orchestra onstage would be too problematic.

My next idea of the 'magical space' (the sixth unspoken location in the script I wanted to try to incorporate) was not well received either. Most of the design team thought that it would be difficult to define this space so the audience could clearly understand the intentions behind it. Professor Blair brought up that he intended to have this sense of 'magical realism' throughout the entire piece and wanted to use the Emcee as the major catalyst for this idea. Professor Blair gave an example from his own experience acting in Cabaret as the Emcee where he would walk around the edges of the 'realism' scenes and watch the action. Professor Blair wanted the Emcee for our show to have this sense of fluidity between the worlds as well. This seemed like a more complete, and frankly easier, way to establish this and I was happy to let the idea drop.

$(114)$


The only other important topic I brought up for discussion was that of the color palette.

Candice Day, the costume designer, and I had held a brief discussions about the "non-red-blackand-white" color palette idea and we were both in agreement that we should steer clear of something so overused. Professor Blair really liked the idea of exploring alternate colors and asked to see some research images to support our idea.

After the meeting, I met with Professor Klingelhoefer and we discussed what my options were for moving forward. He stressed again the importance of focusing on functionality over aesthetic in these initial design phases. We discussed ways of continuing my idea for increasing intimacy and came up with the idea for a 'passarelle' or bridge that was commonly used in Vaudeville theaters. This narrow walkway over the orchestra pit would complete both functions I had hoped to accomplish with my initial ideas. It allowed actors to bridge the gap of the orchestra bringing them closer to the audience, would reinforce the cabaret space, and make the modern Clay Theater feel more like vintage theater. Professor Klingelhoefer also stressed the importance of looking outside of the specific world of nineteen thirties cabarets and suggested looking at other time periods where club culture was flourishing for design inspiration.

\section{The Design Team}

Theater being a highly collaborative art, my design team was a crucial part of the creation of the show. Our ideas needed to mesh well together and we needed to be able to communicate easily. Costumes were being designed by graduate student Candice Day as her thesis project. Candice has a Bachelor of Arts in Painting from Warren Wilson College and has

$(15)$


created circus costumes. I felt confident that her and my design styles would work well together. She and I both relied heavily on pieces of fine art for in our research process. We had previously designed together in classes and we were comfortable with each other's design processes and aesthetic. During the initial design phases, we spent evenings meeting to discuss our color palette coordination, how all of the pieces would function together, and helped each other cement our design concepts. Graduate student Tim Thistleton was assigned as the Lighting Designer. Tim had a history with lighting dance and movement pieces, and I knew his style would translate well to the deconstructed and abstracted look I was hoping to accomplish. We had some initial conversations about industrial lighting, such as using steel pipe and exposed bulbs. We also discussed the fact that we both wanted to see the theatrical lighting fixtures. Tim felt too that there was a great deal of magical realism in the script that would allow us to be flexible about where fixtures where hung. I knew that Tim would be flexible in the design and execution, and be willing to explore and troubleshoot all of the options should problems arise. Lastly, and very luckily, I got to hand select my Prop Master, Joe Dotts. He had previously made beautiful props for other school shows and had a way of finding materials off the beaten path to solve technical problems. I knew there would be some tricky pieces to create and a limited budget for the number of pieces required in the script. I was confident that Joe's taste and his attention to research would support and enhance the overall design.

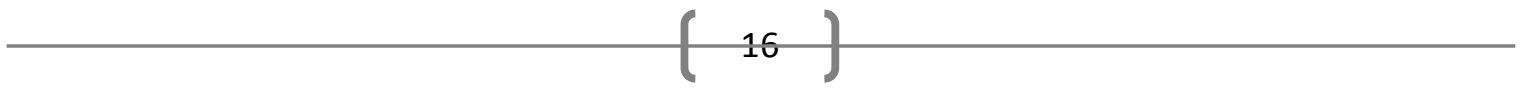




\section{Research}

After my initial impressions of a play the best way to be inspired is to delve into

research. It is an absorbing process of finding inspirational images, phrases, or ideas mentioned in the script and following a sort of 'yellow brick road' of websites and images. Throughout this process, I find images that clearly express not only how I see the world of the show, but how I feel about it and how I want others to feel about it.

My research process started from several different points. I needed to learn about Berlin in the 1930's; what was going on politically and socially. Who were the people living in the city? How did they live, work, and play? What did the city look, smell, and feel like? I needed to know about the major art movements at the time. What statements were artists making? How did those pieces fit into the world that I was trying to create? I needed to understand the cabarets of the thirties; who went to them, who worked in them and what happened behind the scenes? It was crucial to research the types of locations, pieces of art and furniture mentioned in the script. I also did a bit of extrinsic research. Extrinsic research is the type of research that doesn't necessarily end up onstage in a linear fashion. It is not finding a picture of a door you like and recreating that door. Extrinsic research helps to create the emotional undercurrent of the show. It is finding photos that inspire a color palette or a mood, the subject matter has little direct correlation to the pieces that wind up onstage. Luckily, the

$\left(\begin{array}{l}17 \\ (17\end{array}\right.$


fine art of the era was so

exactingly expressive of the

emotional state of German that

many of my extrinsic research

pieces ended up being direct

inspiration for actual set pieces.

Figure 2: Fritz Schmidt's Restaurant \& Festive Halls

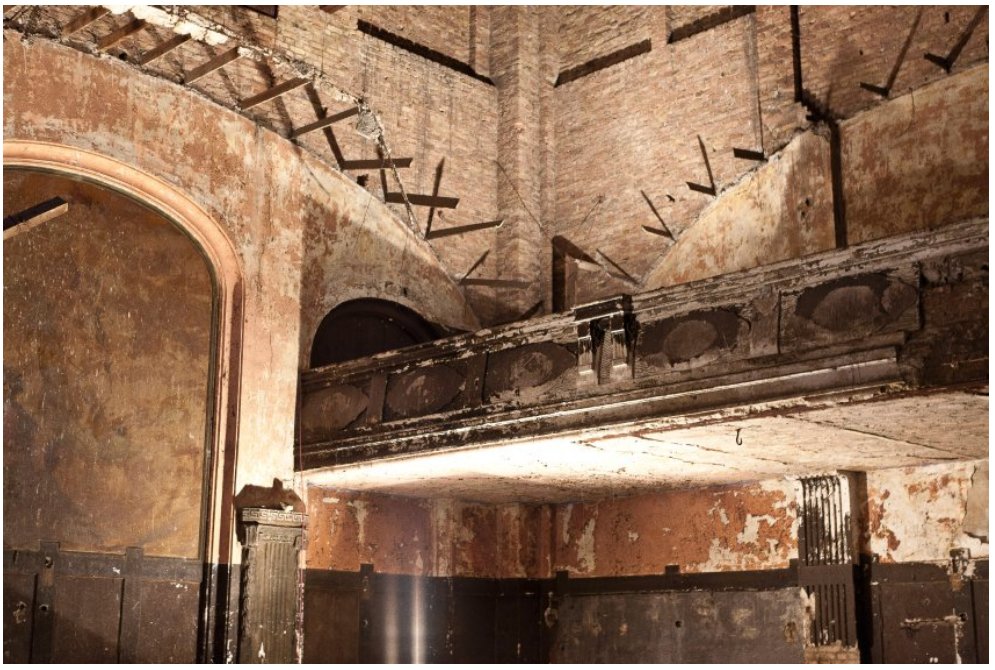

My most significant piece

Figure 3: Fritz Schmidt's Restaurant \& Festive Halls

of research was handed to me by

a mentor, Professor Troy Snyder

from Fairmont State University.

He had designed the same show

the year before and had found an

article online, Secret Garden: An

abandoned cabaret theater is

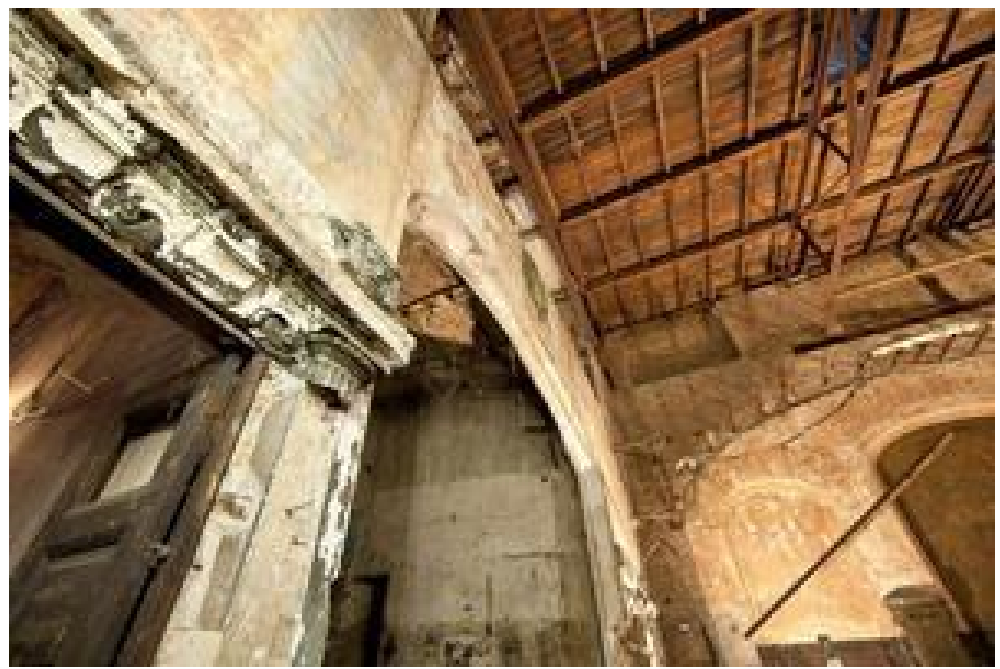

Figure 4: Fritz Schmidt's Restaurant \& Festive Halls

found in Berlin (WONDERLANCE),

Fritz Schmidt's Restaurant and

Festive Halls, had been found in

Berlin buried under tons of rubble

(Figures: $2,3,4)$. This club, in the

basement of an old building, had

many of the pieces I had been

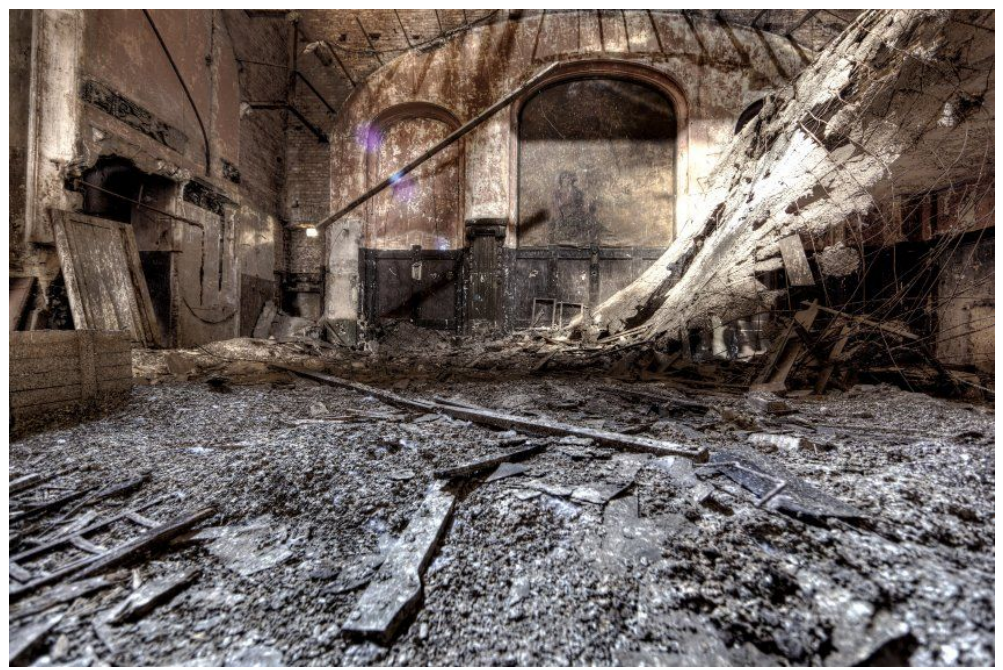

looking for to create the base of my 'Kit Kat Klub'. A cabaret in the twenties and thirties was a

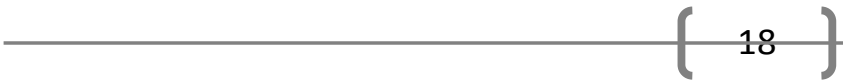


bar that offered nightly entertainment to its patrons. The entertainment varied from singers to dancers to crazier performance art pieces. The spaces had seating and a dance floor for patrons to mingle. The research photos were of an abandoned and broken space that felt similar to the other abandoned industrial spaces I had already been interested in. The research cabaret had a main proscenium arch that surrounded what must have been the band platform, flanked on either side by two smaller arches. It had balconies that overlooked the lower dance floor, where presumably the patrons sat, drank, and watched the activity below. I loved the way the shadows of the broken ceiling beams cut across the walls making the space look aggressive. The general structure of the research cabaret space fit exactly into the function I wanted my club space to perform. These images became the base that all other designs of the set branched off from. No matter what else changed over the course of the production, I knew I wanted to keep those three disheveled arches from Fritz Schmidt's Restaurant and Festive Halls as the base.

Figure 5: Lyonel Feininger - Die Laterne

My next major

source of inspirational

research came from the artists of the 1930's that were creating in Berlin.

Rebelling against the

Naturalism and Realism

movements previous to

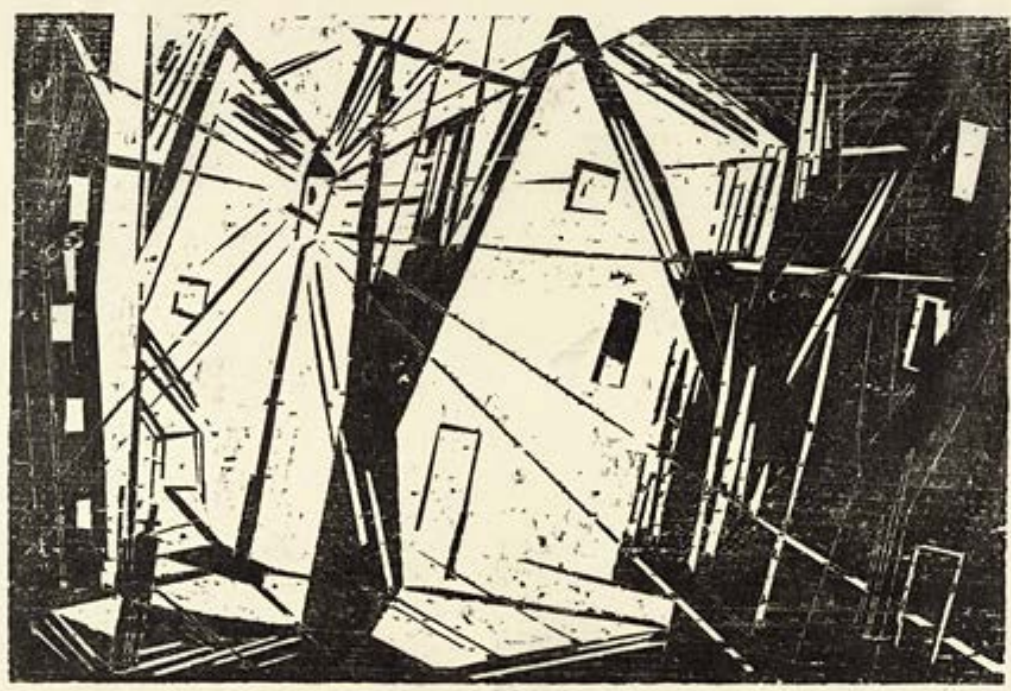

the period, the German

Expressionists sought to portray the chaos and disillusionment of German society after WWI

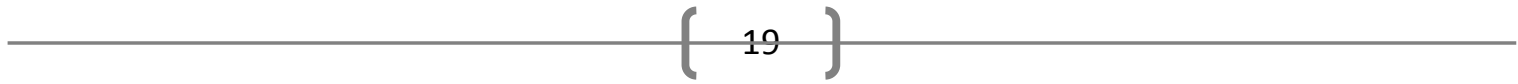


and to shake their audiences out of complacency. Their paintings strayed away from the safe and comfortable realistic paintings of the past. The work was stark, jagged, and extremely emotional, seeking to evoke discontent in its viewers. Some paintings used stark black and white shapes with sharp angles, some even having a shattered look. Others had garish, vivid colors with sexy, risqué subjects. Many of the Expressionists painted in or around Berlin, and the images they created were integral in help me create scenery for the damaged characters of Cabaret. The first artist I looked into was Lyonel Feininger, a German artist known for his graphic woodblock prints. I had used his work before when designing other plays, and knew his work fairly well. The piece I liked the most was his 'Die Laterne (Street Light)' print of a city street at night (Figure: 5). The rays of the street lamp cut through the entire piece creating a jagged broken reality. This painting felt like the type of city that the characters might walk through: gritty, aggressively lit, and slightly uncomfortable. I wanted to incorporate the linear quality into the show, and thought that this would be a great representation of Berlin in the back ground.

Two other artists I was introduced to during my research process were Georg Grosz and Otto Dix. Each of these expressionist painters Figure 6: Otto Dix - Metropolis Triptych (Center Panel)
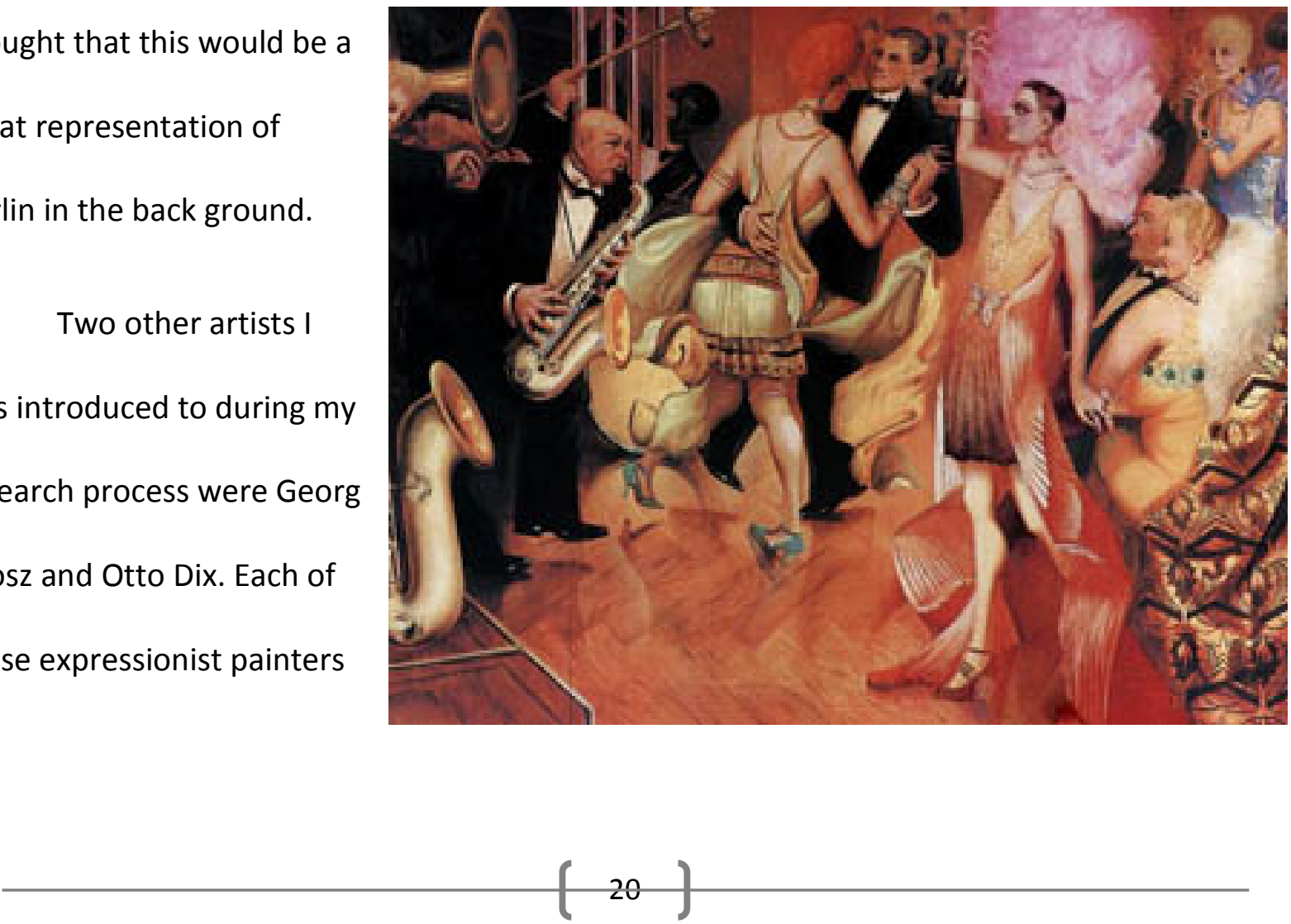
created gritty, vividly-colored paintings of street scenes and characters from Berlin. Otto Dix's portrait of Anita Berber (Figure: 1) was one of the main pieces of research that Professor Blair had presented to us as design inspiration. Anita was famous in Berlin at the time as a cabaret dancer and her propensity toward sexual freedom, lewd public behavior, and drug use was infamous. The stark emotion of this painting was the jumping off point for my research into other expressionist artists. The key piece of research I gathered from Dix was his Metropolis Triptych, especially the center panel (Figure: 6). The painting shows a scene from what appears to be a cabaret or party. There is a band playing while couples dance and a man in drag stands center surveying the scene. We had discussed in the initial meeting that the Emcee and other club characters might be in drag, and I thought this painting evoked the life and vivacity that I wanted to get across to the audience in my design. I loved the discordant and vibrant color palette of bubble gum pinks, tomato reds, and gold.

I also found the expressionist painter George Grosz, who had a similar style to Dix. Grosz was known for his caricatures of city leaders caught in questionable behavior and his riotous street scenes in garish colors. These

Figure 7: George Grosz - Metropolis

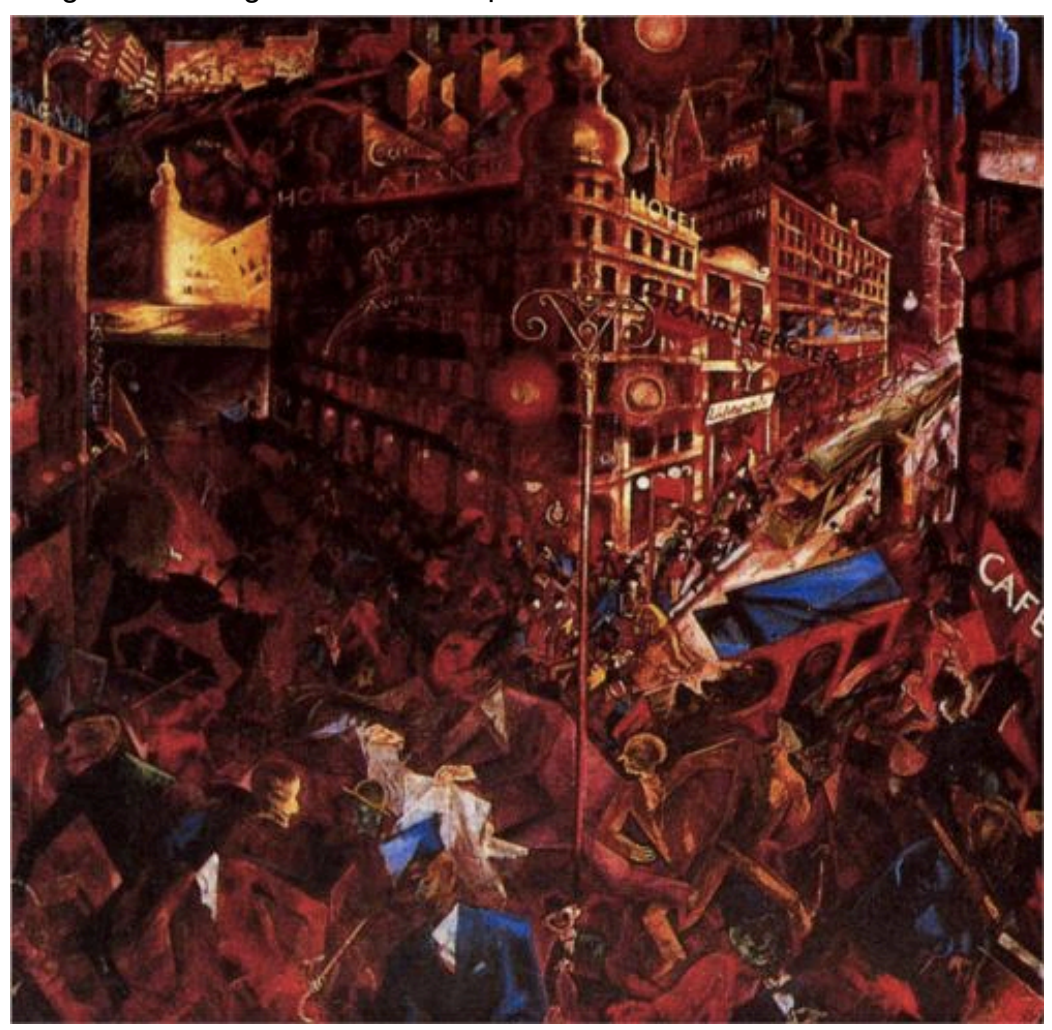

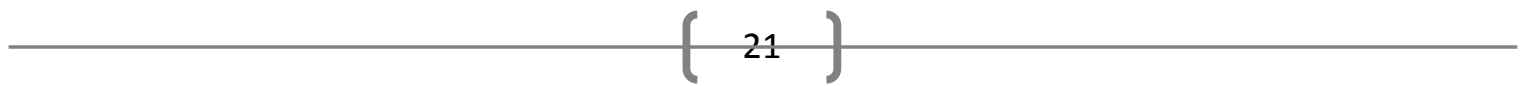


street scenes, such as Metropolis (Figure: 7)

Figure 8: George Grosz - To Oskar Panizza

and To Oskar Panizza (Figure: 8), invoked

images of what Berlin must have felt like at

the time: frantic swirls of color and lights, a

hustle and bustle of interesting characters,

all frenetically paced. These two paintings

became the basis for my color palette for

the club location: Tomato red, violent

orange, pea soup green, denim and gray

blues.

Next, I found the basis for the color

palette of the realism locations. Costume

Designer Day and I met for a long meeting

about the color palette, and during this

meeting she introduced me to the book Art

Deco: The Golden Age of Graphic Art \&

Illustration (Robinson and Ormiston) which

had illustrations by Erte, a fashion designer of

the late twenties and early thirties. Known

for his fantastical clothing designs that made

women look like butterflies and jewels.

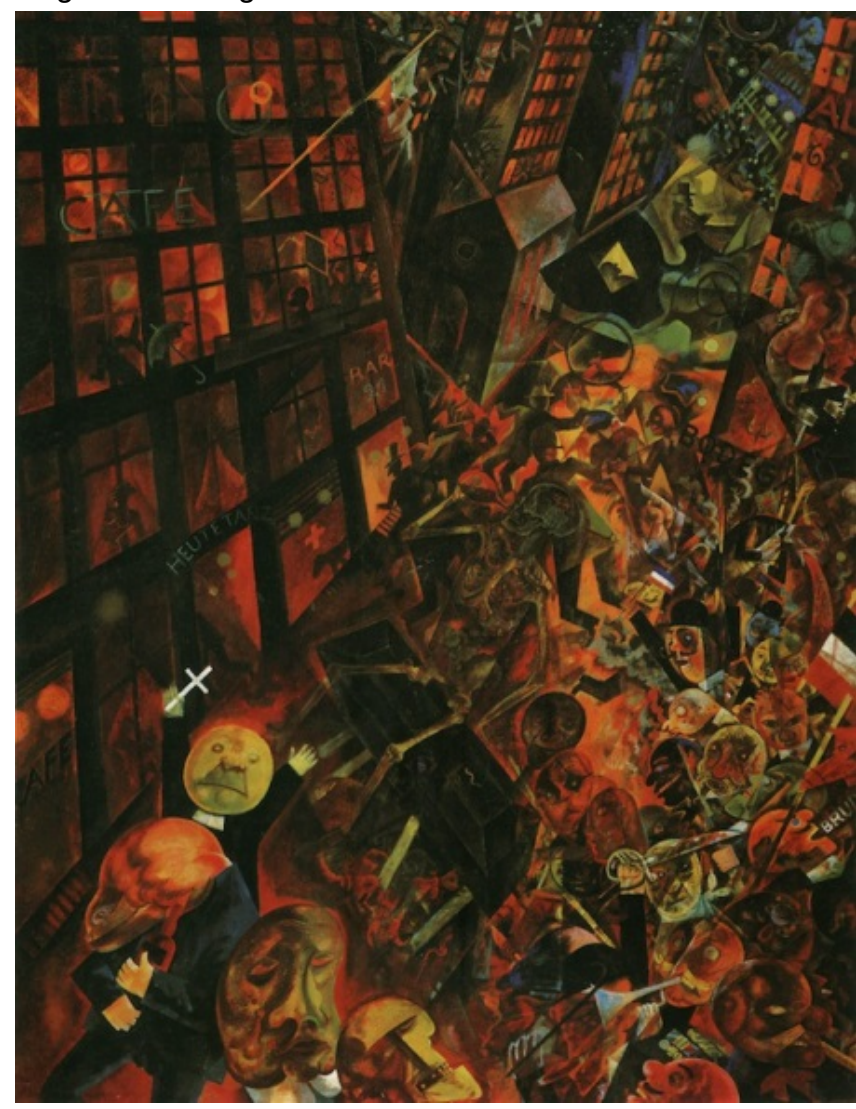

Figure 9: Georges Barbier - L'Oiseau Volage

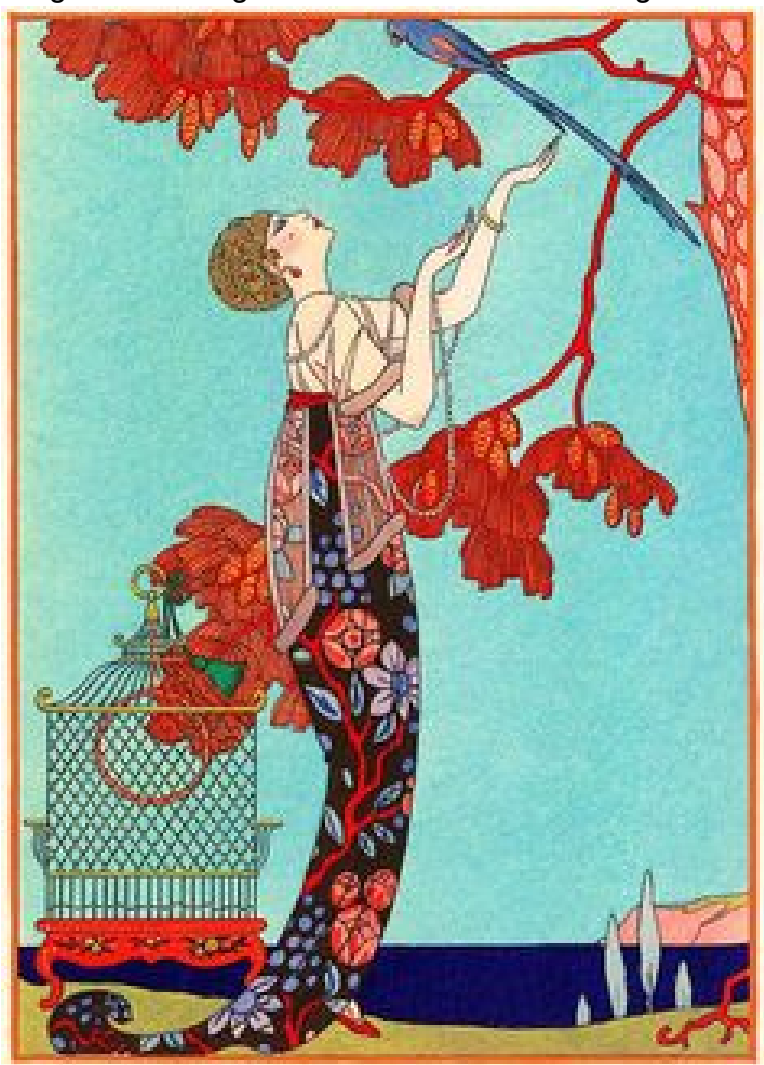


L'Oiseau Volage (Robinson and Ormiston,

p. 108) (Figure: 9), by designer Georges

Barbier caught my attention. I loved that

the color palette was essentially the same

as the Grosz painting, To Oskar Panizza, but

was a softer version focusing more on the

pea soup green, the denim blue and softer

oranges. I thought this softened version

would suit the declarations of love,

marriage proposals and comedy better

than the bright color palette of the club.

This exploration of the Art Deco

style led me to begin thinking about what

the interiors of the period looked like, and

how I would translate that into my

interiors for the cabaret and boarding

house. Because the boarding house was

not a brand new building, I did more

research into what an Edwardian house

would look like. I considered that, perhaps,

Fraulein Schneider had inherited the house
Figure 10: Art Deco Wallpaper

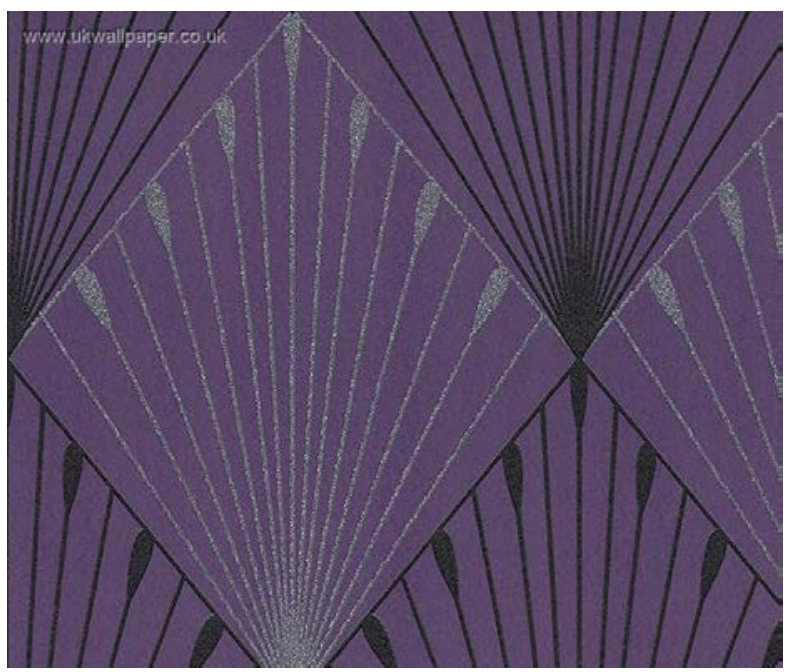

Figure 11: Art Deco Wallpaper

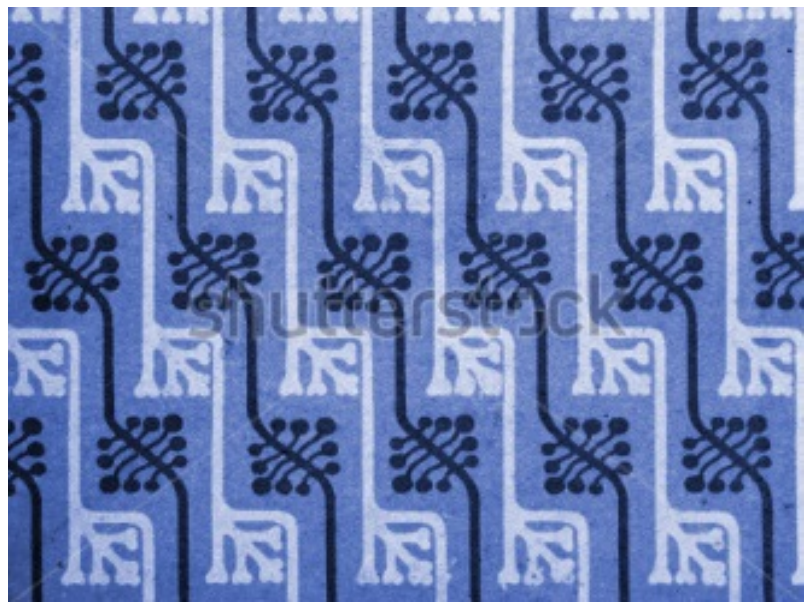

Figure 12: Art Deco Wallpaper

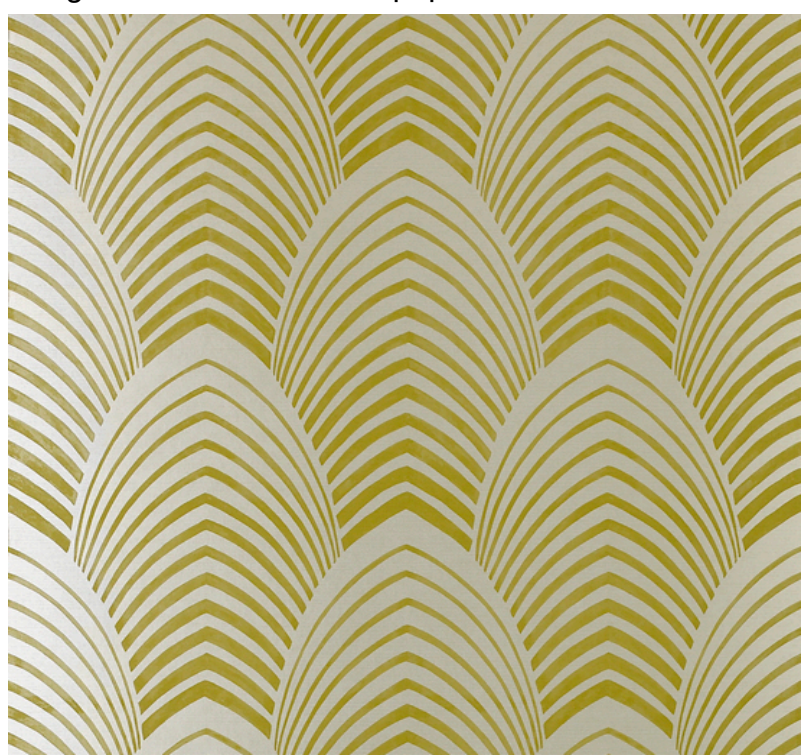


and so the house's interior structure would be older than the current Art Deco style. With this in mind, I wanted the rooms to have some level of fantastical quality to them. The show was a musical and I wanted each location to somehow support the sense of 'magical realism' I was trying to incorporate. Eventually, I stumbled across a series of Art Deco and Art Nouveau wallpaper patters (Figures: 10, 11, 12). They were graphic, bold, and unusual and I thought they would look nice in the interiors of the boarding house.

With all of these images stewing about in my brain, I set to the task of designing the structure of the play.

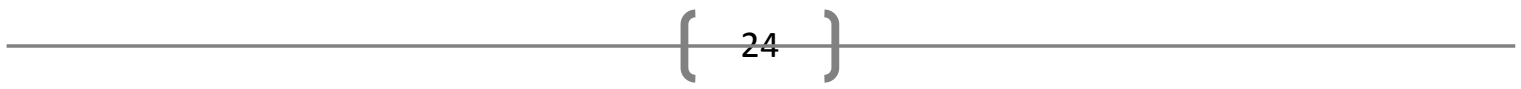




\section{Drafting \& Digital Rendering}

With my research established I sat down to begin drafting. Typically, designers don't launch directly into drafting, but Professor Klingelhoefer and I had discussed that my previous theoretical designs for class were more successful when I skipped the hand rendering stage and went directly into drafting. He thought it would be best considering the complexity of the multiscene show with difficult transitions, and that it would help me create the design while staying focused on the details.

\section{Drafting Version One}

Draft number one (Figure: 13) stemmed from bits and pieces of my research and a desire to use the entire stage space. Since I couldn't use the vertical space of the orchestra pit, I wanted to use as much horizontal space as I could. Upstage center was a raised platform for the club band; it would be approximately two feet off the deck. I added a proscenium arch to the front of this platform that was modeled after my main piece of research (Figures: 2, 3, 4). Off of the upstage center platform came two angled platforms that would jack-knife on a single pivot point. These platforms would be two stories, and when lined up with the band platform, they would create the interior of the Kit Kat Klub. On the downstage edge these pivoting platforms would meet up with two stationary towers that flanked each side of

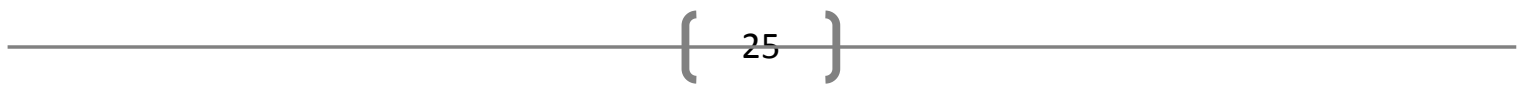


Figure 13: Drafting Version One
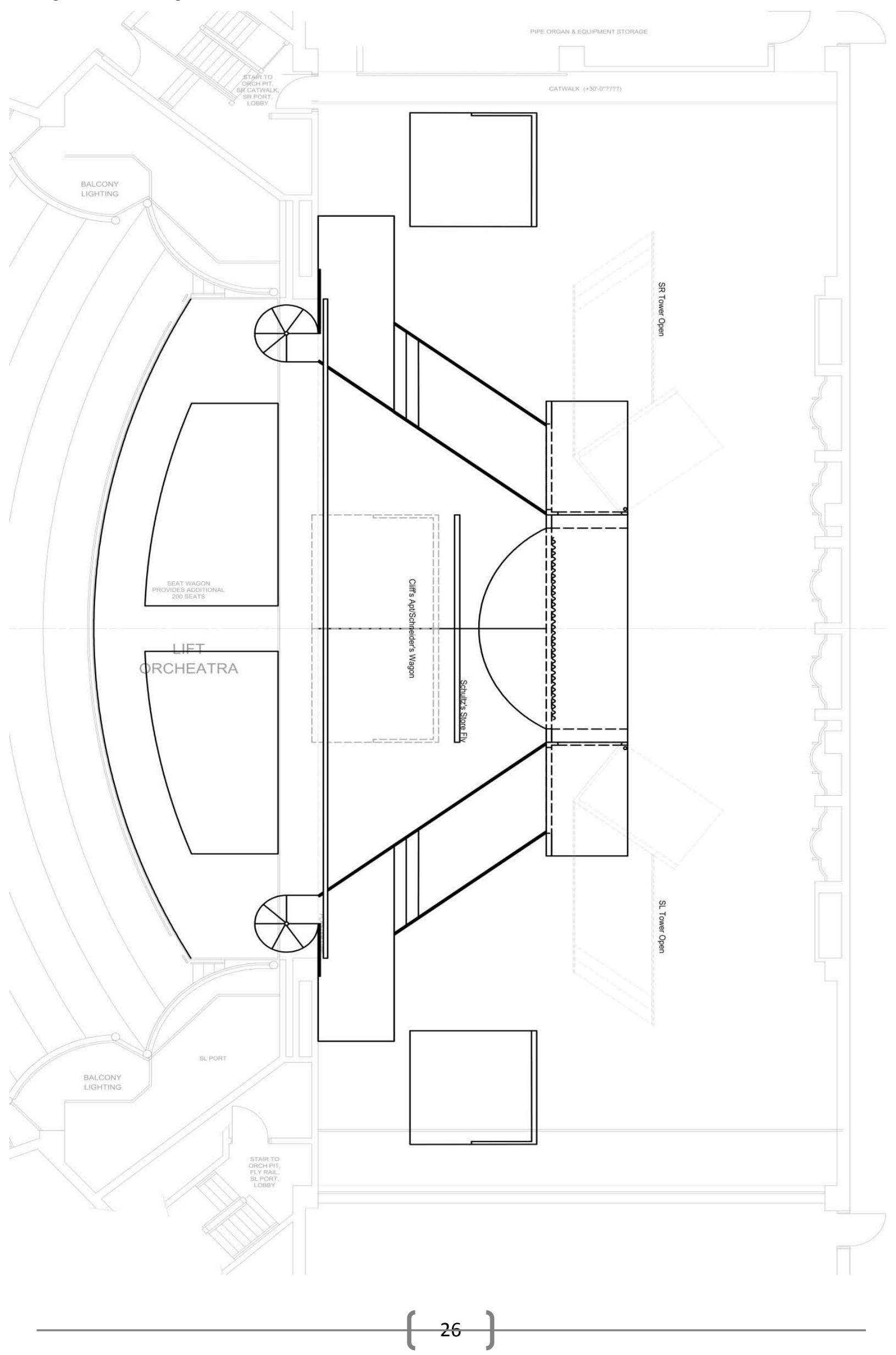
the proscenium arch. The towers would be two floors, matching up by a set of stairs with the pivoting platforms. This would create an exit from the second story of the platforming with an exit on the downstage edge, created by a spiral staircase.

When the two platforms were jack-knifed upstage, in the open position, they left space for two wagons to wheel onstage. I hadn't completely defined what the wagons would look like by the time l'd moved onto the next drafting version. These wagons would have scenes set in them and become two interior locations; Schneider's parlor and Cliff's room. At this point the design still included the passarelle idea that I had discussed with Professor Klingelhoefer that would sit at stage level over the orchestra pit. I had decided that the Schultz fruit shop would fly in mid-center stage, but the design was undefined. There would be a false proscenium on the furthest downstage batten to reshape the existing square proscenium that the Clay Theater has. I wanted the false proscenium to create an arch shape on the backdrop to mimic the upstage center arch. Also, at the suggestion of Professor Klingelhoefer and Professor Neuenschwander, I had stared laying out the drafting for the spiral staircase. We have one in stock and I used its measurements to set up the stair and platforming heights. I showed this draft to Professor Klingelhoefer and we discussed the potential issues and furthered the design ideas.

\section{Drafting Version Two}

Drafting version two (Figure: 14) focused more on incorporating the decorative design of the pieces over the function of them as version one had. Professor Klingelhoefer and I

$(27)$


Figure 13: Drafting Version Two

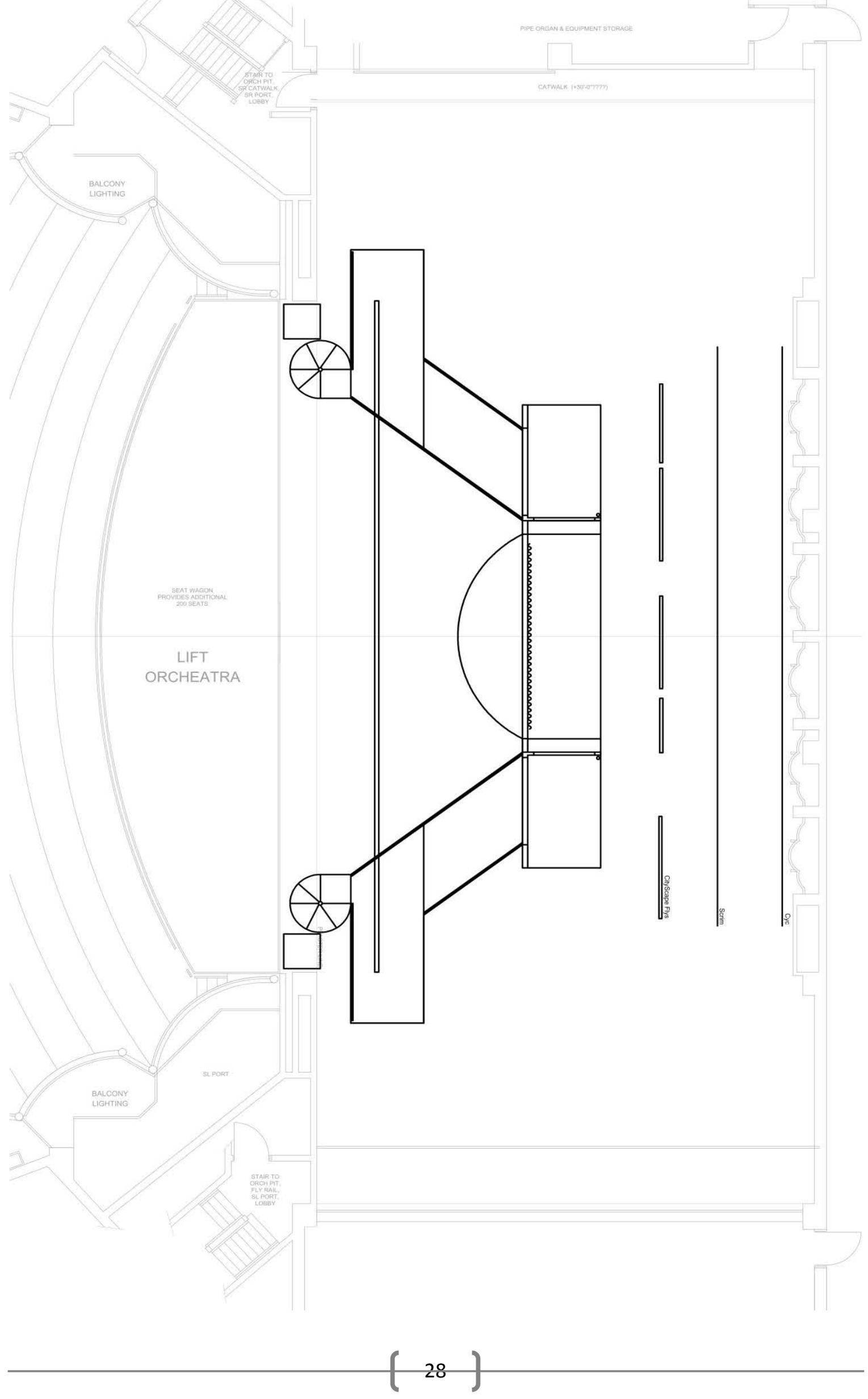


discussed my ideas for using the industrialism of the city and Feininger's graphic pieces and worked on adding them to the design.

First I altered the size and shape of the overall platforming. The band platform moved downstage, more toward mid-center stage to allow room for the backdrop I had designed. I had added a cyclorama and a scrim upstage, which would allow us to use color to support the action on stage. I felt that using a painted drop was not going to work for two major reasons. First, there would already be a large amount of painting required by the crew and I didn't feel confident we could accomplish a drop on top of the rest of the work. Second, a painted drop would lend too much realism too the scenery. I wanted to maintain the sense of 'magical realism' and using a simple cyclorama felt more 'theatrical' to me than a drop. In place of a drop, I wanted there to be large graphic building shapes flown in that would create a cityscape. The design of the cityscape was roughed out in this version (Figure: 15) and was meant to look like an art deco style cityscape in extreme perspective. I wanted the buildings to feel like they were looming over the scenes happening onstage and inescapable. The downstage towers had to be shifted upstage to create an easier entrance near the Clay Theater's proscenium arch. In the first draft I had planned to have walls with doors in them wrap around the base of the two

Figure 15: Cityscape Fly - Initial Design

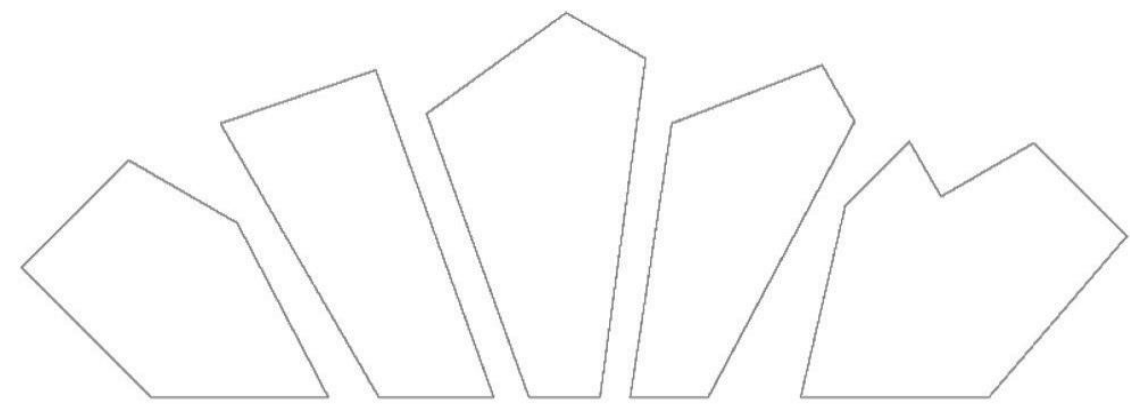

downstage towers. These walls would inhibit the onstage/offstage flow for musical numbers and scenery changes, and

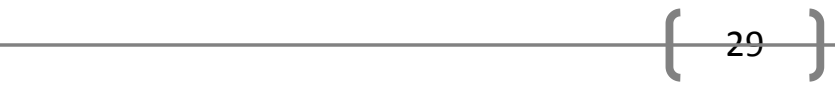


creating a gap would ease the traffic flow. The other reason to shift them upstage was that I was not legally allowed to block the fire curtain's path. The original design of the towers had them touching the walls right at the back of the proscenium arch, which would impede the movement of the fire curtain in case of an emergency.

Another adjustment made was the addition of decorative speaker towers downstage of the stationary scenery towers. These two towers would be much just large enough to fit the unattractive speaker stacks into and hide them from audience view. These also helped fill the gap left by the proscenium arch when the scenery towers were moved upstage. Lastly, the speaker towers would help incorporate more of the industrial textures I was adding to the scenery. I had the rough idea that they would look like industrial trussing, like the type that supports bridges, and would be welded out of steel box tube. Lighting Designer Thistleton and I discussed the possibility of using these towers as additional lighting positions.

At the time the final version of this drafting was saved I had cut the passarelle over the orchestra pit. It was determined that it would be extremely difficult to build and would leave little room for the orchestra to sit down below. Also, it would block a lot of the sound that the orchestra pit is acoustically designed to aid. There had been discussions between Professor Neuenschwander and Professor McEwen, a sound and lighting professor, that the sound system in the Clay Theater had serious limitations and blocking the sound from the orchestra would not help anyone.

Lastly, I moved the false proscenium from its initial space, hanging directly behind the actual physical proscenium, a few feet upstage onto a batten. I had not checked the line set

$-(30)$


schedule when I began and had assumed there would be a pipe in the original location. Again, I met with Professor Klingelhoefer and Professor Neuenschwander and we discussed this latest version. With these changes, I moved onto my next draft.

\section{Drafting Version Three}

In version three (Figure: 16) I went back and worked on more of the issues with functionality of the scenic pieces. The false proscenium was moved all the way upstage behind the scrim. This would ensure that the site lines would be clean from every seat in the house. If hung downstage the straight borders flown to obscure the electrics would alter the shape of the arch for some seats.

One of the most drastic changes in the version was cutting the stationary scenic towers. The primary reason for the cut was to allow the train car wagon to track across the stage. I had always intended to use a rolling train car, but I thought I could be moved on and off stage when the pivoting platforms were jack-knifed open. Professor Klingelhoefer and I agreed that it would take too much time during scene transitions to move all of these pieces. Eliminating the towers helped expedite the transitions. Another reason for cutting the towers was to eliminate the difficult transitions happening between the pivoting platforms and the towers. The towers second level needed to be $6^{\prime} 6^{\prime \prime}$ high to match up to the spiral staircases correctly. The pivoting platforms needed to be over 7' high in order to make enough room for the base level platforming and the height of the actors. With these two different high platforms either the pivoting platforms or the tower needed to include stairs on the second level to make a smooth transition. Once the towers were eliminated, I maintained the spiral staircases to access the

$-(31)$


Figure 16: Drafting Version Three

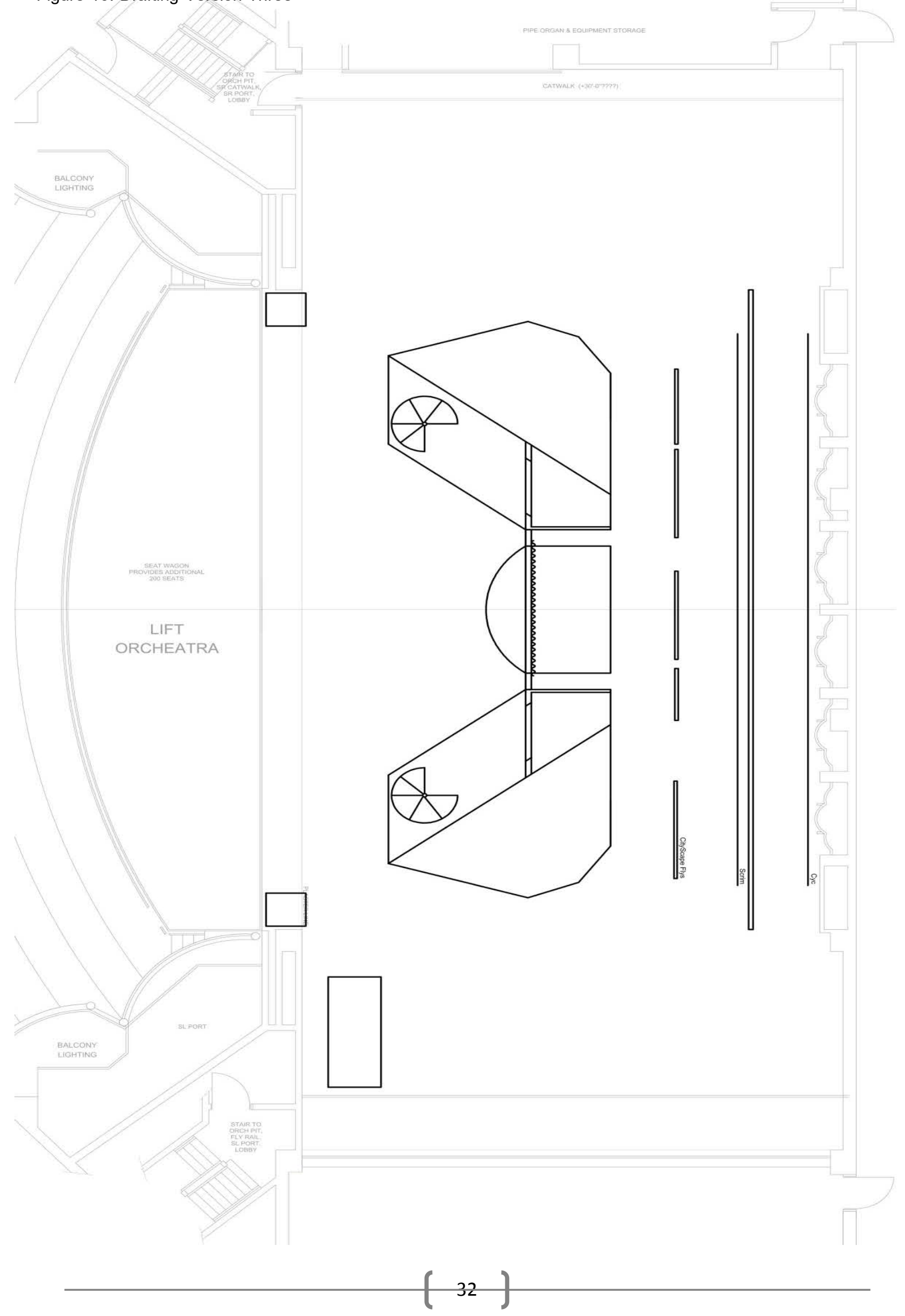


second level and moved them onto the pivoting platforms. Keeping the spiral staircases also helped me preserve the industrial feeling.

Another adjustment made to the scenery was to alter the location of the pivot point of the two moving platforms. The towers were gone, and now the platforms had additional space to move. Originally, there had been two additional wagons designed to bring Schneider's parlor and Cliff's room on and off stage. These would no longer need to be separate units but could be attached to the back of the pivoting platforms. I gave the new platform spaces a jagged front edge to echo the shapes of the cityscape fly. The pivoting platforms now brought on scenery with them when they rotated, yet again simplifying more of the transitions. The only drawback to this new scenario was that the band platform at center stage had a rounded front. The pivoting platforms did not have enough space to rotate on fully with the platform in the way. To solve this problem, I made the lower rounded level of platforming into a slip-stage. The slipstage would be pulled back under the upper level of the band platform during the transition and make room for the larger pivoting platform to fit cleanly in the space. Creating the slipstage had other benefits as well. It allowed us to make more space at center stage in the club when there were large dance numbers. Alternately, it allowed us to have more band platform space if the slip-stage was pushed further downstage.

With these major changes Professor Klingelhoefer recommended that I should start working my design into a 3D format. I had worked with Google Sketch-Up before to create 3D digital models for classwork, so I used that program.

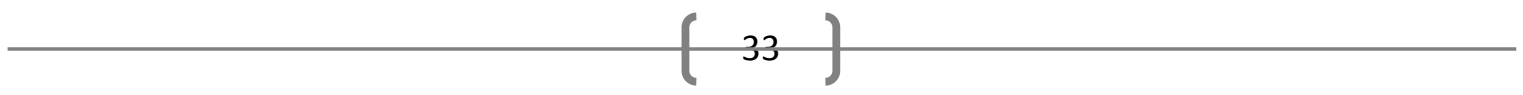




\section{Sketch-Up Version One}

Version one of my 3D Sketch-Up model (Figure: 17) was a very rough configuration of shapes, general ideas I liked, and a vague color palette of greens. It was more important at that time for me to see how the pieces moved in three dimensions than it was to create a model that was fully fleshed out. From this model I learned how the pivoting platforms interacted with the rest of the scenery, how they looked when they moved, and the overall look, scale, and shape of the scenery. After creating this model Professor Klingelhoefer and I sat down again to

discuss the design and how I should move forward. The next version of the design would be the one I took into the design presentation with the design team and had to be a finalized, completed draft. All of the units seemed to be functioning well so my primary goal was to finalize every detail of the scenery. How would each element look? What textures would I use? How would I apply my color palette?

\section{Drafting Version Four}

Version four of the drafting (Figure: 18) was the completed version that I handed in for design team and director approval and for budgeting. It was complete showing detailed drafting for each wall, door, railing, platforms, etc. The design included the band platform with its proscenium arch, two double story/double sided pivoting platforms, a castered train car, two decorative speaker towers, a false proscenium cut drop, Schultz's fruit shop fly, the cityscape fly, and a light up sign that said 'Cabaret'. I gave each room its own individual touches but used the repeating images of the arches, the industrial materials, and the city shapes to tie all of the pieces together. Cliff's room had simple molding and exposed roof beams to create an

$-(34)$


Figure 17: Sketch-Up Model Version One

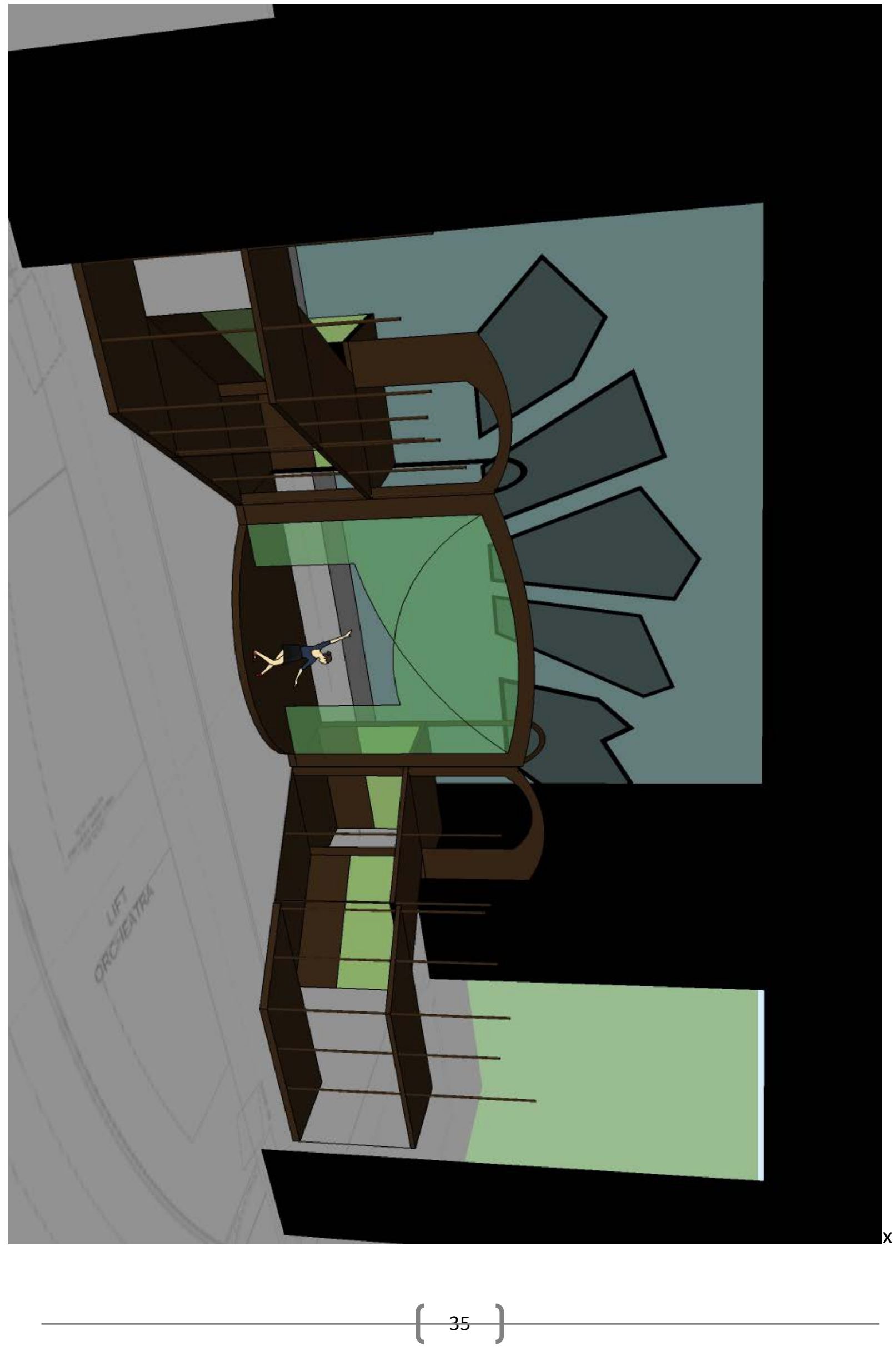


Figure 18: Drafting Version Four

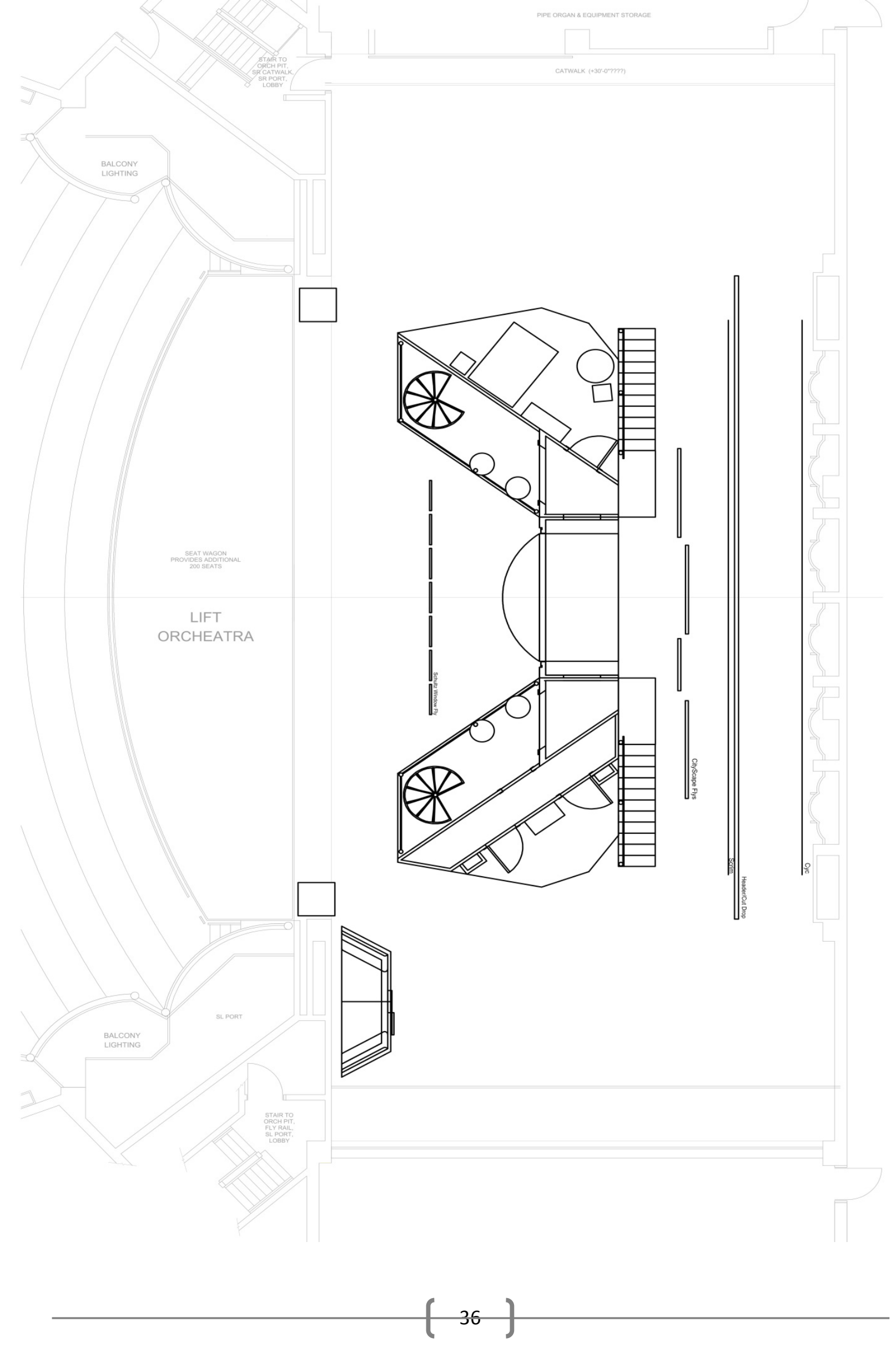


arch shape. I chose a shell patterned art deco

Figure 19: Cliff's Room Wood Grain

wallpaper (Figure: 12) and a pale worn wood

grain for the floor (Figure: 19). I wanted the room

to appear worn and dingy, but still have a sense

of hope and life to it. I experimented with

blowing the wallpaper out of proportion to help

support the 'magical realism' feeling. In

Schneider's parlor I chose a more complicated

molding pattern, adding columns and arching the

molding over the doors (Figure: 20). I chose to

include only two of the doors mentioned in the

script. I felt that Fraulein Kost and Fraulein

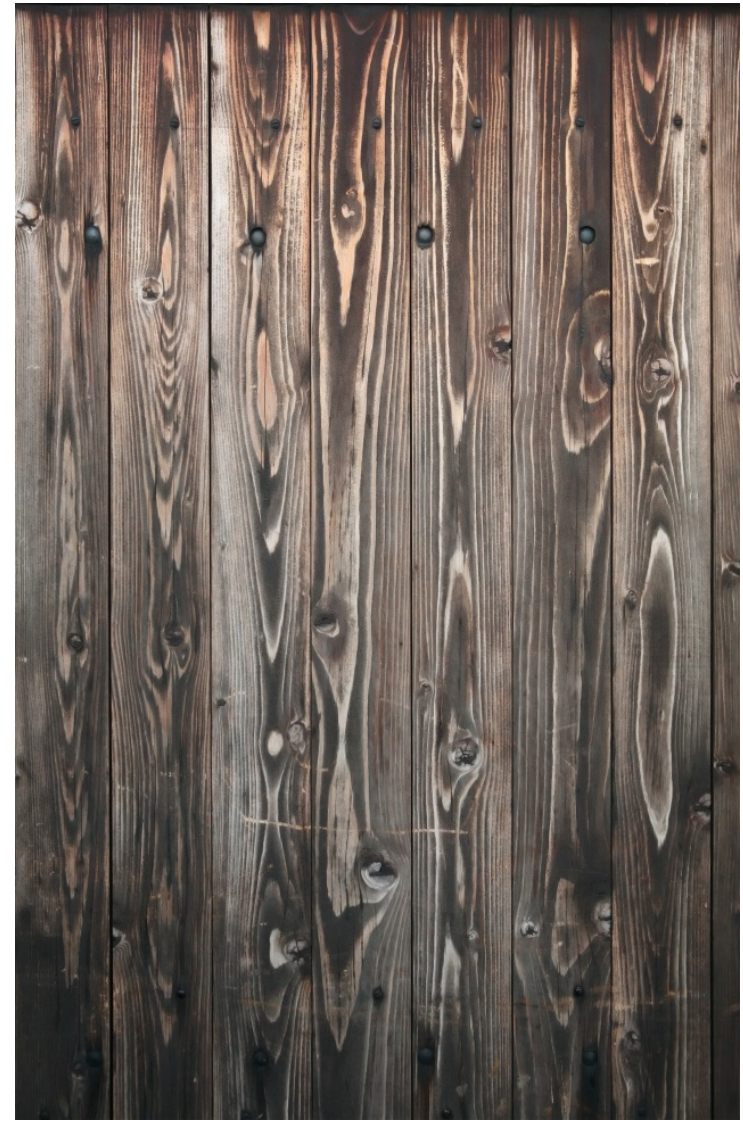

Schneider's doors were the only two that were necessary to the action of the scenes. The other

doors that would

Figure 20: Schneider's Parlor Wall Elevation

lead to Cliff and

Schultz's rooms

could be inferred

offstage. Also, for

Schneider's I chose

lively, upbeat, art

deco wallpaper

(Figure: 11) using

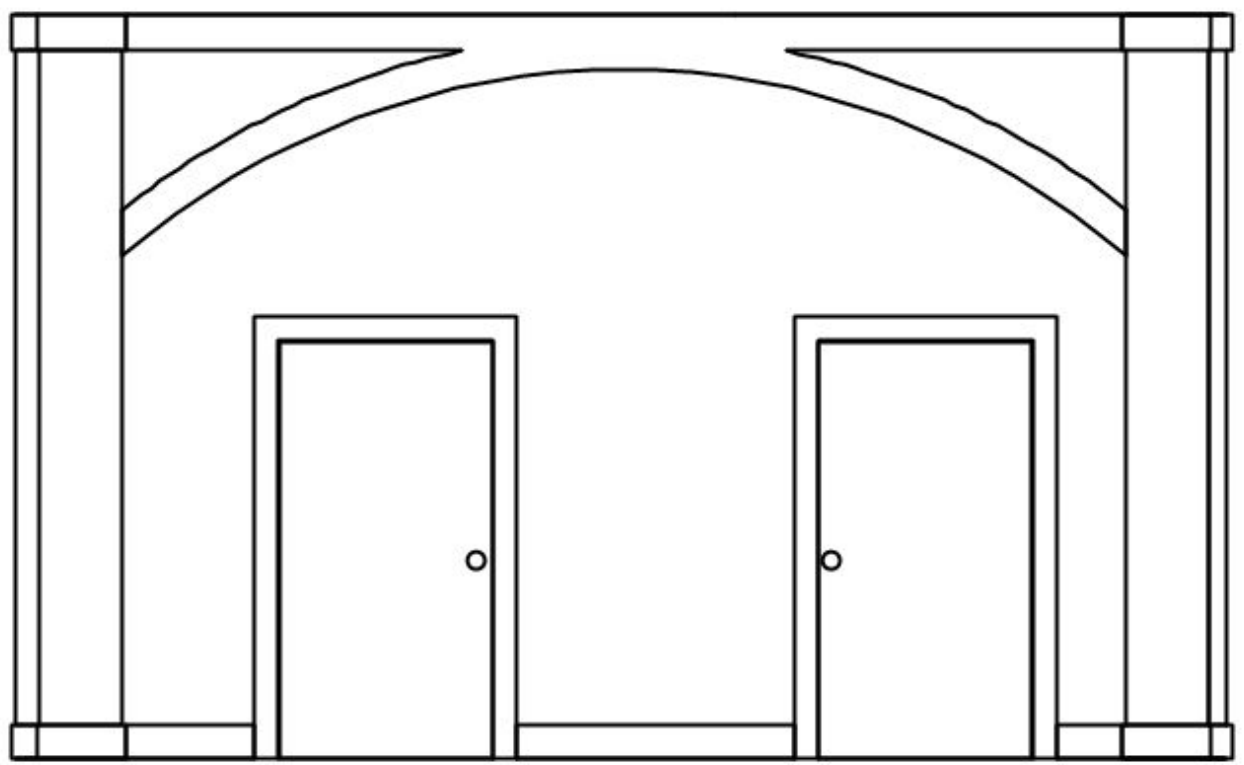


the denim blue from my color palette. Again, I chose to blow the print out of proportion to support the comedy of the scenes in the room.

The Kit Kat Klub's structure remained basically the same as it had in former versions. I specified the use of a sheer bronze fabric in the club's proscenium arch. The slip-stage was designed with two levels in front, one straight and one rounded, which gave me the shape I was looking for but allowed the actors to use it as stairs. I added railings to the second level of the club for aesthetic and actor safety. The design was inspired from railings I had seen in the Creative Arts Center at WVU in certain stairwells. They had an art deco feeling to them, and despite the fact that the originals were bright mint green; I felt mine would support the industrial feeling when colored in steel and bronze. The club's set also included sets of vertical steel poles that acted as, not only as platform supports, but also as more industrial texture and height. The railing on the second level ran in between these supports. Also attached to these poles on the second level were a set of 'high-top' tables. These tables were added to save floor space on the platforms, as

Figure 21: Cityscape Fly Version Two

the spiral stairs took up a lot

of property. I also altered the

design of the cityscape fly. It

was originally designed to

look like city buildings from

an extreme perspective,

creating the effect of the
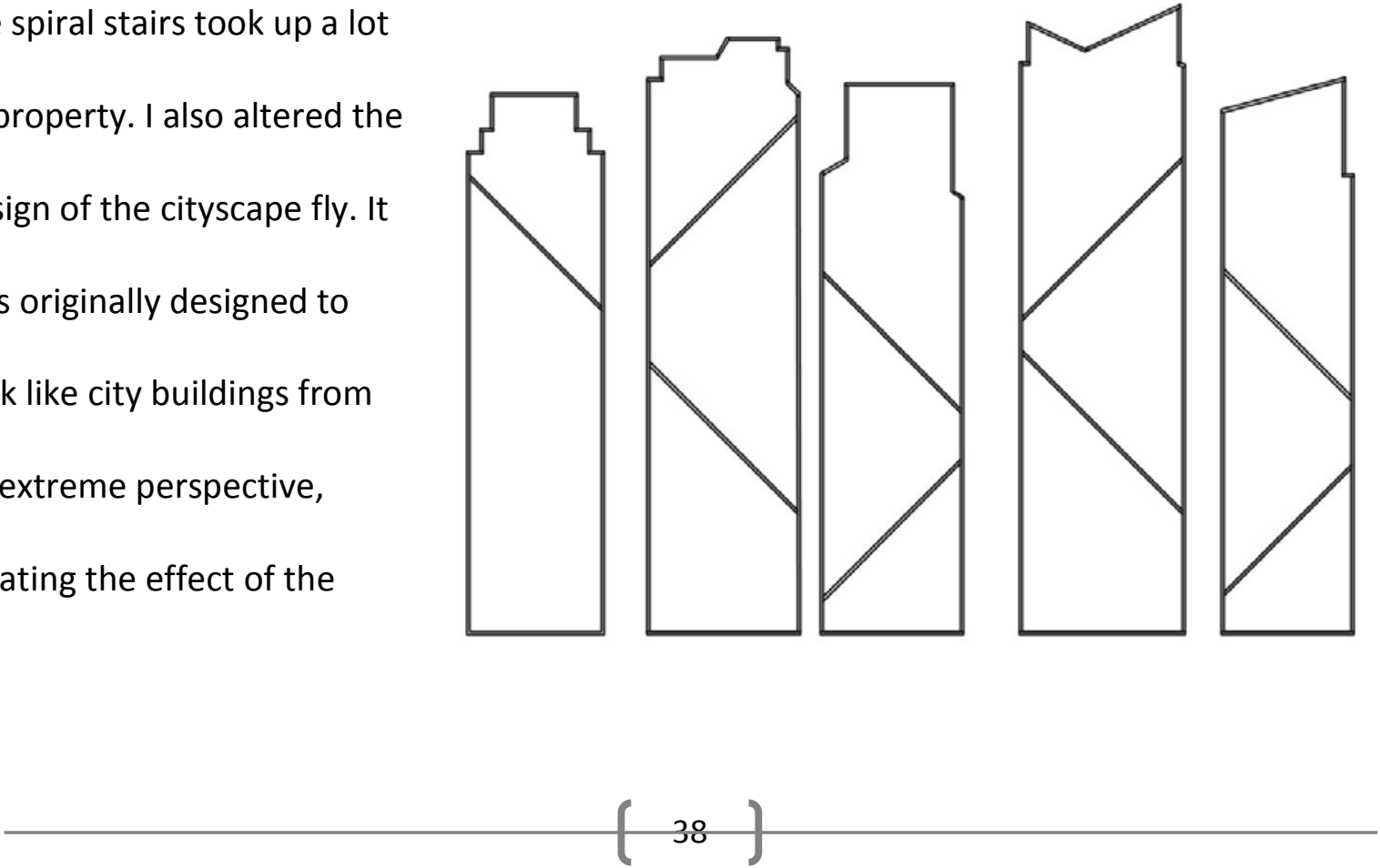
Figure 22: Schultz Fruit Shop Fly

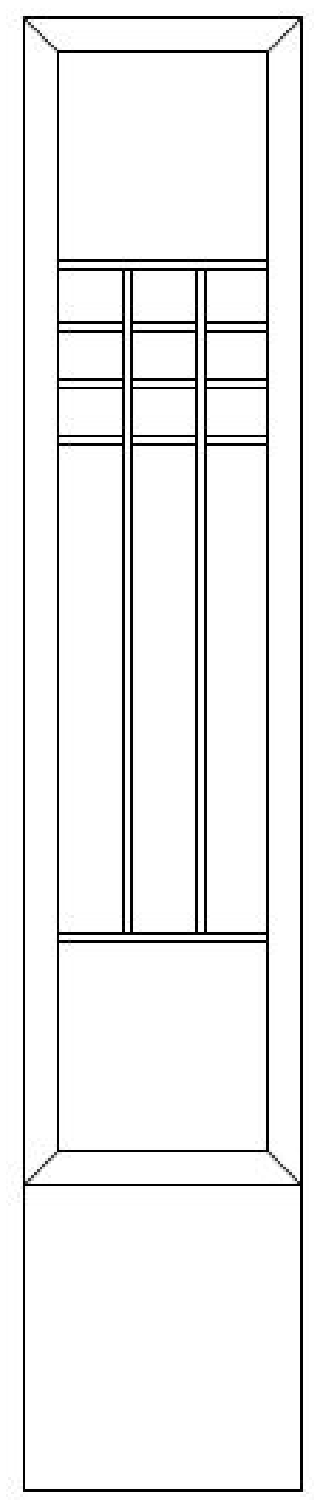

buildings looming over the rest of the set. Somehow in my drafting I had never successfully accomplished the overbearing feeling I was trying to portray. The design then became more straightforward: a series of straight, steel framed panels that created the shape of a building at the top (Figure: 21). I mimicked the $V$ shaped truss supports from the speaker towers to visually tie them together. The Schultz fruit shop fly was designed as a series of seven identical art deco inspired windows (Figure: 22), each almost fifteen feet high. The first three feet of each wall was left as just flat wall before the window began. This when painted to look like wallpaper would reinforce the idea that this was the interior of the shop. Lastly, the train car was designed in a wide V shape to improve the sightlines for the audience. I included a sliding door at the back, two seats on either side for passengers, and luggage racks. The train car had a slight curved ceiling at the top, but was open in the center. This assisted the illusion that there was an actual ceiling, but the center was removed to allow for lighting.

All of these pieces were drafted into a packet of elevations to be turned in to Professor Neuenschwander for budgeting.

\section{Sketch-Up Version Two}

Along with the detailed drafting packet, I also went back and updated my Sketch-Up model (Figure: 25 ) to present at the design presentation. With little time left before the design

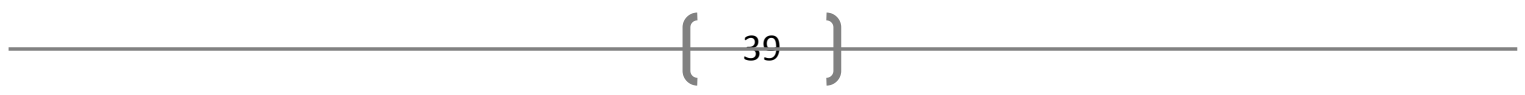


presentation to build an actual scale model, Professor Klingelhoefer thought that a 3D computer model would be the best way to communicate my design ideas and show the functionality of the set to the rest of the design team. I imported all of the textures, wallpapers, and fabrics I was planning on using and applied them to the computer rendered units. I also used 3D rendered furniture available from Google's free library to flesh out the model and communicate where I thought the furniture should be placed in each scene. I added images of the completed 3D locations to my design boards and brought the digital file with me to show if there were additional questions.

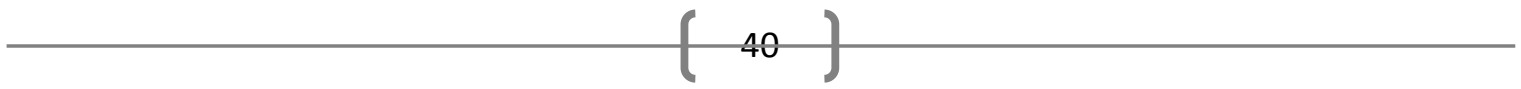


Figure 23: Sketch-Up Model Version Two

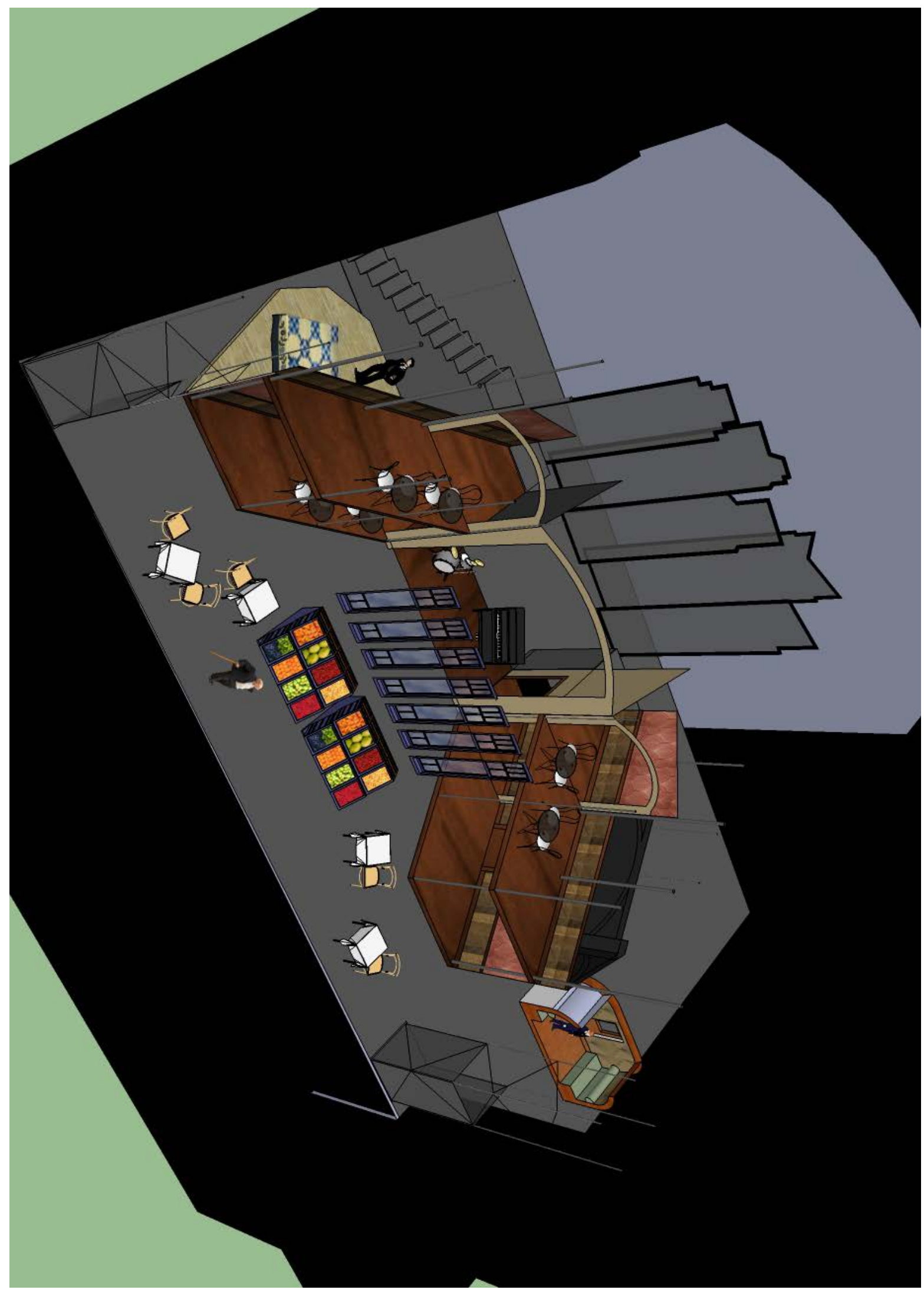




\section{Design Presentation}

With design boards and my 3D rendered model in hand, I presented my ideas to the director and the other designers. I discussed each look and its individual functions, as well as the overall function of all the units and how they transitioned from one space to another. I showed the ideas for the color palette and briefly discussed what types of furniture required. There were a few questions from Professor Blair about functionality of spaces and how the pieces moved on and off stage. I had the 3D model pulled up on the computer and was able to show him specifically how each piece would move during transitions. Professor Blair also suggested that the "Cabaret" sign hanging in the club scenes was not aggressive enough and perhaps needed a different font.

Lighting Designer Thistleton asked a few questions about where certain lighting practicals would hang or be used. He wondered if we still wanted to put rope lighting above and underneath the second floor platforming in the club. We all agreed that it would be beneficial for adding ambiance and dimension. Rope lighting was already being used in the club arch to add dimension and additional lighting effects. We also discussed where cable would run for the rope lighting, as well as for the individual lights that would sit on each cabaret table. Professor Neuenschwander stated that the cable could be run next to the "jack-knifed point", and that there would need to be plenty of extra cable to compensate for the platform

$(-42)$


movement. In general everyone seemed to like the overall design, color palette, and textures I had brought together. 


\section{Budgeting Crisis \& the Re-design}

The largest challenge of this entire process came during the budgeting phase. I was

originally allotted $\$ 5500$, which included scenery and paints. While designing the show, Professor Klingelhoefer had told me not to worry about the budget, just design exactly what I wanted. The design could always be scaled back, but it is harder to add pieces back later. My initial design was completed and I had turned in my drafting packet to Professor Neuenschwander to price out each individual piece of scenery. In the meeting following his completed budgeting of the show, he told me that I had designed a show that would cost the department $\$ 14,356$, almost $\$ 9,000$ over my $\$ 5500$ budget (Figure: 24$)$. The stage left wagon alone was $\$ 2,747$, over half the budget. I was completely emotionally overwhelmed, this had never happened to me before. I had been over budget on designs before, but never to this degree. How was I supposed to edit out over half of the set I had designed? I had become so invested in the design I could see no way around the situation. I already felt that the set was very minimalistic and lacking in detail. I didn't know where, or what, to start cutting. Professor Klingelhoefer and Professor Neuenschwander gave me a week to work on a redesign, and I took the first day of that to just emotionally recover. I called my family and friends asking for advice. I was so disappointed in myself for aiming so off the mark. So after my emotional recuperation, I sat down with Professor Neuenschwander and started to edit pieces off of my set.

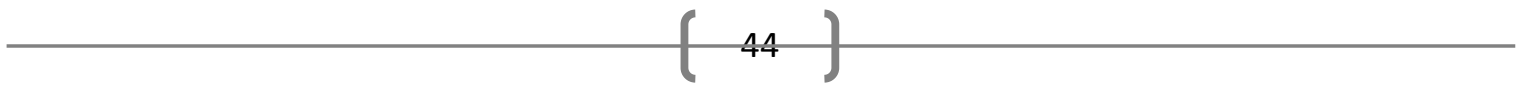


Figure 24: Production Estimate Cover Page

\begin{tabular}{|c|c|c|c|}
\hline \multirow{3}{*}{\begin{tabular}{|} 
West Virginia University \\
College of Creative Arts \\
School of Theatre \& Dance
\end{tabular}} & \multicolumn{3}{|c|}{ PRODUCTION ESTIMATE } \\
\hline & \multicolumn{3}{|c|}{ PRODUCTION Cabrares } \\
\hline & \multicolumn{2}{|c|}{ PREPARED BY: $\mathrm{SC}_{2} \mathrm{~N}$} & DATE: $4 / 30 / 13$ \\
\hline \multicolumn{4}{|l|}{ DEPARTMENT: SCeneman } \\
\hline \multirow[b]{2}{*}{ ELEMENT } & \multirow[b]{2}{*}{ COST ESTIMATE } & \multicolumn{2}{|c|}{ TIME ESTIMATE } \\
\hline & & CONSTRUCTION & LOAD-IN \\
\hline \multicolumn{4}{|l|}{ SL wayan $\$ 595147$} \\
\hline \multicolumn{4}{|l|}{$2^{2}$ Lewel 1 wema 11966475} \\
\hline Wall F \$509:135 & & & \\
\hline \multicolumn{4}{|l|}{ wall $\& D D / 20 / 28$} \\
\hline \multicolumn{4}{|l|}{$\operatorname{lall} 1-1 \quad \$ 227<21$} \\
\hline \multicolumn{4}{|l|}{$\operatorname{coc} C \mathrm{H} / 12 / 16$} \\
\hline \multicolumn{4}{|l|}{ wael I \$1 $85 / 16$} \\
\hline \multicolumn{4}{|l|}{ crace E \#1/3t $/ 11$} \\
\hline \multicolumn{4}{|c|}{ 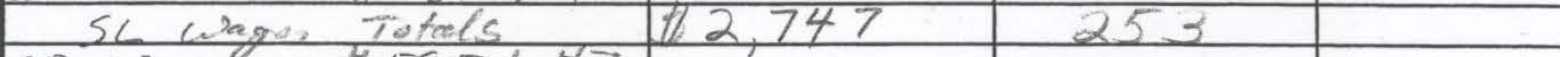 } \\
\hline \multirow{2}{*}{\multicolumn{4}{|c|}{ 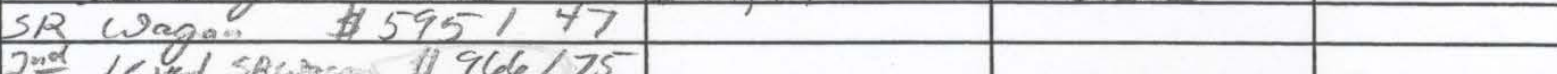 }} \\
\hline & & & \\
\hline \multicolumn{4}{|l|}{ chall $4 \mathrm{E} \beta$ क 745,171} \\
\hline \multicolumn{4}{|l|}{ WALL C\&D $1120 / 28$} \\
\hline \multicolumn{4}{|l|}{ Whell हl $म 1734 / 11$} \\
\hline $3 R$ wangan iofole & $\$ 2560$ & 232 & \\
\hline \multicolumn{4}{|l|}{$C l e c$ Ares $\$ 1.043<50$} \\
\hline \multicolumn{4}{|l|}{ Wall EsL $\$ 134 / 11$} \\
\hline WaUl ESR $\$ 134 / 11$ & & & \\
\hline Slip stage $4660 / 34$ & & & \\
\hline Band Platfarm, $18309 / 14$ & & & \\
\hline Center T-itel= & $\$ 2285$ & 122 & \\
\hline Stair Lenits & $11+82$ & 32 & \\
\hline Train & \$6.24 - . & 53 & \\
\hline Cuet Drop & $\$ 285, \ldots$ & 5 & \\
\hline Shattz Elivdaen is & 81622 & 34 & \\
\hline Cifo, $\mathrm{fl}_{\mathrm{c}}$ & A 476 & 28 & \\
\hline Eost lights & 420 & 5 & \\
\hline Cabaref sign & $\$ 169$ & 24 & \\
\hline Speakep tacien: & & & \\
\hline Prapecasue privot & & & \\
\hline Pai-t & 4450 & & \\
\hline & & & \\
\hline & & & \\
\hline & & & \\
\hline & & & \\
\hline & & & \\
\hline & & & \\
\hline & & & \\
\hline & & & \\
\hline SUB TOTAL & 12,430 & 738 & \\
\hline $5 \%$ Hardware & 621 & & \\
\hline SUB TOTAL & 13,051 & & \\
\hline $10 \%$ Contingency & 1305 & 79 & \\
\hline TOTAL & 14,356 & 866 & \\
\hline
\end{tabular}


The first, most glaringly obvious piece to be cut was the second floors of the rotating wagons in the club. This eliminated almost $\$ 2000$ in steel and lumber. Once we the second floor was cut, this eliminated the need for the two sets of upstage stairs. The stairs would have been stock, but the steel I incorporated as vertical supports for the hand rail, and to mimic the steel vertical supports on in the club, would cost $\$ 175$. The $1 / 4$ " lauan to face the front of the stairs was another $\$ 146$ and the $2 \times 4$ to create the runoff platform was $\$ 81$. Eliminating these stairs cut another $\$ 482$. Another item that could be altered was the curtain in the onstage club arch. I had planned to buy bronze sheer fabric from Rosebrand, but it priced out at $\$ 798$. We discussed replacing it with either cheaper fabric, or another material that would give the same effect, but not cost as much. The last major expensive item that could be eliminated was the false proscenium arch to shape the cyclorama. We had discussed building it out of lumber, but Professor Neuenschwander suggested getting a cut drop that could be used over again by the department. The drop, sourced from Rosebrand, would cost an additional \$995. Thus far I had eliminated $\$ 3400$ from my budget, a good chunk but not enough to bring the design back under budget.

During this meeting Professor Blair walked by and inquired what we were doing. We filled him in on the discussed cuts and other cuts that we were planning to get the set back within budget. Professor Blair understood about the first few cuts, the second level of the club, upstage stairs, and cut drop. As we discussed other options he began to become agitated and at one point walked out of the room saying "If you cut any more there'll be no set!" He and Professor Neuenschwander walked down the hall into, Professor Josh Williamson, the director of the theater department's office and negotiated a budget increase. Professor Williamson

$+(156)$


gave the show an additional $\$ 2500$. I was relieved, this budget addition would not allow me to retain everything I had designed, but would let me to keep some of the details that made the design a complete thought. Professor Neuenschwander and I went on to simplify many of the units, shaving off unnecessary pieces. The rotating platforms no longer had a second floor which allowed there to be fewer and shorter walls. We also discussed simplifying the cityscape fly. By shortening them slightly and eliminating the complicated shapes at the top, we could save ourselves money on box steel. Another easy cut was eliminating the Plexiglas I had asked for in the Schultz fruit shop windows, which would cost $\$ 1265$. Additional changes were made to some of the materials that the trim and moldings would be made of. Most of the molding would have heavy paint treatments on them, and could be made out of the cheapest materials possible as opposed to fancy routed molding.

After the cutting process with Professor Neuenschwander, I met up with Professor Klingelhoefer and we discussed how to redesign the pieces of the set that were remaining. I had a small amount of my budget to add a few pieces back in but had lost the majority of the visible steel and most of the elements that gave an industrial feeling. What was left was the two rotating platforms, the center band platform with an arch, a train car, a city fly, and the Schultz fruit shop fly. I had to find some way of returning the sense of industrialism without adding expensive materials.

\section{Drafting Version Five}

Redrafting version five (Figure: 25 ) of the set after the budget cuts was to determine if I had all of the elements I needed to tell the story, and make sure that those pieces still conveyed

$10(17)$


the emotional messages necessitated by the script. My first endeavor was to make the remaining walls on the rotating platforms reflect more of the jagged, industrial feeling I had lost. Professor Klingelhoefer and I discussed using more of Feininger's art to fill the void left by the deleted second floor. My walls had always had a basic cityscape look to them, but Professor Klingelhoefer suggested that I push this idea further. I carried over the design of the top of the cityscape flies onto the tops of the walls and decided to use the Feininger painting 'Die Laterne' as the texture (Figure: 5). This gave me back some of the jagged broken feeling I was missing. Each platform now only had two walls: one long wall with the cityscape top and one archway wall as support. I had eliminated all of the other supporting walls and hallways. The doors that used to lead into these hallways would now lead directly into the club side of the platform. On the stage right platform this was not an issue as there was only one door and it let out upstage of the action. On the stage left platform the doors now led through a piece of wall that I had intended to be a mural. Professor Klingelhoefer gave me the idea to omit the molding on the mural side and just continue the mural across the doors.

I next carried the hand rails down from the eliminated second floor to the first. The actors could not move on and off the platform if I used the entire piece, so I created chunks of railing to maintain the look. Also in the club, the center arch curtain that was deemed too expensive would be replaced by bronze colored chain. Again, this was an attempt to add in any pieces of metal back into the design to regain the industrial feeling I had lost. The chain would be significantly cheaper than fabric, could provide the same shape, and create the same division of space.

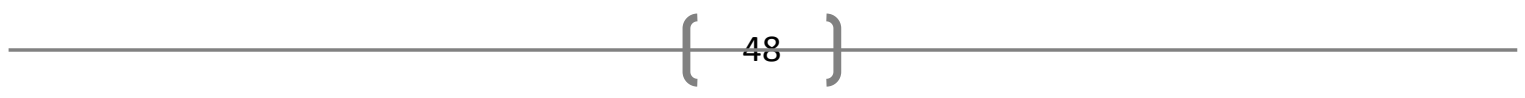


Surprisingly, most of the main elements retained their basic designs and my redrafting consisted mainly of cutting or reshaping items already drafted. After all was said and done, it felt like an extremely bare and stripped down version of what I had originally intended. I knew that a very heavy job fell on what textures I chose to paint to help rebuild the void left by the cuts. I left for the summer feeling completely emotionally worn out, but I was excited to dive into the build phase.

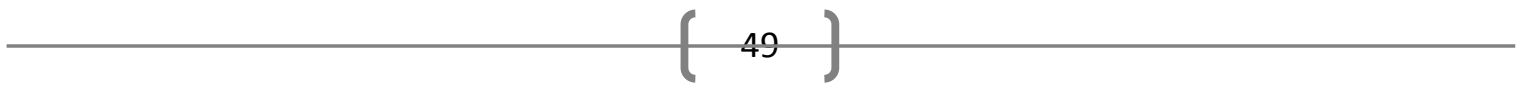


Figure 25: Drafting Version Five

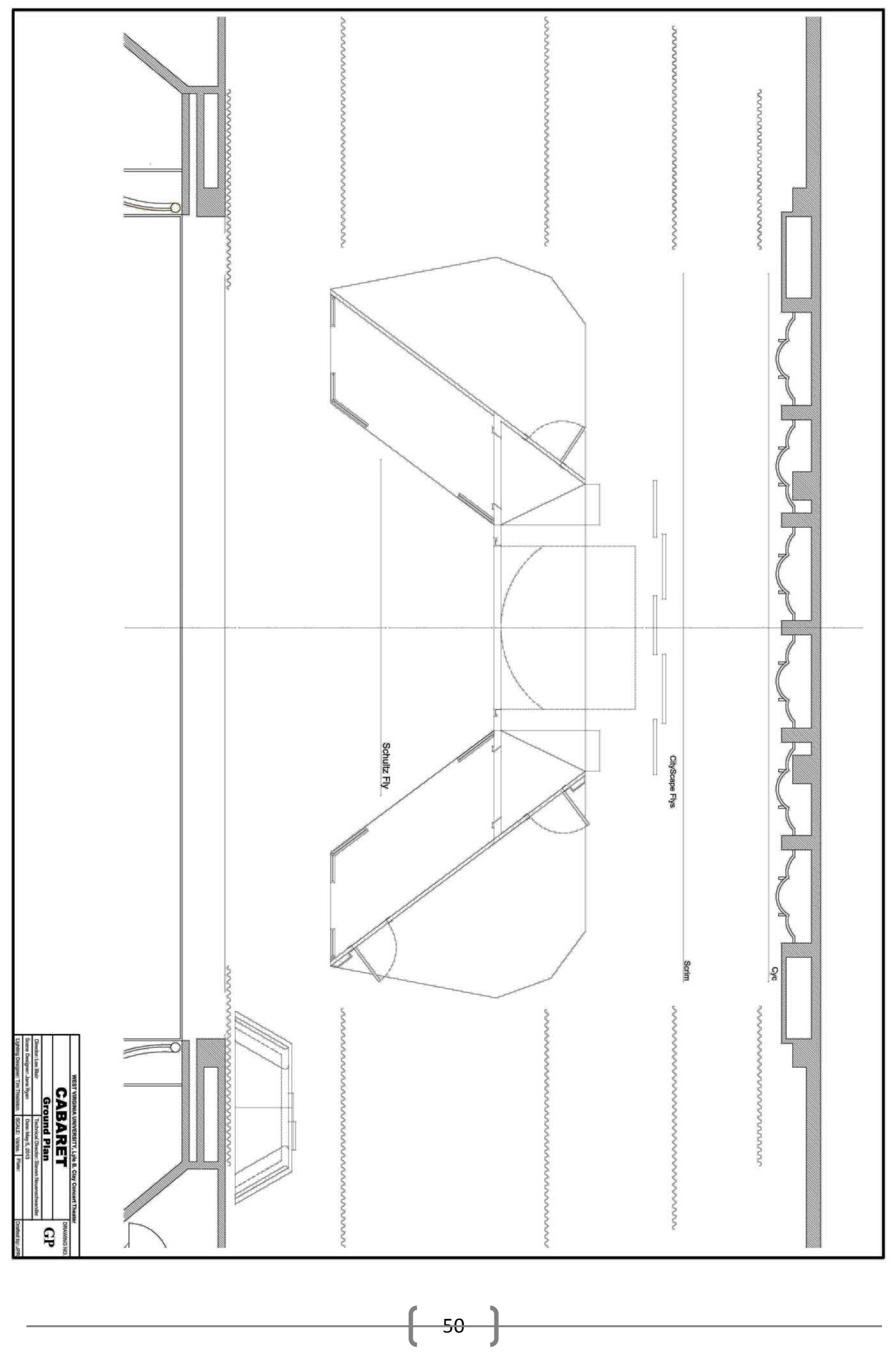




\section{Director's Summer Changes}

After all of the design pieces were approved, we all left school for the summer. When we returned we would launch straight into the build with not much time to get organized so everything had to be prepped and approved before the summer. I was surprised when with less than a month before I was slated to return, I received a call from the Professor Neuenschwander. The director had had time to review the design and think more about his blocking and he wanted to make some changes. Luckily, none of these changes were seriously drastic, but I was out of state and without access to the internet, my drafting programs or Sketch-Up. Professor Neuenschwander had spoken to Professor Blair about the changes he wanted and had kindly drafted up general ideas for me to look at. None of these ideas were set in stone, but it was helpful to be able to see what we were discussing in conference calls.

First Professor Blair had rethought the Schultz fruit shop fly, and had decided that he really wanted a door in it. He needed somewhere for people to enter and exit from, and my idea of people arriving from the wings did not have the impact he wanted. Professor Blair wanted a working set of doors that swung open and shut, but as the piece of scenery was a fly this would be almost impossible to accomplish. Doors need to be counter-weighted when they swing open. A door frame attached to a batten by aircraft cable does not allow any support for counter-weighting the door. Professor Blair adamantly did not want just an open gap in the

$(51)$


windows and felt there should be more of a definition of a door way. After speaking to Professor Klingelhoefer, I came up with the compromise of creating a door frame with doors attached (Figure: 26), but those doors would be affixed to the frame in a permanently open

Figure 26: Schultz Fruit Shop Fly - Final Version
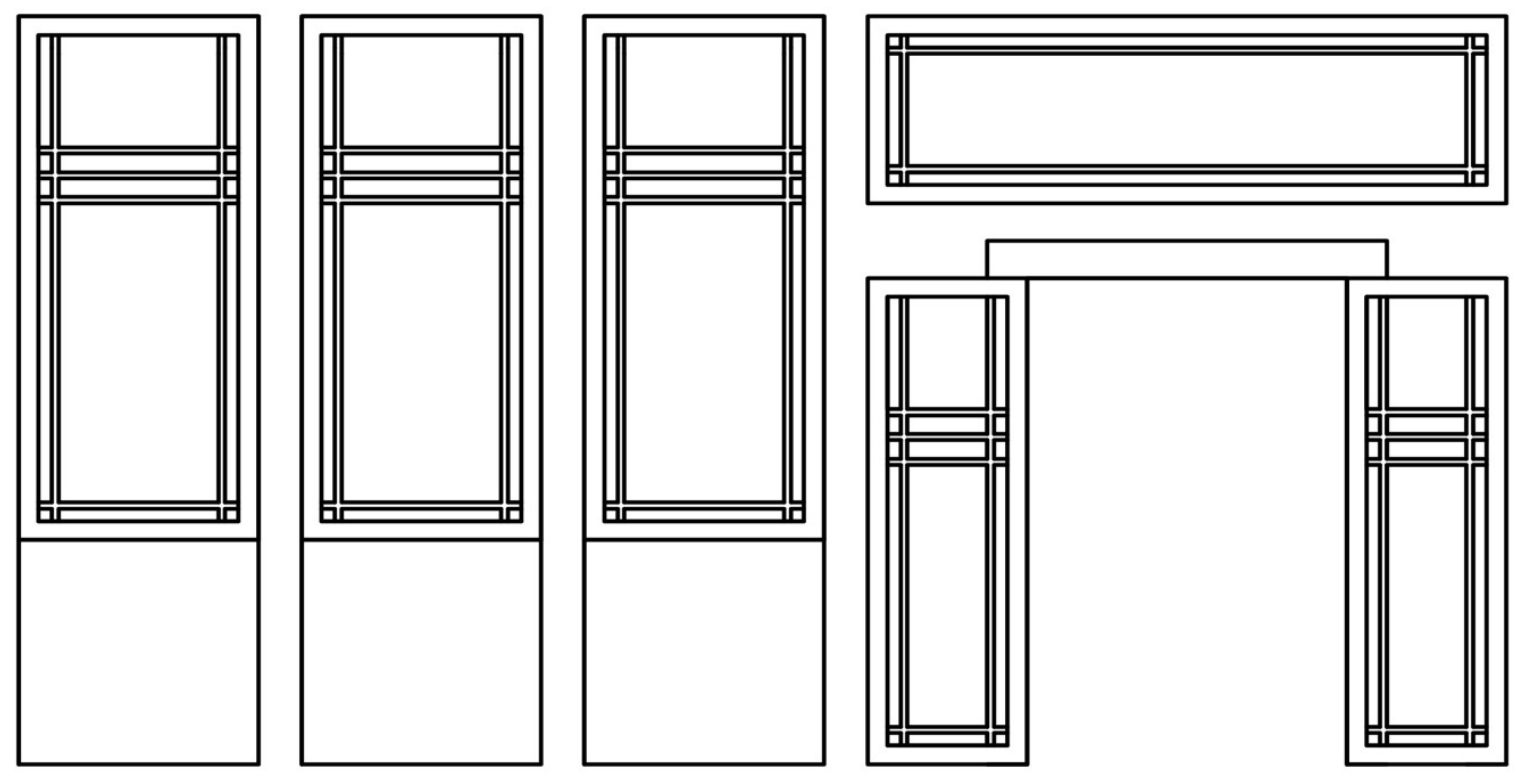

position. This gave Professor Blair the doorway he wanted, but eliminated the difficulty of having to figure out how to support a fly with swinging doors.

The next major change that the director wanted was to add two doors onto the stage left wagon's main wall. The two doors there were to lead to Fraulein Kost and Fraulein Schneider's rooms. Professor Blair wanted to have exits available for Herr Schultz and Cliff's rooms as well. I was against this decision, because the doors he proposed would be used so infrequently. I believed it could be just as easy to infer the other spaces off stage. Professor Neuenschwander stepped in at this point and stated that adding two more doors to a single straight wall that large would seriously jeopardize the stability. So, after some discussion, we compromised on three doors, adding in one that would exit to Herr Schultz's room. This meant

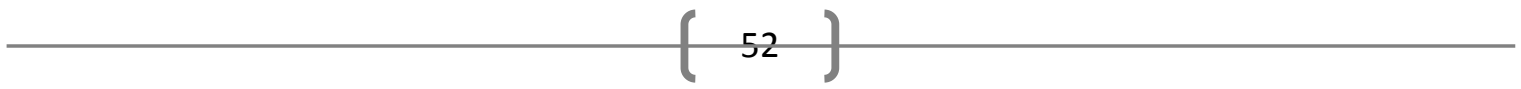


that I had to reconfigure the columns and the molding on the walls. I started with the initial idea to evenly space the doors across the wall and have columns in between each one. The issue with this came on other side of the wall. If I placed the new door in the center of the wall it would mean I needed to relocate the bar and move the supporting archway. It also meant that the door would open through the molding I had planned to go around the murals on the

Figure 27: Schneider's Parlor Wall Elevation - Final Version

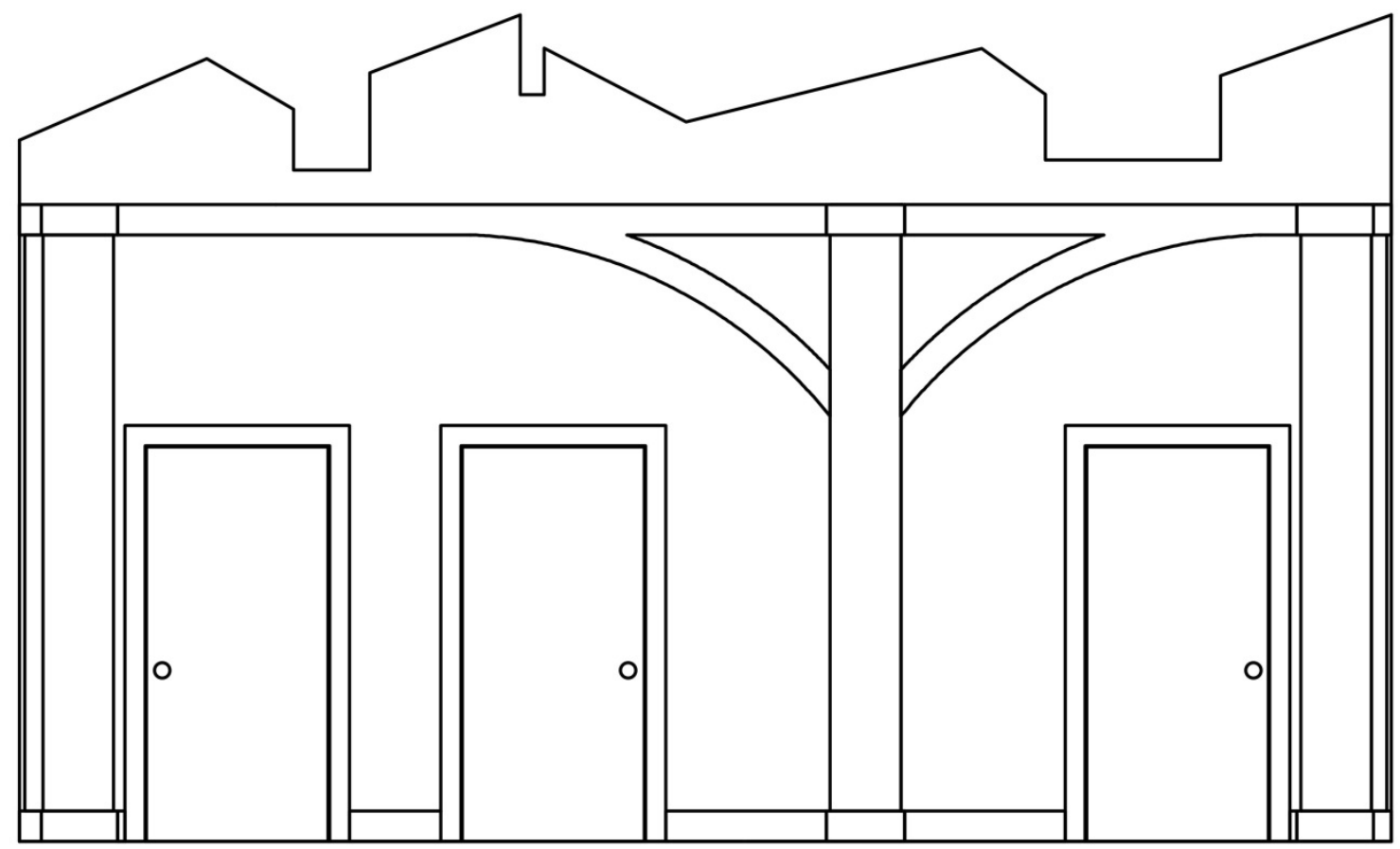

club side of the wall. The solution was to place the door over to one side within the mural on the opposite side (Figure: 27). The molding and columns had to be adjusted to fit, but I very much liked the result of the off center column and arched molding.

The next problem Professor Blair brought up was that since cutting the second floor platforming in the club, there were limited levels left for him to stage actors on. The solution became a smaller raised platform on top of the stage right rotating platform. It could only go in this location as the stage left platform already had the bar and two doors. I left a step up all the

$-(53)$


way around the downstage edges of the platform to act as a stair and moved the hand rails up onto the higher platform

(Figure: 28).

Figure 28: Stage Right Platform - Height Addition

The last major change

proposed was the altering of

the sign that said 'Cabaret'. It

had originally been simply

the word with 6" metal

flashing around the edges to

create the look of a marquee

sign and would be wired for

carnival lights (Figure: 29).

Professor Blair had already

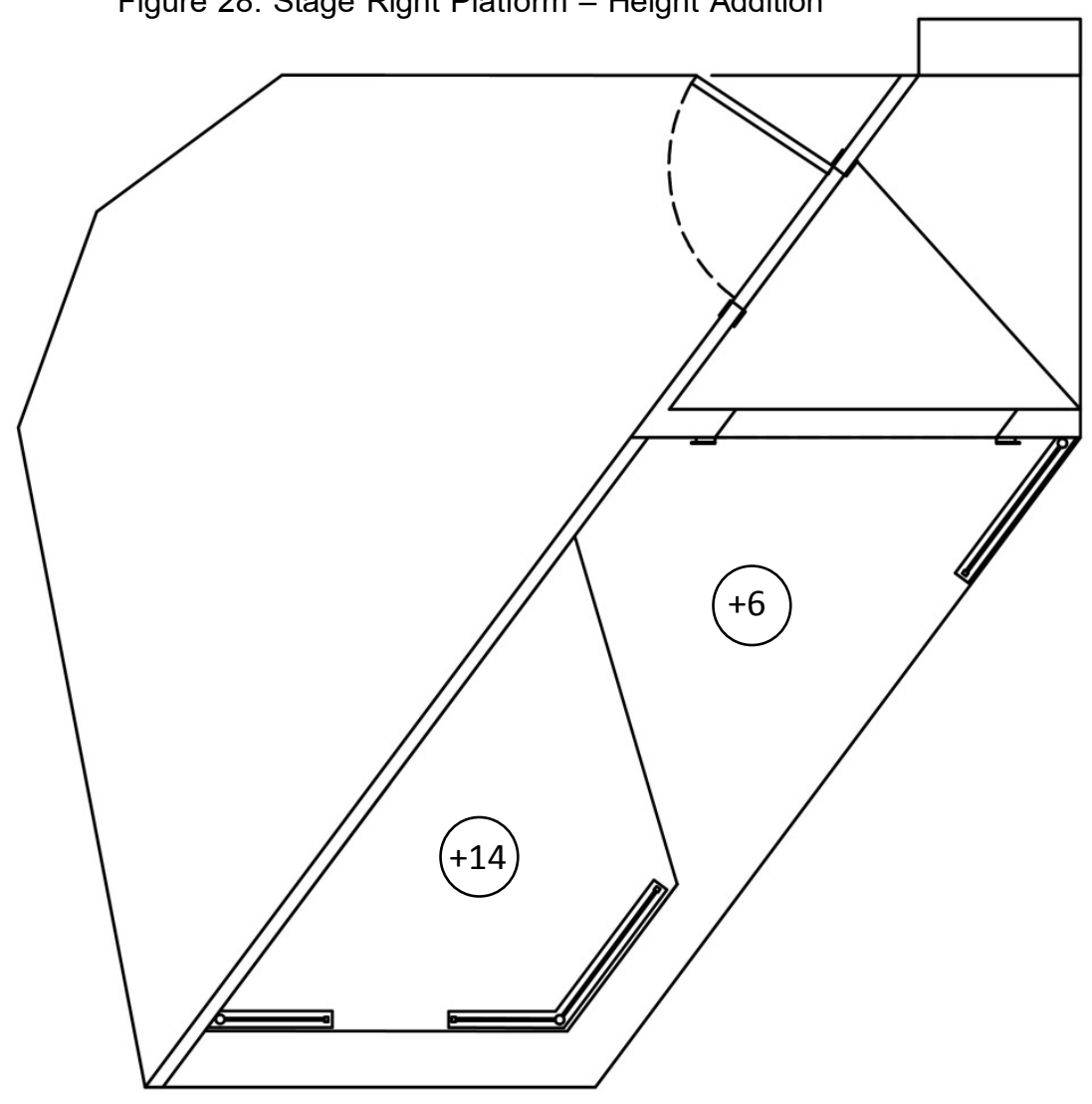

expressed his desire to make the font a bit more edgy; he felt the initial one was too 'polite'. In addition to an edgier font, he suggested that we physically break the sign up. He wanted it to feel more in line with the rest of the cityscape with its Feininger images. In the recreation of the sign, I went through several fonts before settling on one that was more aggressive but still retained the art deco feel (Figure: 30). Then I decided to slice the letters apart at certain areas as though it had been cut. The cut lines were clean and not jagged and destroyed as I felt this echoed the straight lines of the Feininger painting. Also, as the play started on a lighter note and we would see the sign from the beginning I didn't want the sign to stand out in an odd way. 
All of these changes were agreed upon over the phone before I returned to school and once I returned I set about redrafting the changes.

Figure 29: Cabaret Sign - First Version

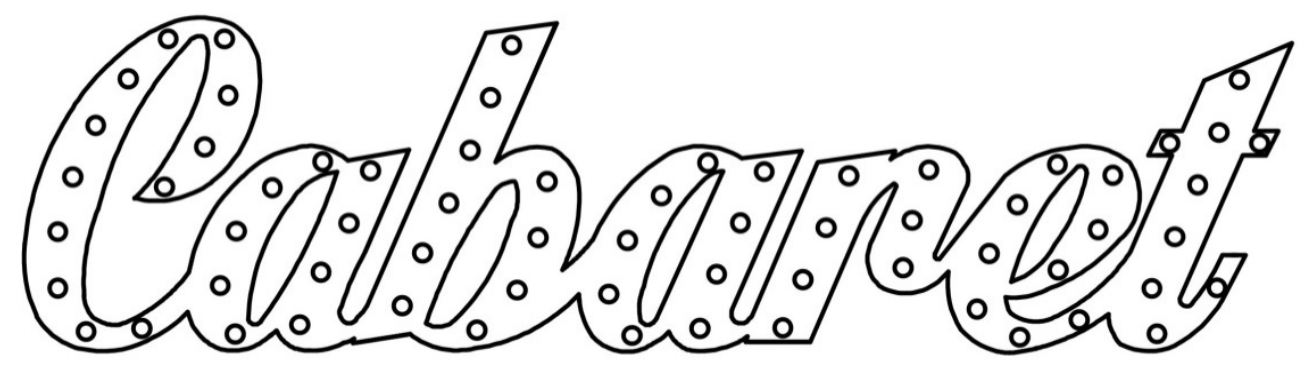

Figure 30: Cabaret Sign - Final Version

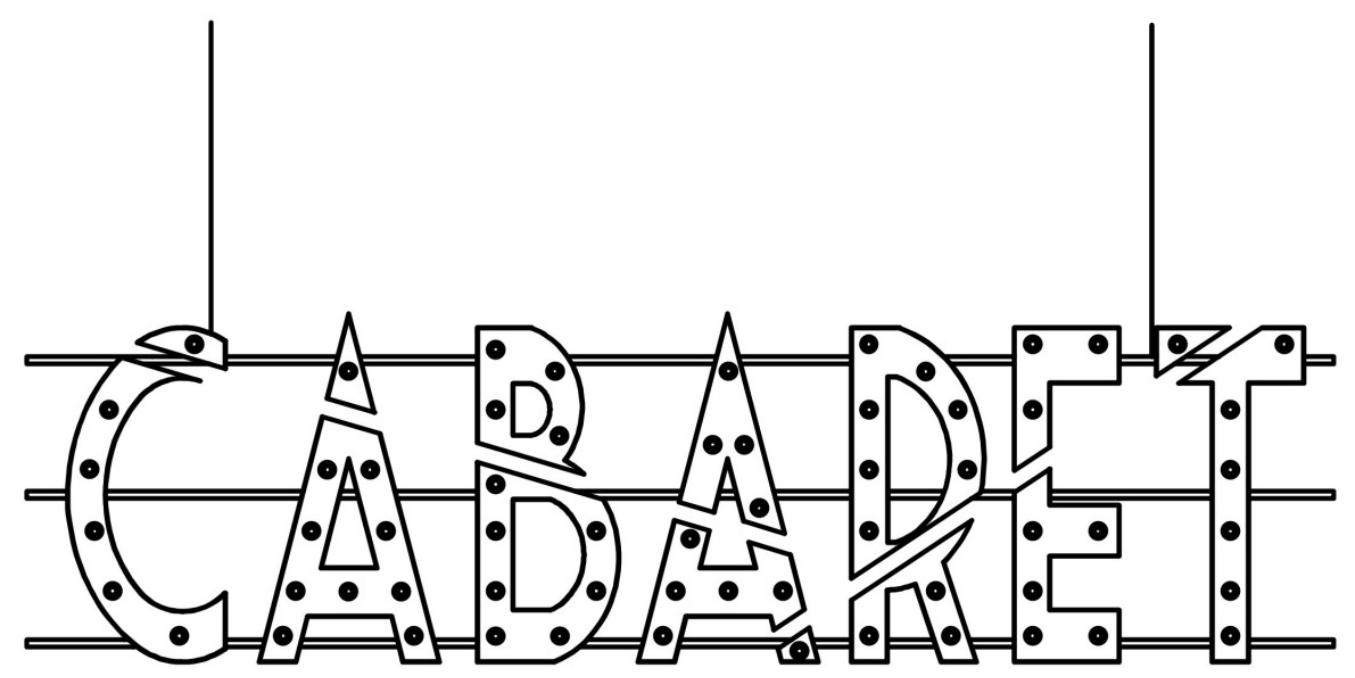

Drafting Version Six

I hit the ground running when I returned for the fall semester as I was returning a week

late. I had a lot of drafting to catch up on, very little time to get it completed, but after the budget cuts from the spring these changes seemed simple and easy to accomplish. Here is where I hit another bump in the road. The drafting seemed easy, but once turned into Professor 
Neuenschwander, it was full of errors and inaccuracies. Professor Neuenschwander and Professor Klingelhoefer held a meeting with me to discuss this problem. They were dissatisfied in the quality of work I was producing, as it was making work difficult for other design departments and not the level of work I should have been producing as a graduate student. They spent time detailing out all of the places I could improve my drafting and asked for new elevations. The new drafting reflected all of the changes that the director had requested and was essentially my final version (Figure: 31 ). In these elevations (Appendix A: Final Elevations) I attempted to fix all of the drafting issues I had been advised about. I spent time double checking dimensions, correcting line weights, and looking for errors.

With the final draft completed we launched into the build phase. As I had arrived back a week late from summer work and there had been so many last minute changes the build phase got pushed back a week as we waited for Professor Neuenschwander to complete the working drawings.

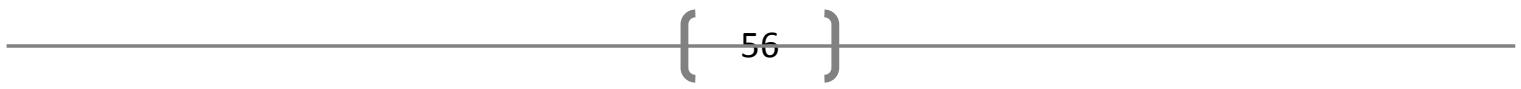


Figure 31: Drafting Version Six
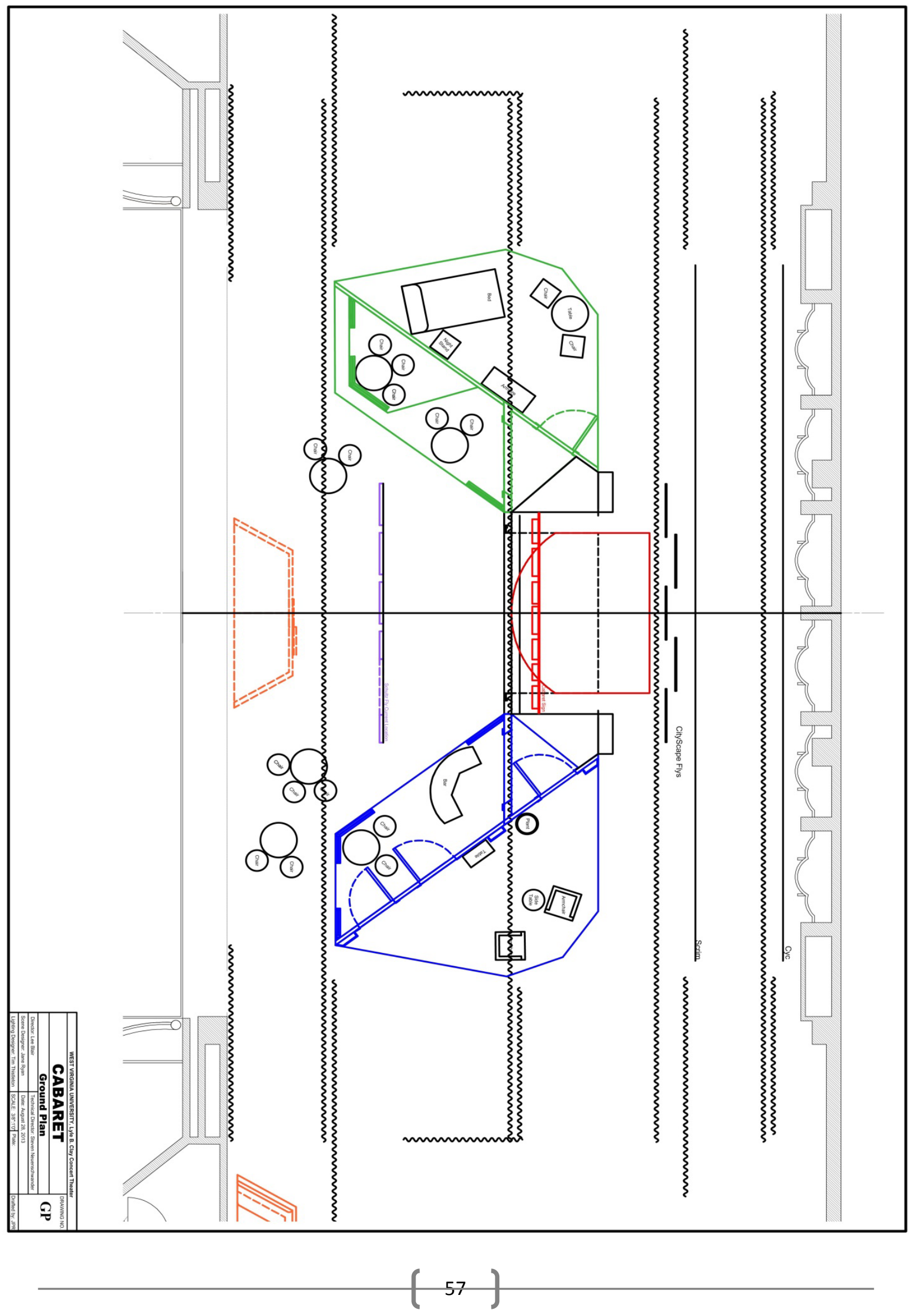


\section{Construction Process}

Building began a week later than anticipated, but we caught up quickly thanks to a massive amount of work from our scene shop supervisor, Caila Ruggieri. She came in early and left late to make sure that work was constantly moving forward. My primary job for the build was to act as the scenic charge artist. This was a job I was extremely comfortable with, having worked as a charge artist for many shows at WVU. I trusted my skills and knew I could use my scenic painting skills to support the weaknesses I had in drafting elevations. My assistant charge artist was Jessilyn Lawson, a sophomore undergraduate student who had shown exceptional talent at painting from early in her freshman year. As she aspired to become a scenic charge artist professionally, this was an opportunity for me to teach her everything I knew. I understood that I would have to be more on top of the schedule and the painting process as I had to instruct Jessilyn along the way. I could not whip things out quickly with little documentation and had to take the time to explain each step to her as we went.

I had allotted $\$ 500$ out of my scenic budget to cover paints. I knew we had a decent inventory of latex paints in a variety of colors that I could use for tinting, but I had worked the summer previously using primarily Rosco Off-Broadway scenic art paint and I knew with the amount of painting that had to be completed opting for the higher quality of paint would help me a lot. I divided up my budget and ordered approximately $\$ 300$ of it Off-Broadway paint. I

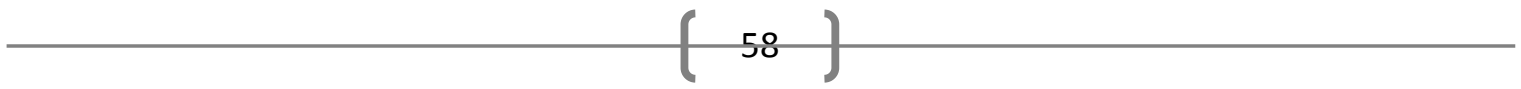


mainly bought varying shades of browns and yellows, as we had many of the other basic OffBroadway colors in stock. The next $\$ 100$ went to purchasing a five gallon bucket of white and 5 gallons of black paint that would be used for base coating and shading the other colors. I left the remaining $\$ 100$ to reorder paint we'd run out of or in case of emergency.

The first few weeks of build consisted mainly of carpentry. I was involved with this process on and off as I was assisting the team putting up the first show of the season (Cabaret was the second show). I helped construct the smaller complicated platforms that would create the rotating platforms. This was a learning process for me, as I had never built anything other than square platforms where you build the frame first and then attach the lid. With these odd shaped platforms we cut the lids out and then built the frames to the lids. Working with some of the undergraduate students who had been given leadership roles in the shop, this process took over a week to create the six custom-sized platforms. Mistakes were made on all of our parts that necessitated breaking apart what we had built to fix and rebuild the platforms.

Professor Neuenschwander has an exacting eye and would not let messily built scenery onstage. Other than helping create the platforms, I assisted in the framing of some of the walls and Schultz fruit shop windows, as well as prepping materials for other build projects. Once the first few pieces of scenery were created I left the carpentry process for the remainder of the build and focused solely on painting.

My first step on entering the painting process was to create a set of painter's elevations. There are a few different types that can be created, the main difference being that one type consists of drafted wall elevations painted with the desired textures and the second type being

$-(50)$


merely a picture of the desired texture. As

Figure 32: Paint Elevation - Schultz Fly

we were already a week late getting into

the build and my time was limited, I opted

mainly for the second type and printed off

large images of each texture I wished to

use. These worked easily for the pieces of

scenery that were entirely covered with

one texture. There were other places on

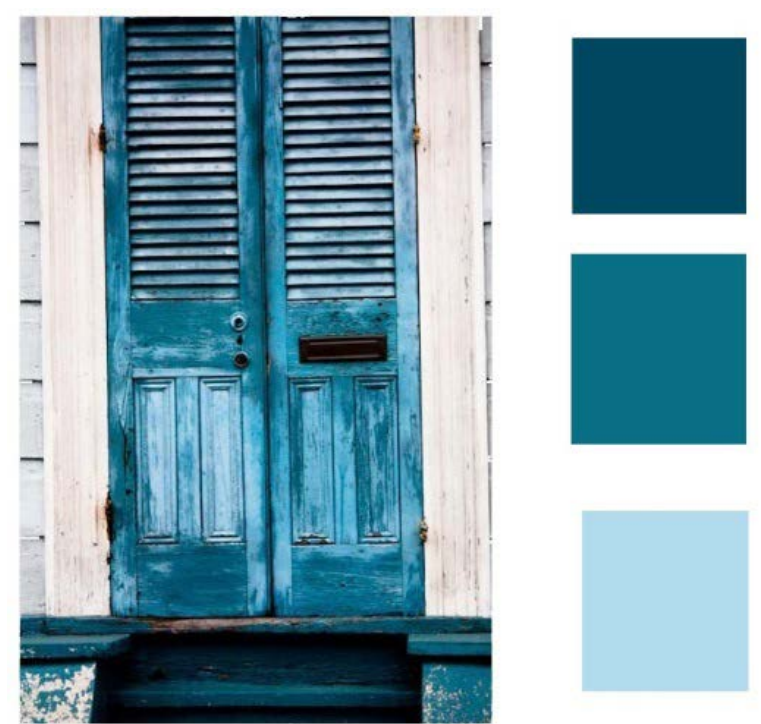

the set where printing the texture did not help me. Many of the pieces of the set I had planned on using a digital projector to copy the exact texture onto the walls. I created all of the elevations in a digital format intending to use the department's digital projector to copy the images onto the scenery. Once the scenic pieces were laid out in the space, I attempted to use the digital projector and hit a snag. I had chosen to use the digital projector due to its high resolution images that made laying out painting work easier, but it was not as flexible as I thought it would be in the space. This often meant that half of the image would be blocked by columns or tables in the shop. Also, the digital projector would mirror the images I had uploaded causing me to have to create multiple versions of each image just to make sure they would work. Professor Neuenschwander suggested that to save time I use an overhead projector instead. Despite the fact that the images were sometimes key-stoned or unclear, using the overhead projector did end up saving me hours of re-Photoshopping all of my projector images.

$(50)$


Once the elevations

were completed I spent time

with Jessilyn mixing the

majority of the paint colors we

would need to complete the

first few projects. I left some

paint to mix for later as I was
Figure 33: Schultz Window Distressing

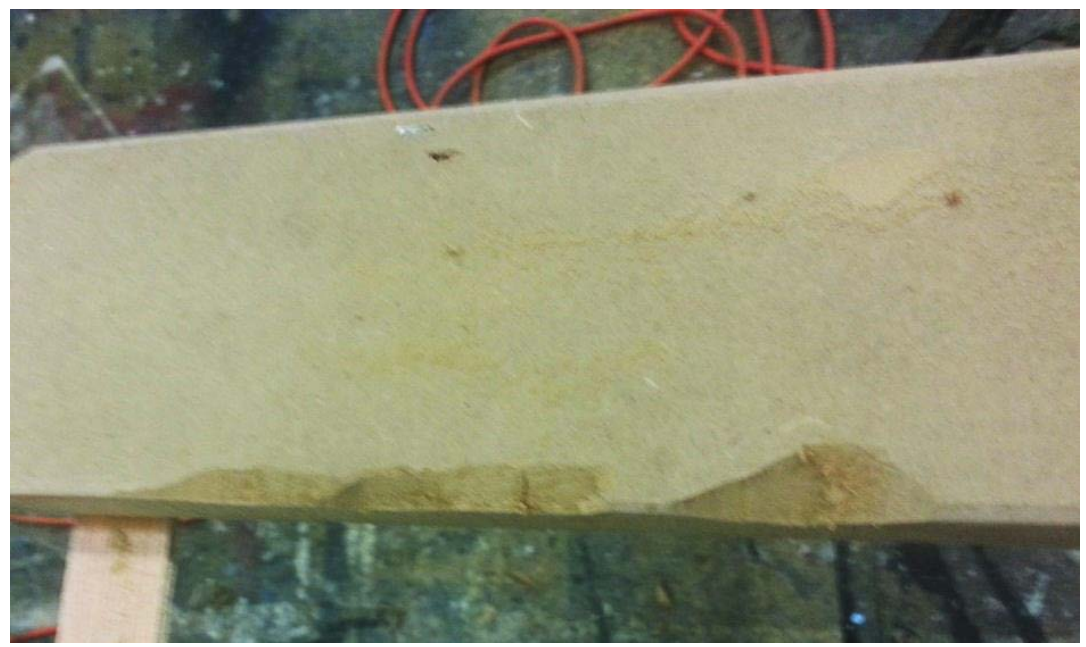

unsure of how the first pieces of scenery would use up paint and I wanted to be able to change things as I went along. Each texture was pinned to the corkboard in the paint cage with a piece of acetate over it. In Photoshop I had pulled out individual squares of colors I thought we needed to paint each piece of scenery. The process was then to match the paint to the square of color (Figure: 32). This process went fairly quickly, only taking two days to complete. We kept track of the initial Figure 34: Schultz Window Painted

colors we had

used to create the final paint colors

in case we ran out and needed to create the colors again.

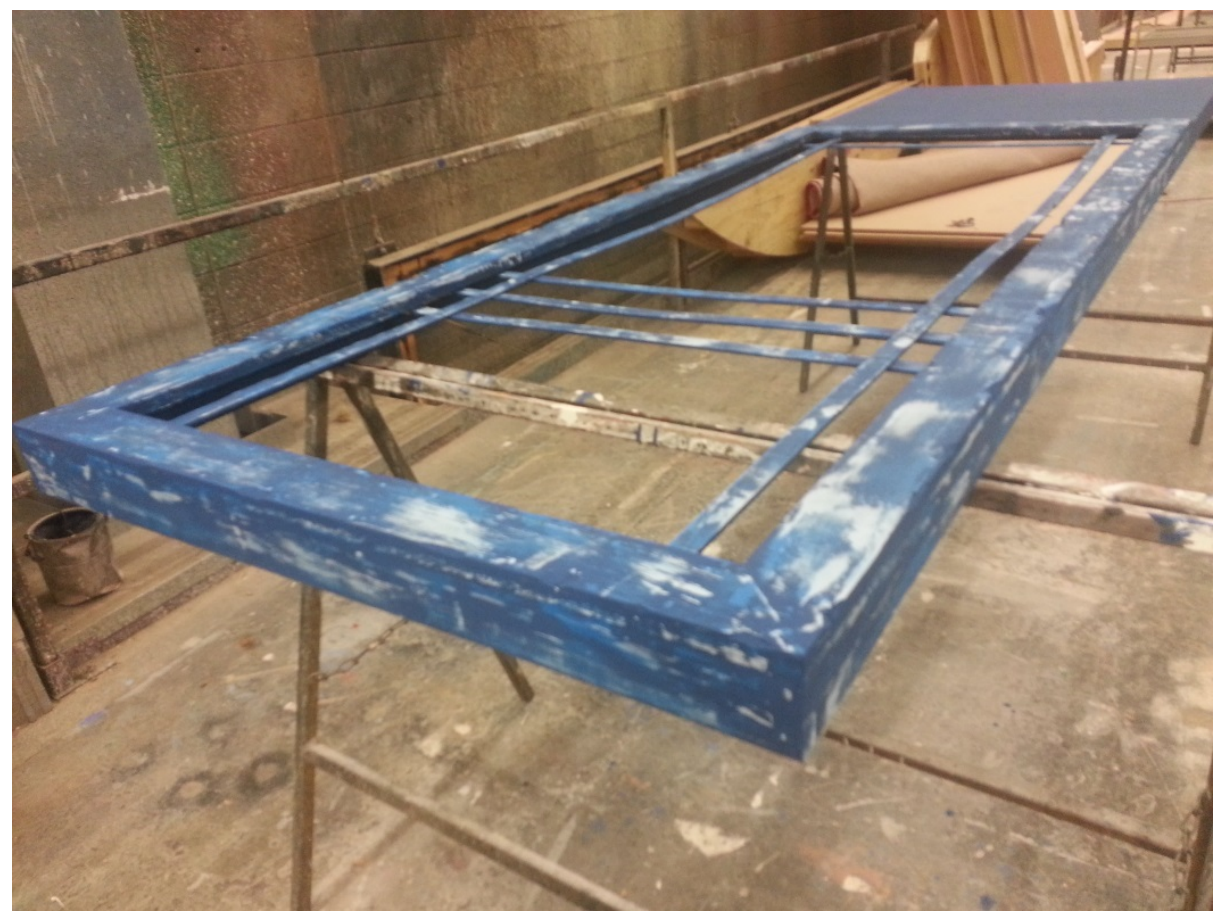


The Schultz fruit shop fly pieces

were among the first to be completed. I

was attempting to make the windows

look like an image I had found of a set

of aged shutters (Figure: 32). We

distressed the windows by carving at

the square frames to give them a worn

and battered look (Figure: 33). They

were then base coated in a bright blue

and given a texture created by a wood

blocking painting technique that makes

the paint look flaked and chipping
Figure 35: Schultz Window Projection and Painting

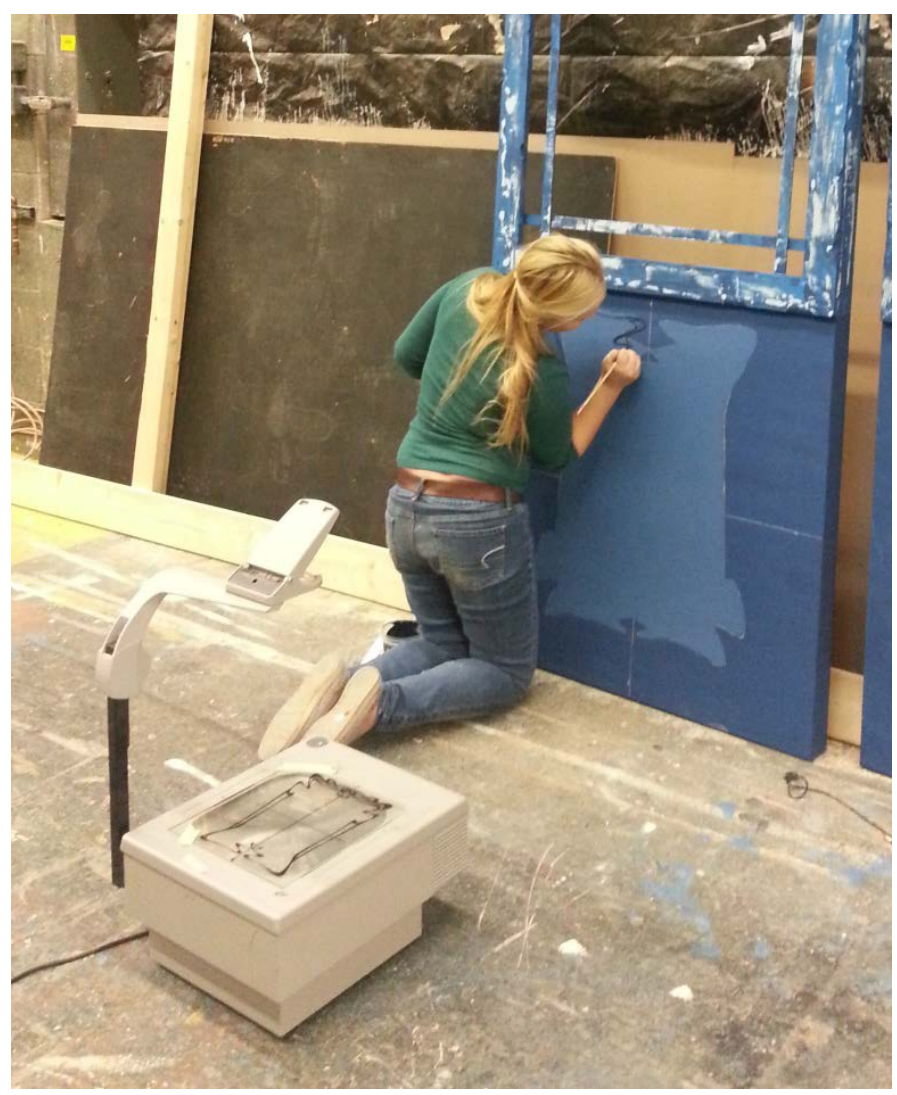

(Figure: 34). Once the upper window was finished, the lower wall portion looked plain. I had not picked out a design for this area yet, as I had not realized it would look like an empty void. I

found an image of an art nouveau

pattern and projected the image onto

the walls (Figure: 35$)$. Jessilyn and I then

painted them in the similar tones used

in the distressing. The next pieces to be

completed were the main club

proscenium arch and the two smaller

supporting wall arches. These were

Figure 36: Club Arch Texture Sample

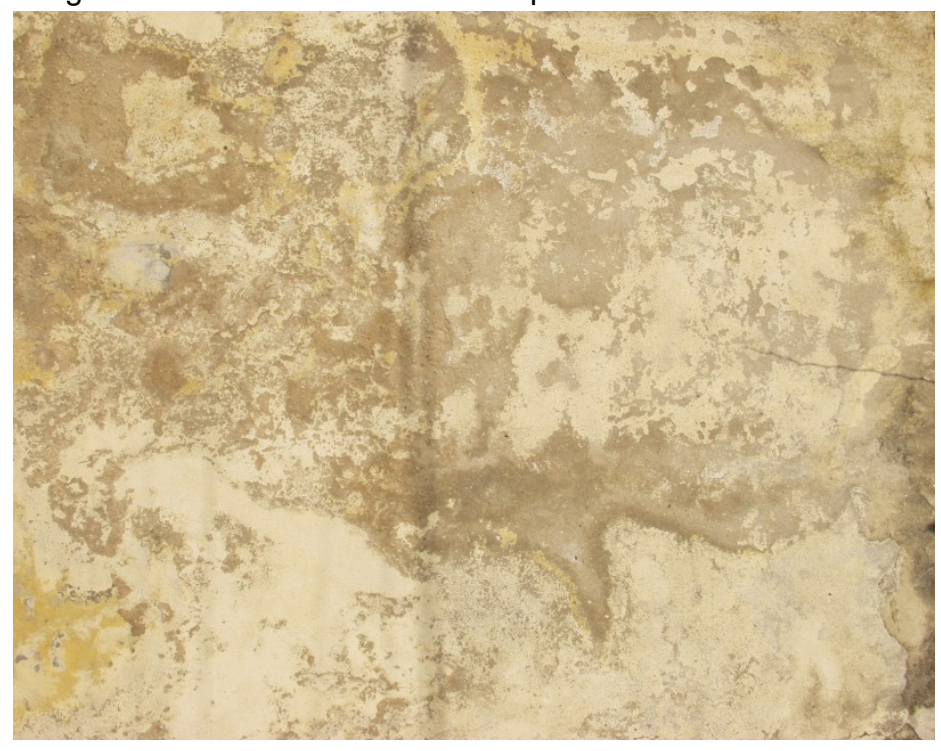


getting a paint technique to make them look like faded crumbling plaster (Figure:36) like the arches in my initial research (Figure:3).

We base coated the pieces in a two color scumble and then used the same wood blocking technique to complete the texture (Figure:37).

The next few weeks flew by in a haze of paint and by midterms I thought we were sitting in a good place. I had not taken the time to create a painting calendar partially because the build calendar had arrived so late in the process (another

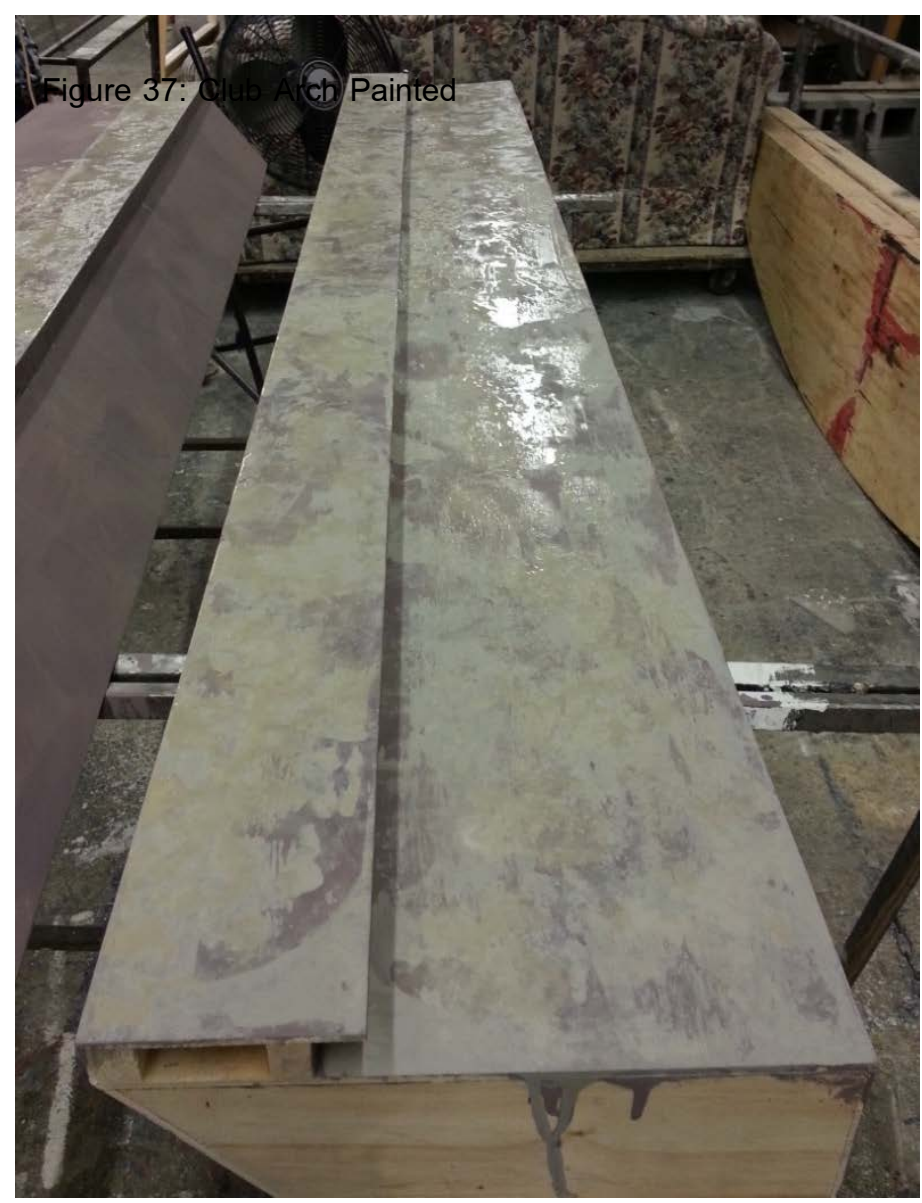
casualty of the entire process being pushed back) and partially because I thought I was handling the work load well and had a good grasp on what was coming down the pike. I had a discussion with Professor Neuenschwander about the progress and his comments seemed to imply that overall the show was going according to plan and on schedule for load-in. Much to my surprise, I was told exactly the opposite in a mid-semester review a few days later. Professor Neuenschwander had meant that the scenery build was going according to schedule, but he thought my painting process was falling far behind. I was facing painting some complicated wood grains and mural work which would end up taking more time than I anticipated. He was disappointed that I had not already begun staying after normal work hours to get ahead. So

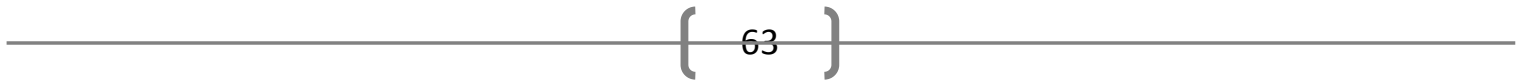


with much contrition, Jessilyn and I stayed in the evenings, weekends, and holidays to make sure that the painting would be completed on time. In the end, every piece of scenery was painted before it left the scene shop and everything loaded in on time. Some of the paint techniques did not get pushed as far as they could have had I worked harder in the beginning, but everything looked complete and coordinated from the house.

There were a few minor adjustments made to scenery pieces during the construction process. The majority of these revolved around the fact that once assembled the single walls on the rotating platforms would be extremely fragile and wobbly when in motion. Moving these hulking walls around the scene shop had already become a trial and Professor Neuenschwander and Professor Blair insisted we needed an additional way of supporting the walls. On the stage left wagon the columns designed into Schneider's side would offer enough support to keep the walls from shaking as the platforms moved. Also on the club side we attached the bar to the floor and also to the wall so it too could act as support. The stage right wagon needed much more support. There was an unused corner on the stage right wagon, the way the furniture had Figure 38: V Shaped Wall Support

been oriented left a gap. We came up with the idea to create a V shaped support in the gap that followed the edge of the platform and cut back into the room (Figure: 38). This would be painted

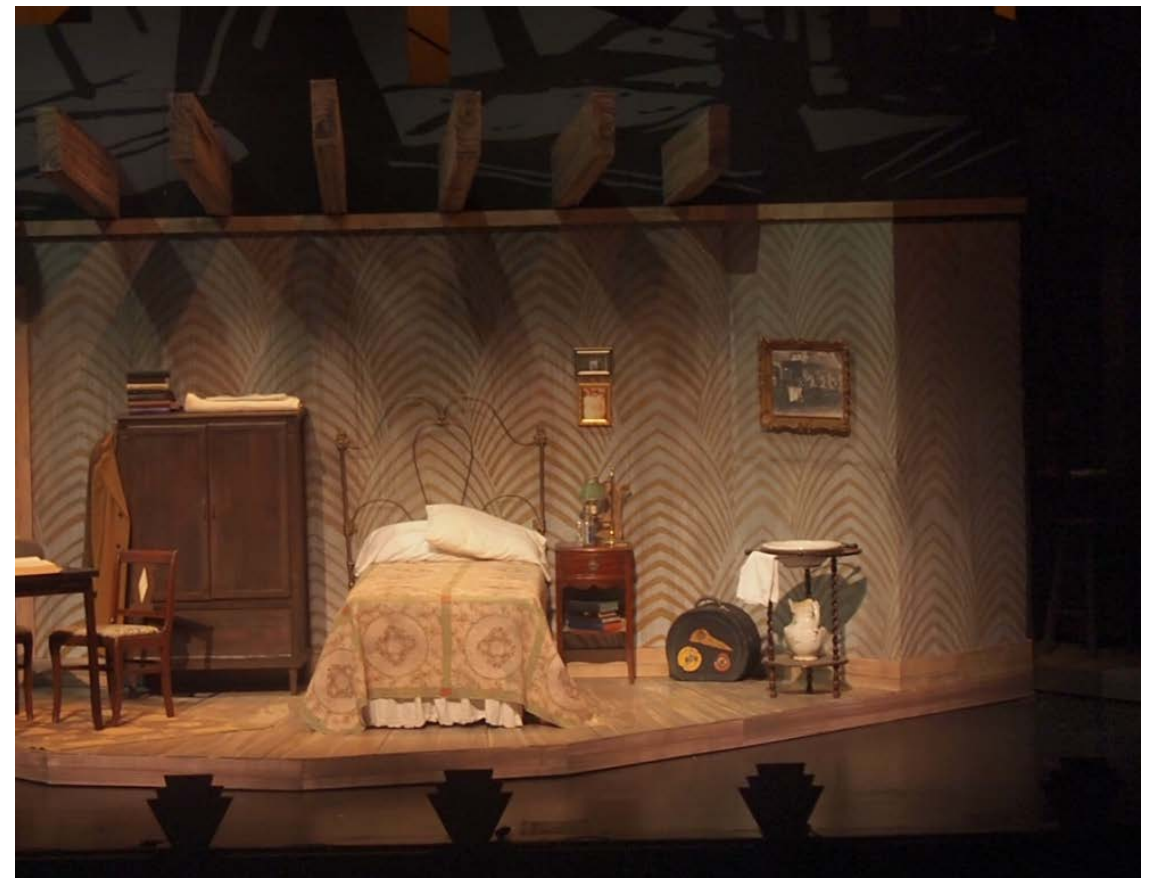
$(64)(54)$ 
like the rest of the wallpaper and appear as

though the room merely had a corner in it. This

new addition created an issue with the ceiling

beams that were located above, and I made the

decision to cut the two beams that hung over the

new wall. In addition to the $V$ shaped wall we also

attached the armoire to the floor and the wall, like

the bar, to offer more support.

There were other little aesthetic

changes that happened as the construction

process finalized. The chain curtain intended for

the center proscenium arch was split and moved
Figure 39: Chain Curtain attached to Side Arch

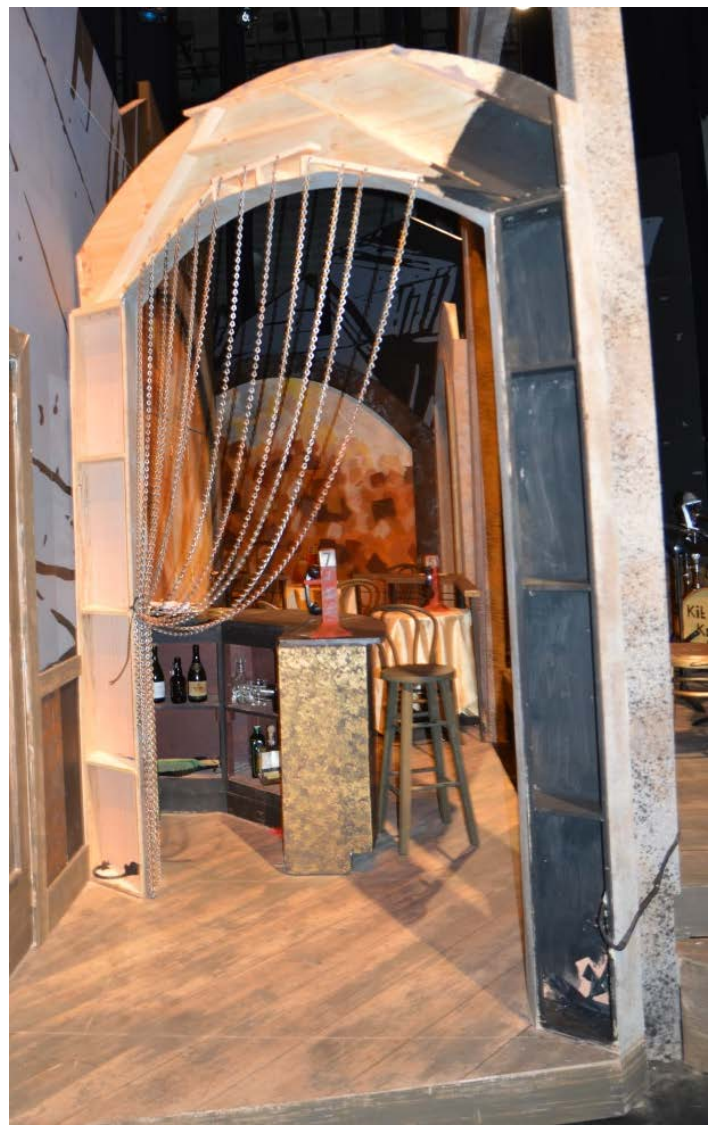

to the two side arches (Figure: 39 ). Along the line, the train car lost its roof and got an arched

Figure 40: Train Car

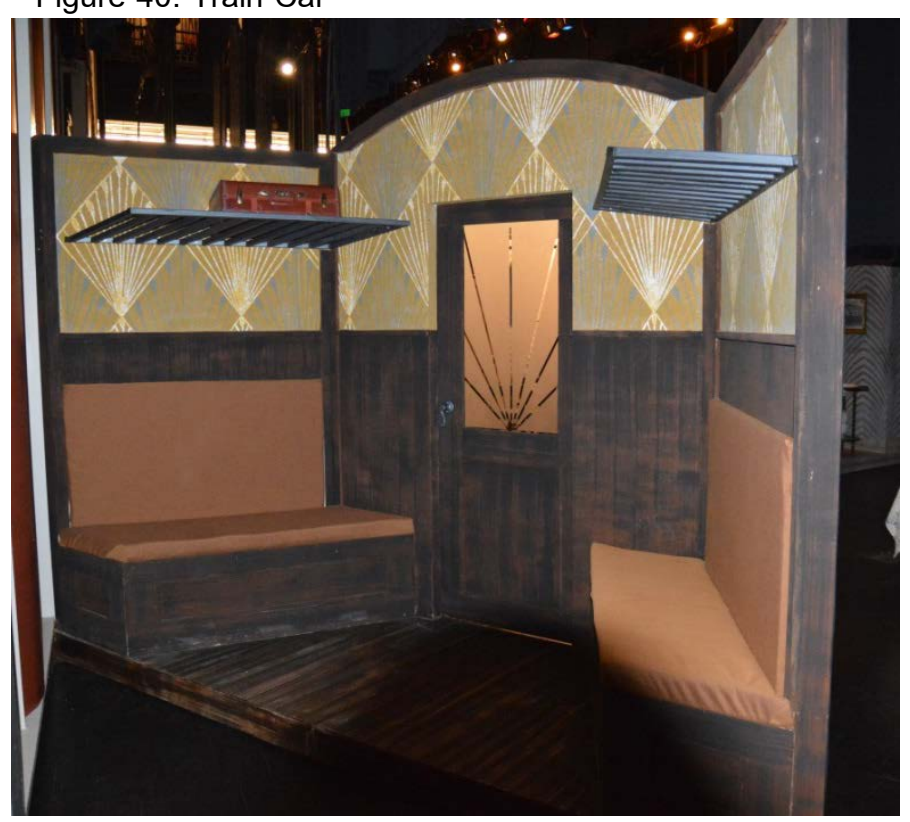

back wall to mimic the other arch shapes

all over the set (Figure: 40).

\section{Load-in}

Load-in process went fairly

smoothly from my point of view. For the

majority of the process I was still painting

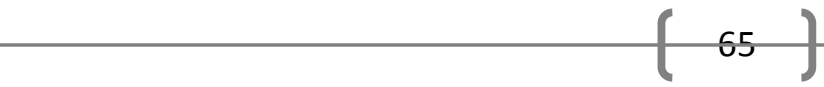


pieces of scenery I had yet to finish so the bulk of the

Figure 41: Platform Pivot Mechanism

load-in for carpentry I missed out on. I was involved

with the process of loading in the turning points for

the rotating platforms, as well as the rotating

platforms themselves. We had decided in the initial

design phases to create a pivot point for the

platforms that went through the stage floor into the

trap room below. This would allow us to have the

platforms rotate 'magically' without seeing a stage

hand pushing the scenery around. Professor

Neuenschwander designed the entire turning

mechanism, as I was completely inexperienced with

creating this type of machinery on this scale. The

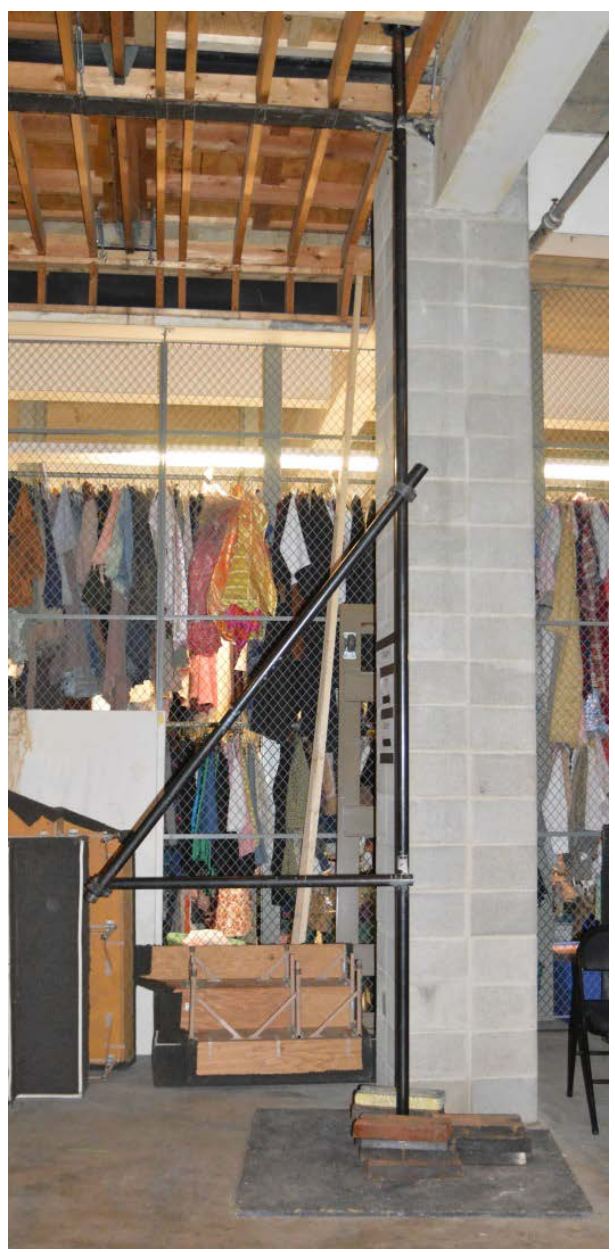

entire mechanism

consisted of a steel

schedule 40 pipe attached

to the bottom of the

platform fourteen feet

above that fed through a

hole in custom made floor

traps into a floor flange at

the bottom. We attached

Figure 42: Custom Built Traps

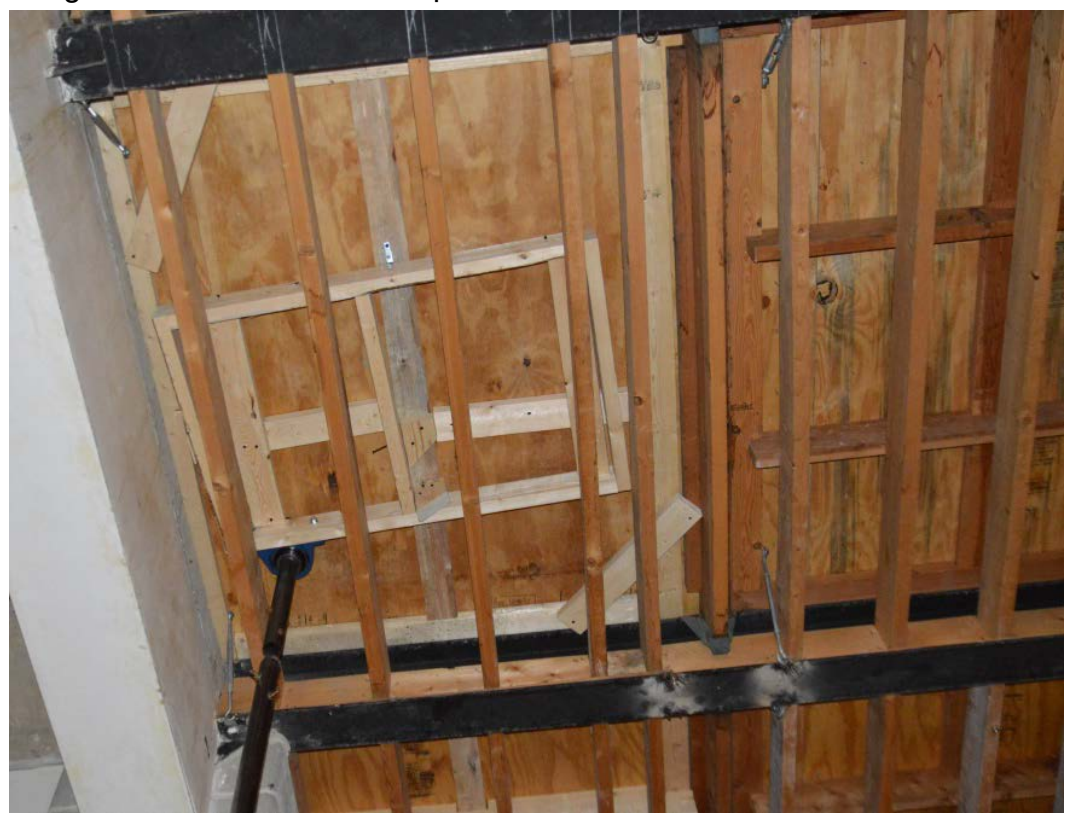


push bar pipes at the bottom for leverage and weighted the entire mechanism down with stage weights (Figure: 41). First the traps in the stage floor had to be replaced with the custom traps

Figure 43: Cable running through Sheaves under Slip Stage

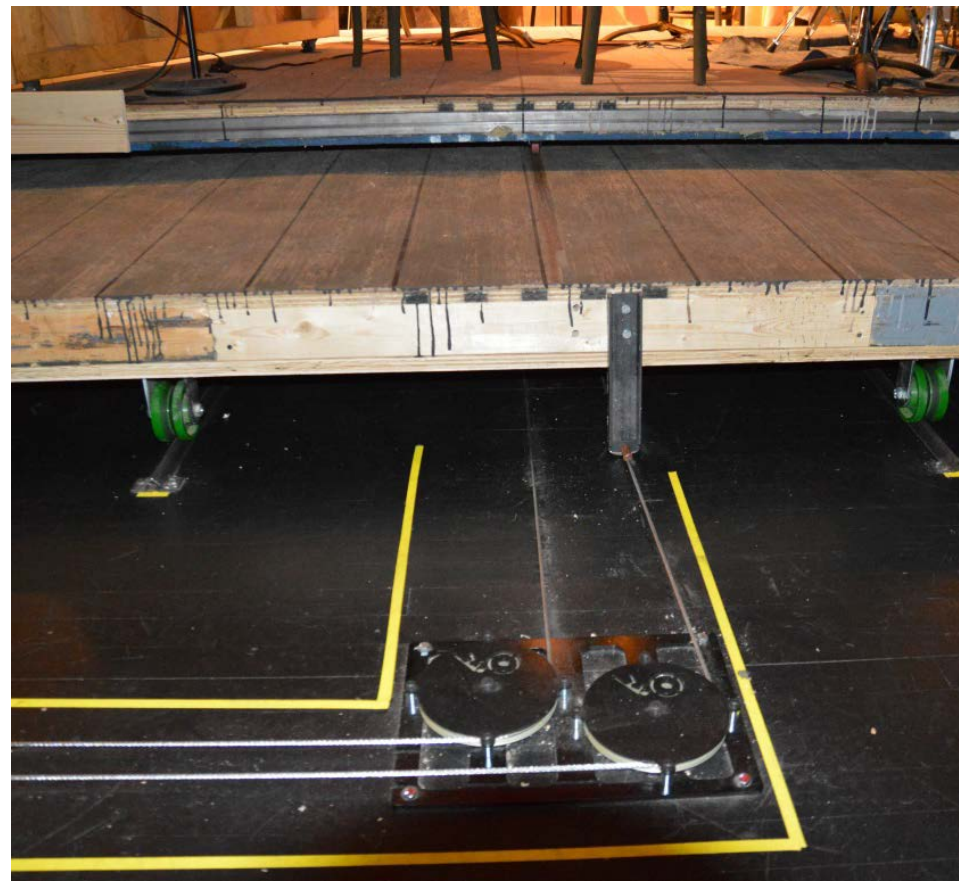

that we built (Figure: 42). Then the platforming had to be loaded in and lined up with the traps. The rotating platforms consisted of six smaller platforms bolted together to create the one large shape. We fed schedule 40 pipe under the platform and with two people on each end lifted them into place. It took 14 people to move each one. Once the platforms were in

Professor Neuenschwander and the carpentry crew installed the rest of the rotating

Figure 44: Cable running to winch \& computers controlling Automation

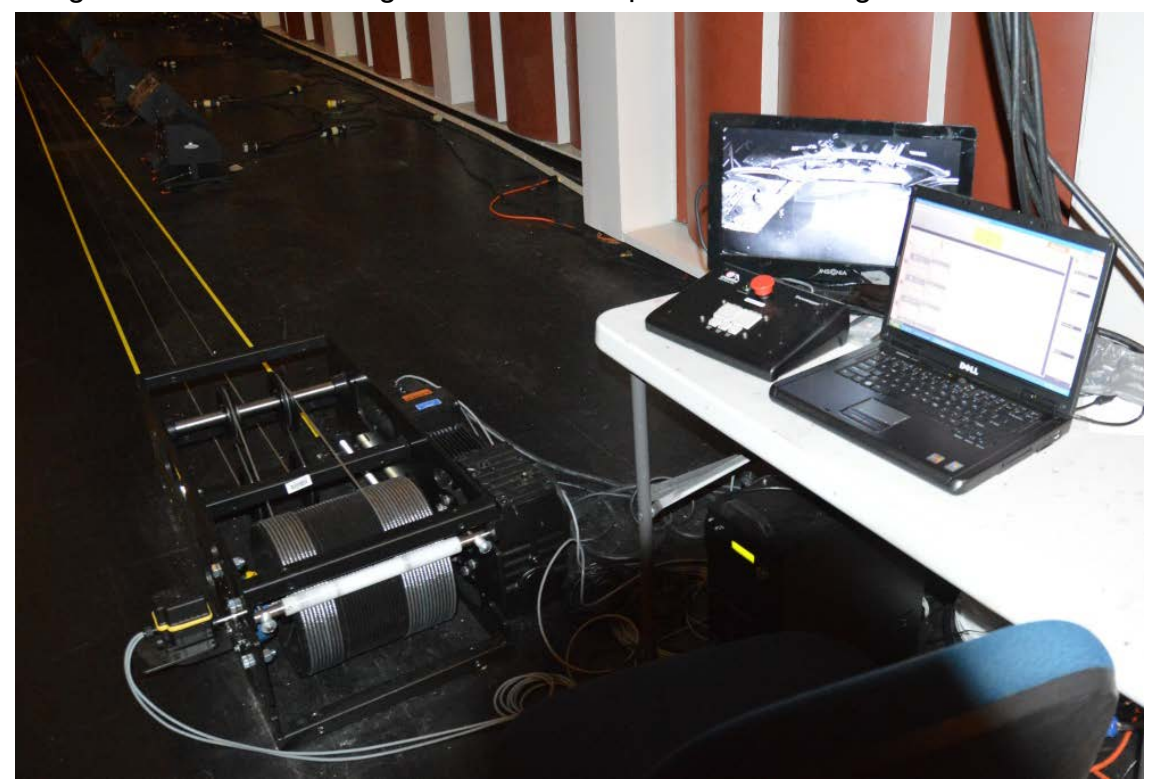

mechanism.

\section{Another interesting}

part of load-in was the process of rigging the slip stage to an electric winch.

This winch would move the slip stage in and out with the push of a button.

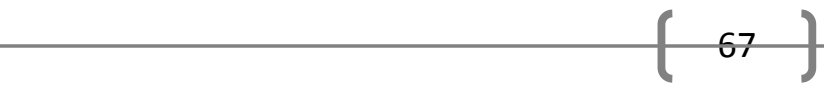


Professor Neuenschwander had wanted to start an automation program at the school for a few years. He worked with Professor Williamson to get a grant for $\$ 21,000$ to purchase the automation equipment that would benefit the school beyond our production. Again, as I was busy painting, I did not see the entire process of loading the equipment in. The slip stage was attached to aircraft cable that ran through sheaves attached to the stage floor and run into the winch (Figures: 43,44 ). The computer had to be programed to know exactly how far to send the platform forward and backward. There was one mishap when the programmer was not paying attention and ran the slip stage backward too far during programming. The entire slip stage got crunched up under the band platform. We also discovered that the machinery could move at a huge variance of speeds. We ended up running slip stage for the show at $7 \%$ of its maximum speed.

Other than those two pieces of equipment load-in went smoothly and for me consisted mainly of paint touch ups and organizing props with Prop Master Dotts. I spent the time helping him finish up and paint the props he hadn't completed yet and together we dressed the set. With all of the pieces completed we went into the tech process.

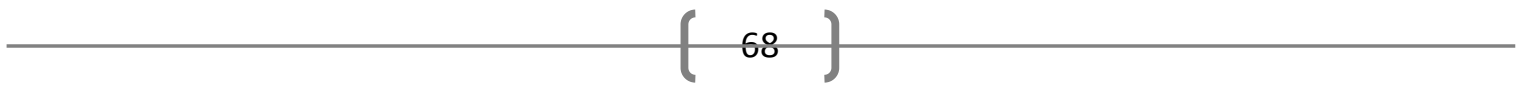




\section{Tech Week \& Strike}

The tech process went smoothly overall. There were a couple of major hiccups with the design, but the process was generally drama free. There were the usual small touch up notes, most having to do with paint, props, and minor construction issues. The center building in the cityscape fly was being blocked entirely by the scenery and had to be adjusted up a few feet. This created a stair step effect at the bottom that I ended up really liking as it mirrored the sunburst shapes I had used for my footlight covers. Most everything I had taken notes on during the process was a simple fix.

There were a few issues that came up that required input from more than one department to solve. The first was with the turning points of the rotating platforms. The turning stations down in the trap room ending up not being enough leverage to rotate the massive platforms above them. The stress caused by the teams turning the platform from below would cause the bolts holding the pipes to the platforms to snap. This happened a few times in the first few run-throughs. Professor Neuenschwander determined that the platforms had to have at least one crew member on the deck to help the platform move. This was understandable, considering the size of the scenery I had designed, but I never reconciled myself to the look of the stage hand pushing the rotating platform across the stage at each transition. The design team discussed not having the crew visible for scenery transitions and this just felt like a failure to me. The other transition issue we ran into was the speed at which the Kit Kat Klub was being

$=(60)$




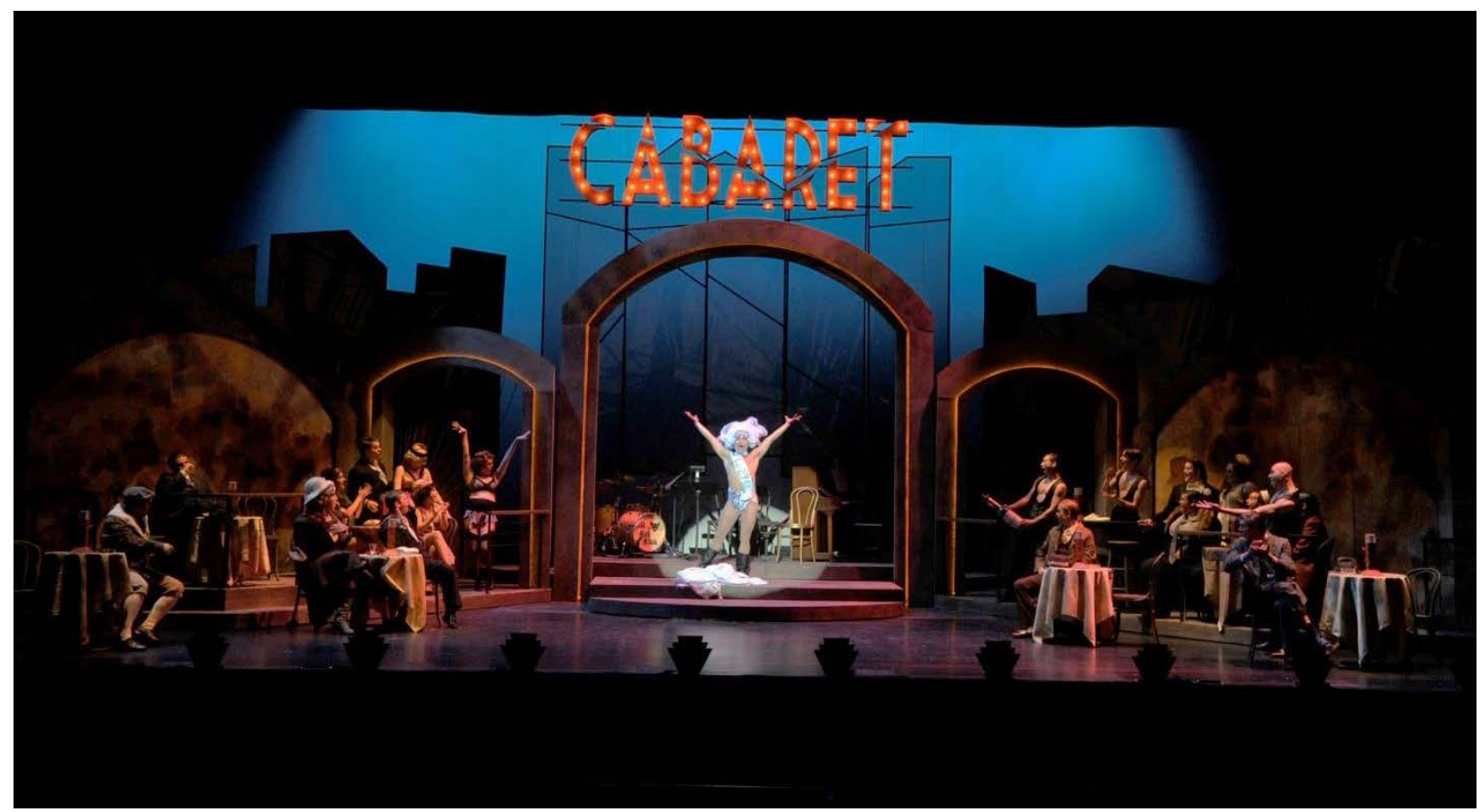

set up and struck at the beginning and end of each scene. The cabaret was set up with a series of tables for patrons to sit at (Figure: 45). The tables on top of the platforms had no need to be moved and simply rode around during the transitions. The tables that sat on the stage floor had to be moved out of the way of the oncoming platform. Professor Neuenschwander spent time, as he does for every tech, teaching the stage hands how to safely and efficiently move scenery on and off stage. The transition consisted of up to eight stage hands walking on, picking up either two chairs or a table and exiting the opposite side of the stage. In the midst of these transitions the actors would be attempting to exit or enter around the crew. After many attempts of re-blocking these transitions they were still moving extremely slowly. The Stage Manager was consulted about how quickly she was calling the cues and the crew was informed that they needed to move faster and remain in determined order. After this discussion, the rotating platforms started moving more quickly, and attempts to cut down the amount of furniture being moved each time, the transitions sped up slightly. We never quite got them to

$(70)(70)$


look as clean as I would have liked. The tables being set and struck still looked like odd floating jellyfish.

The only other massive issue that I hadn't foreseen going into tech were the blank spaces stage left and right when a rotating platform was turned onstage. In the original design the rotating platforms had exit stairs leading off of the second floor of the club. They had been designed with vertical steel poles to mimic the platforms supports in the club and continued the design down into this upstage space. They were cut during the "over budget redesign" and during the hustle and bustle of getting the show up I never really found a solution to the open space. Once we got into construction I had completely forgotten about it all together. The first time the platform rotated onstage there was the open expanse of cyclorama that I hadn't planned. Many options were thrown around in the beginning, one of which being a hastily thrown together ground row, but a ground row had never been part of my design and I was reluctant to add one. Also we were out of time to build anything that substantial. The next idea from Professor Blair was to fill the space with the bentwood chairs being used in the club scenes and have the dancers pose on them. This would have created a beautiful silhouette against the cyclorama and added to the 'magical realism' I was trying to accomplish. Unfortunately, this idea was vetoed quickly by Professor Blair as it made transitions and quick changes even more difficult as well as distracting from the action onstage. The second option was to separate the full stage black already hung in the space into its two halves and attach it to two separate battens. Each batten could be flown in individually to cover the cyclorama on either side. The downfall with this plan came when after an early morning call we discovered that the full stage black was actually that, a curtain that spanned the entire stage. Unable to

$(71)$


divide it in half,

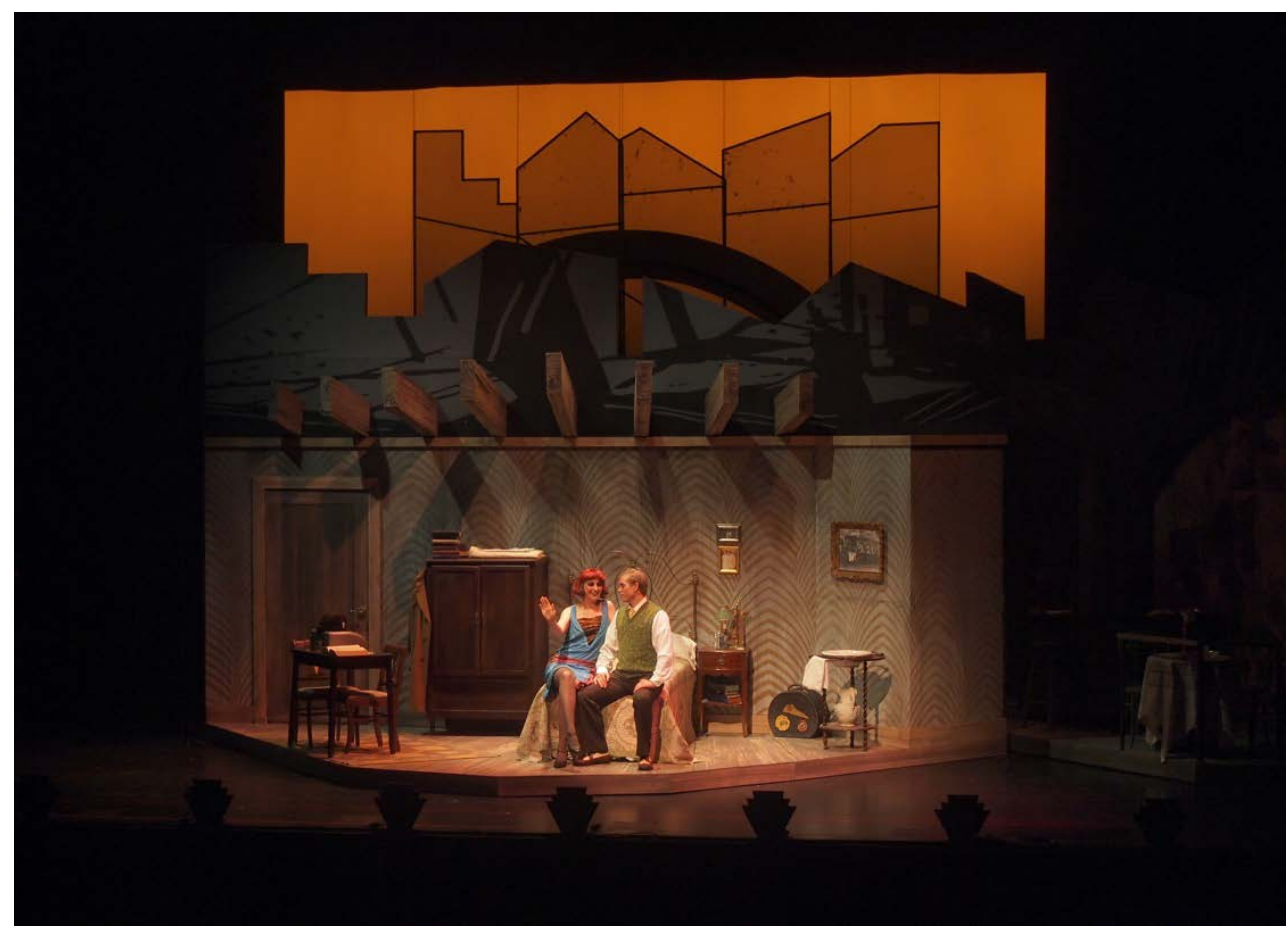

we abandoned the

plan, we moved

onto the third idea

of using the

traveler opened

halfway. One

downside of this

plan was the

traveler had

fullness, meaning it had pleats at the top, while the legs and borders were flat, creating some concern of it looking out of place. The other drawback being that the traveler could not be split onto two separate battens and we had to fly in both sides at once. These two drawbacks were minimal compared to the problems with previous solutions and we ended up using this method. I think that the border created by the traveler framed the scenes nicely and was a nice change from seeing the entire cyclorama (Figure: 46). Also, the pleating was never visually an issue as the lighting designer took care not to focus on it.

With all of the large and small issues out of the way the show opened. The show ran for one weekend of four performances. There was really not enough time for too many things to go wrong and I did not need to come in for touch-ups or repairs during the run. 


\section{Strike}

It always amazes me after so many weeks of hard work and sweat how quickly a set, no matter how large, is demolished during strike. This show was no exception. Strike began after the matinee and was in full swing quickly. Professor Neuenschwander had organized everyone's jobs and locations. My job was to head up the deconstruction of the scenic pieces once they left the stage. I had stations where students were breaking down walls and stripping stock platforms of lids, legs, and hardware. Most of the pieces constructed out of steel were stripped of their decorative elements and left in piles for later. There were huge piles of broken down materials after. It is always hard to see something you've worked so hard on demolished, but with this strike I was ready to be done. After over six months of discussions about every little detail, I really didn't want to look at it any longer.

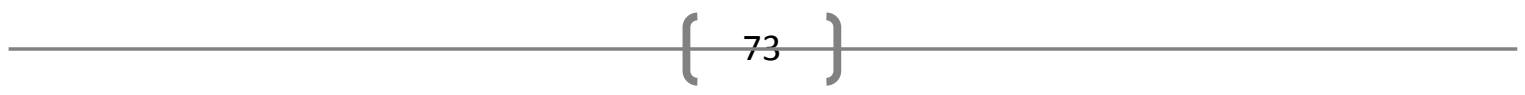




\section{Conclusion}

Cabaret was a huge learning experience for me, as I'm sure it was intended. I often pushed myself past my limits, but I tried to approach the project from a place of humility. My father always said "the more you know, the more you realize you don't know anything at all" and I tried to go into this project like a sponge. I hoped to soak up all of the experiences and knowledge that was being thrown at me faster than I could absorb it. I truly think I was successful in a lot of areas. I am very proud of the painting on the show, I think I challenged myself and it came out beautifully. I also think that I still have a lot to learn, and more importantly practice, in a lot of other areas.

Looking back the first glaringly obvious improvement would have been to my paperwork trail. Detail work has always been a shortcoming of mine, and on this project it truly shows. Every piece of paperwork could have been made cleaner, clearer, and more organized. My drafting was often sloppy or incomplete. Design team members often waited to receive paperwork from me longer than they should have. I should have kept a better notebook and paper trail as I went along each step, taking time to document my thoughts and issues. Going back through my notebook and trying to decipher what I wrote has not been a fun challenge a year later. Many of the details and experiences I had at the time seemed so fresh, and I was sure I wouldn't forget them, I was wrong. I remember feeling extremely rushed at the time, but perhaps I could have gone with a few less hours of sleep if it meant that my work was neater

$(714)$


and easier for everyone else to understand. I have since worked with quite a few other designers and I am always impressed by their drafting. It is a personal goal of mine over the next year to spend time making drafting and paperwork templates with pretty title blocks, headings, and borders so that my work always looks professional.

Another big lesson stemmed from the budgeting crisis and that was: reacting to a huge mistake, but not letting it get in the way of the big picture. I emotionally broke down for a while after the budget mishap, which given the circumstance is understandable. One of the things I am thankful for is that the professors I worked with did not let me off the hook at this crucial juncture. I was able to keep moving forward and not drown in the lake of issues I had created for myself. I had to remember that in such a collaborative field where we all rely on each other so intensely, I could not be the one to lose it. In short, one must maintain perspective.

I also learned a lot about my creative process and how I personally like to approach a show. I am more successful creating a design if I spend a significant chunk of time drafting. I can draw, but trying to sketch an idea out on paper does not help me creatively think about how all of the pieces fit together. One problem that I have found after completing this design is that it does not allow me to fully explore all of the options of a design. Diving straight into drafting tends to lock me into the design ideas I initially had in my head. I think a lot of the issues with the scenery and transitions in Cabaret could have been solved by exploring a wider range of ideas, shapes, and movement. I never threw out everything I had done and taken a completely different view of the project. I need to not be afraid to take more time to explore.

$(75)$


Despite all of the challenges and occasional lack of sleep, I am intensely proud of the work I have done. It has challenged me in ways I didn't know were possible, and I came out the end with a beautiful piece of art. I realize the road ahead is going to require even more hard work, but the process of completing this has made me realize I have the skills I just need to be more careful and calculated in how I apply them. 


\section{Appendix A: Drafting Elevations}




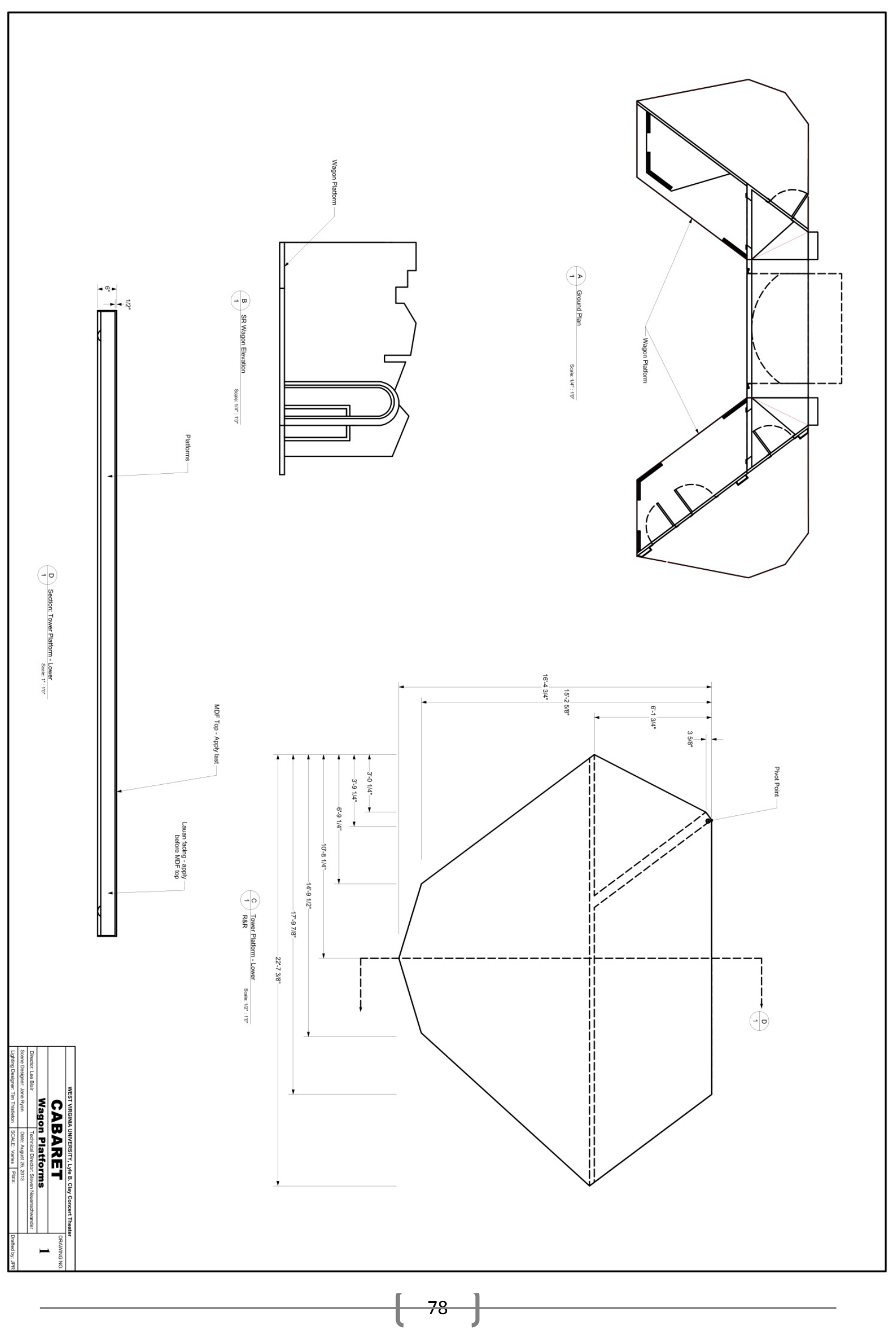




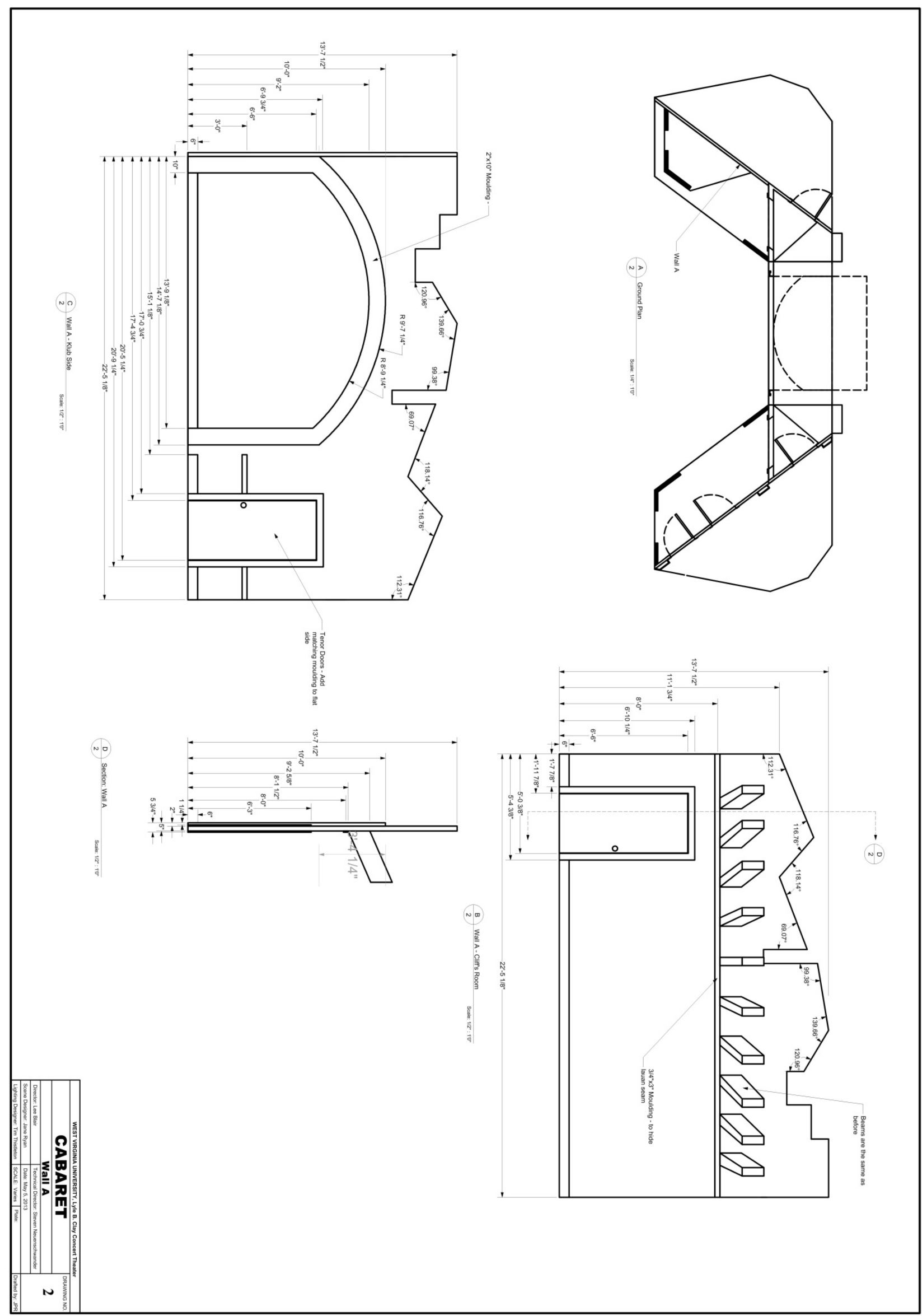




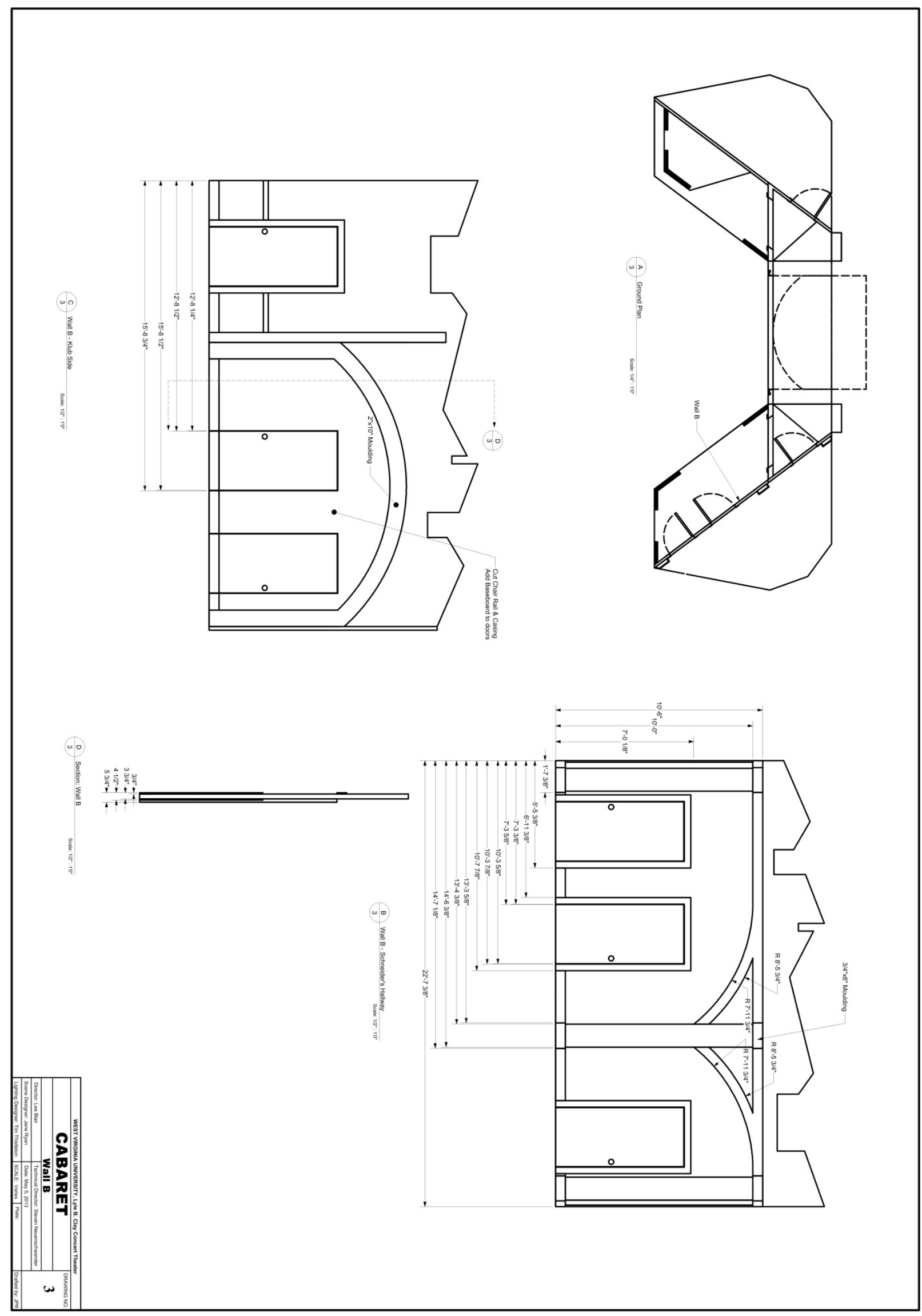

$(80)$ 


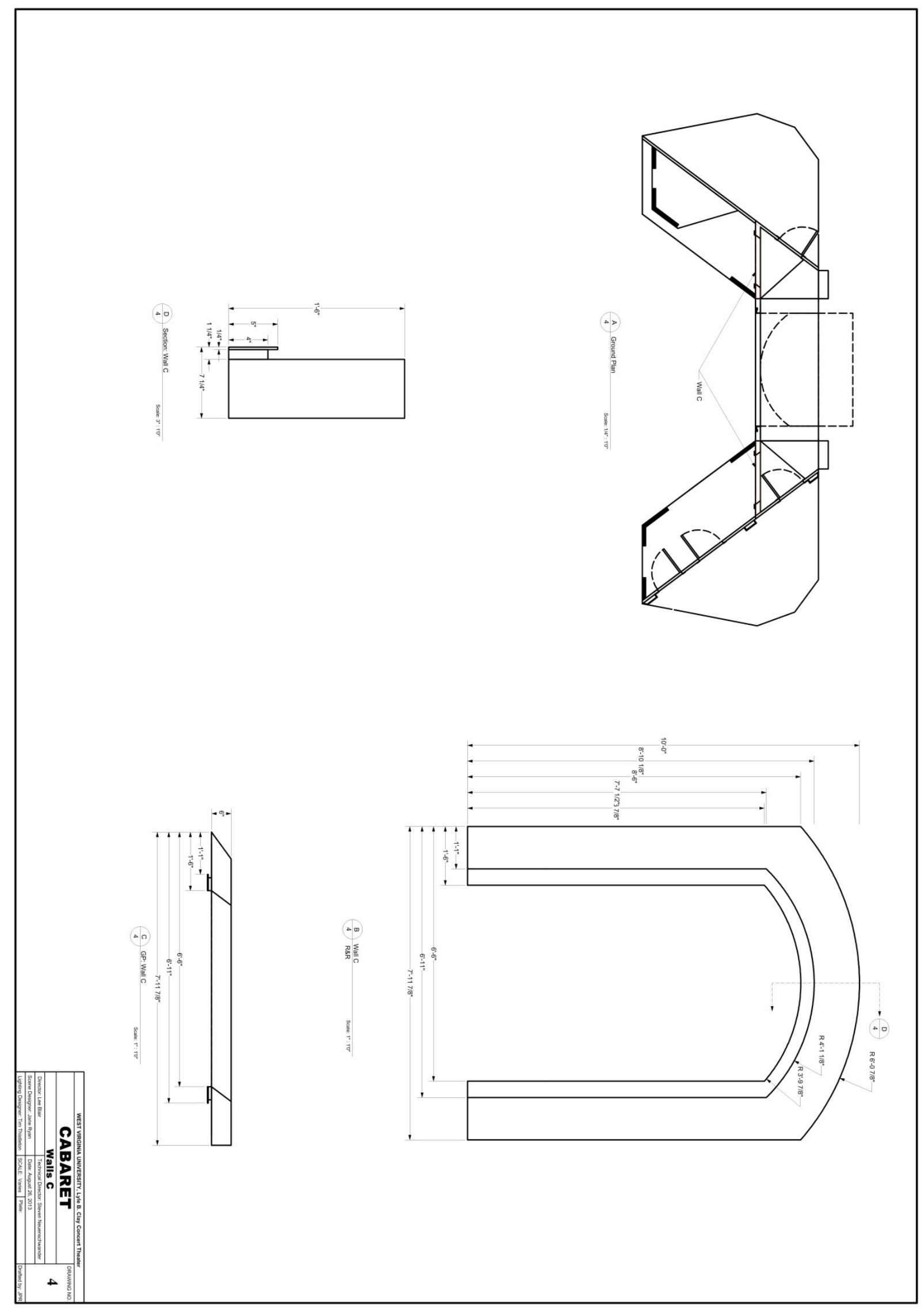

$(01)$ 


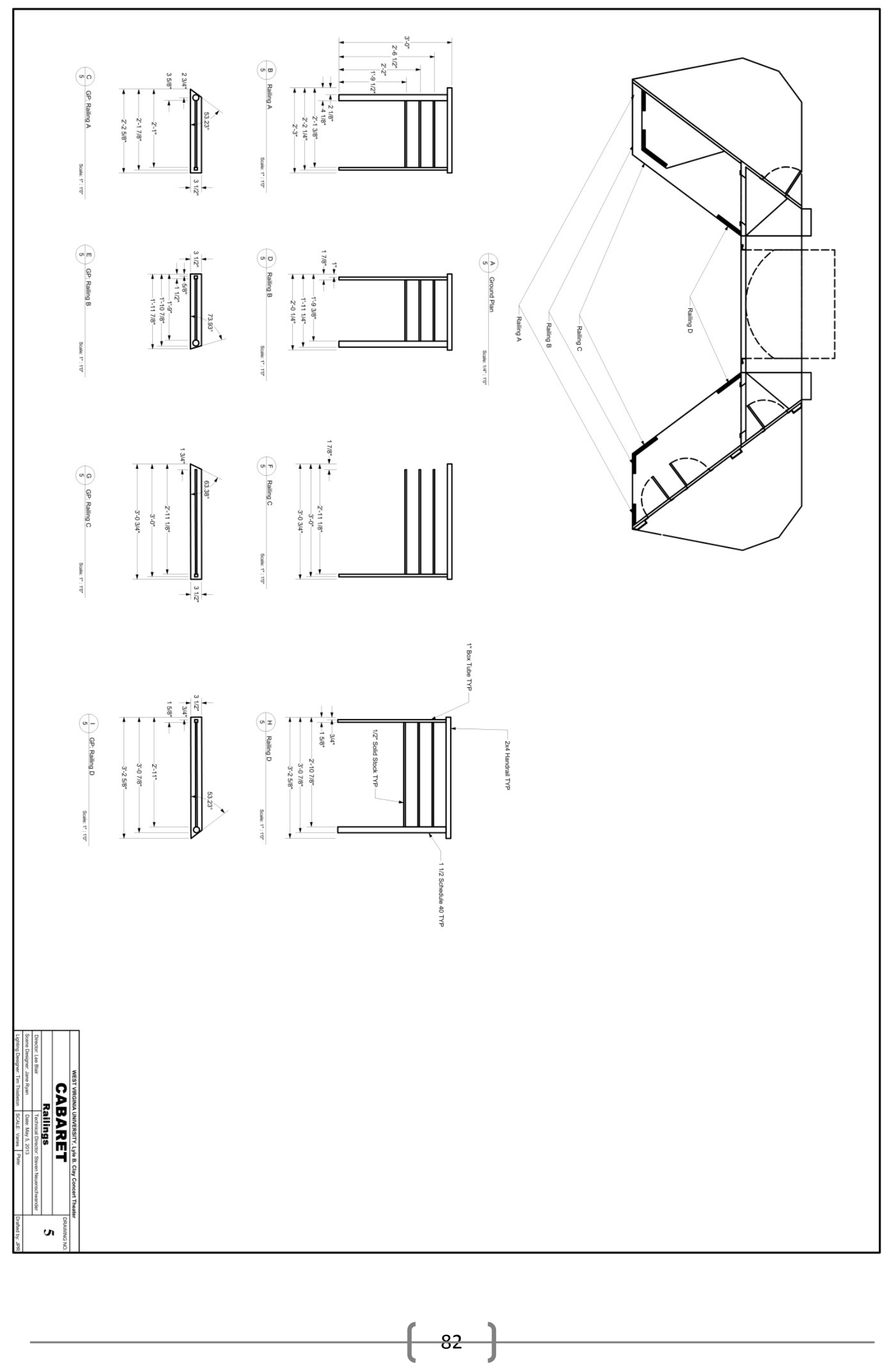




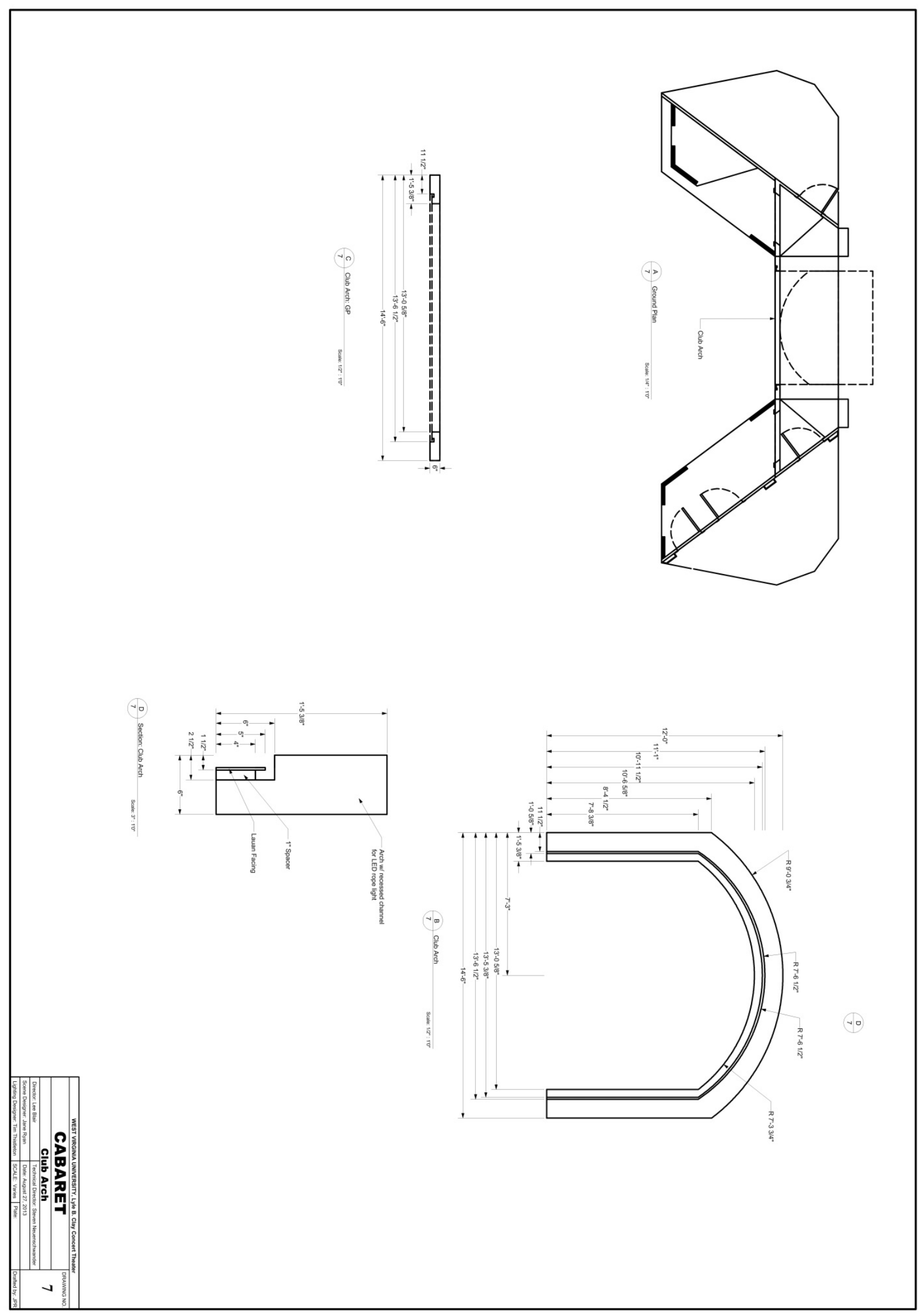

$(03)$ 


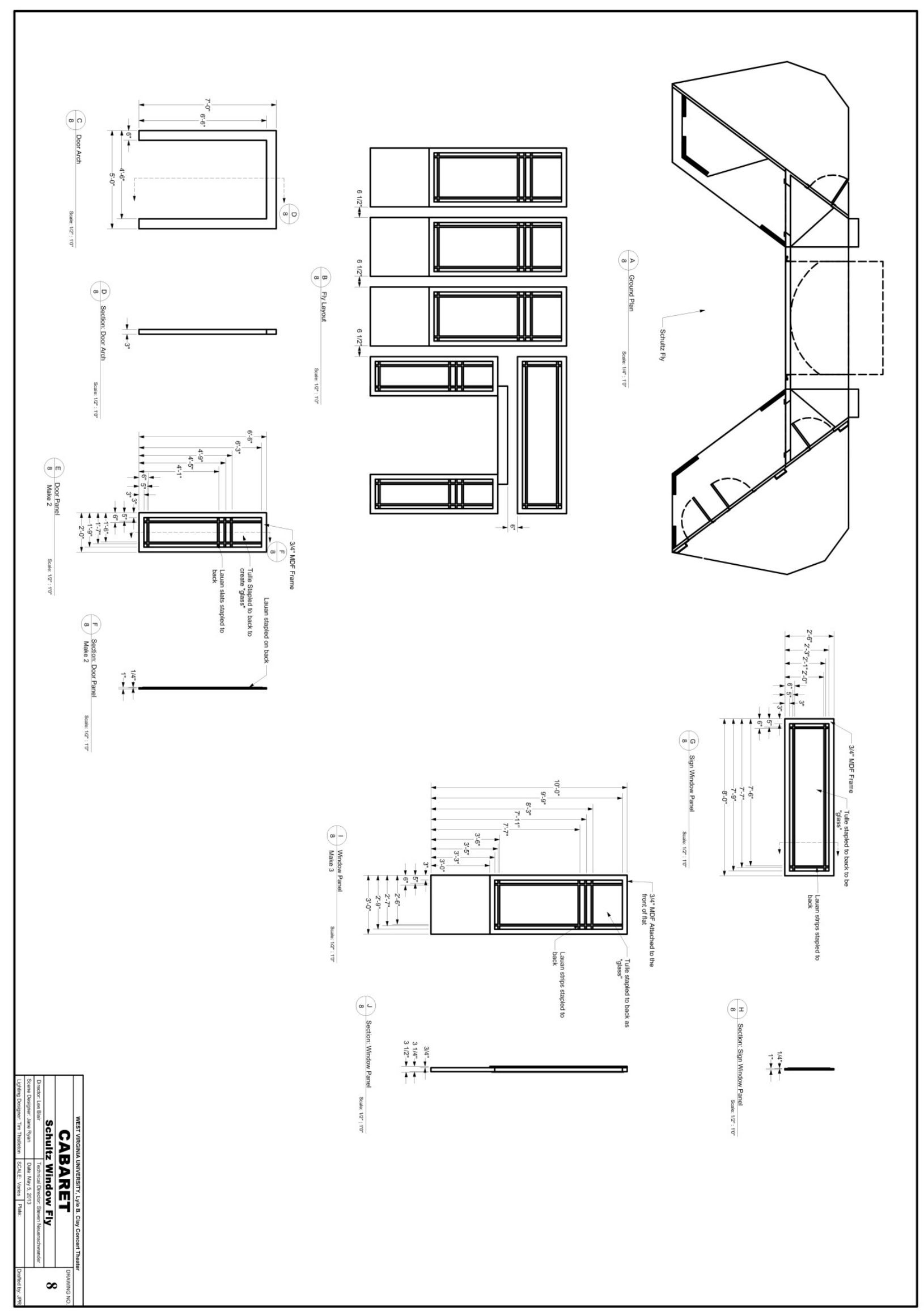




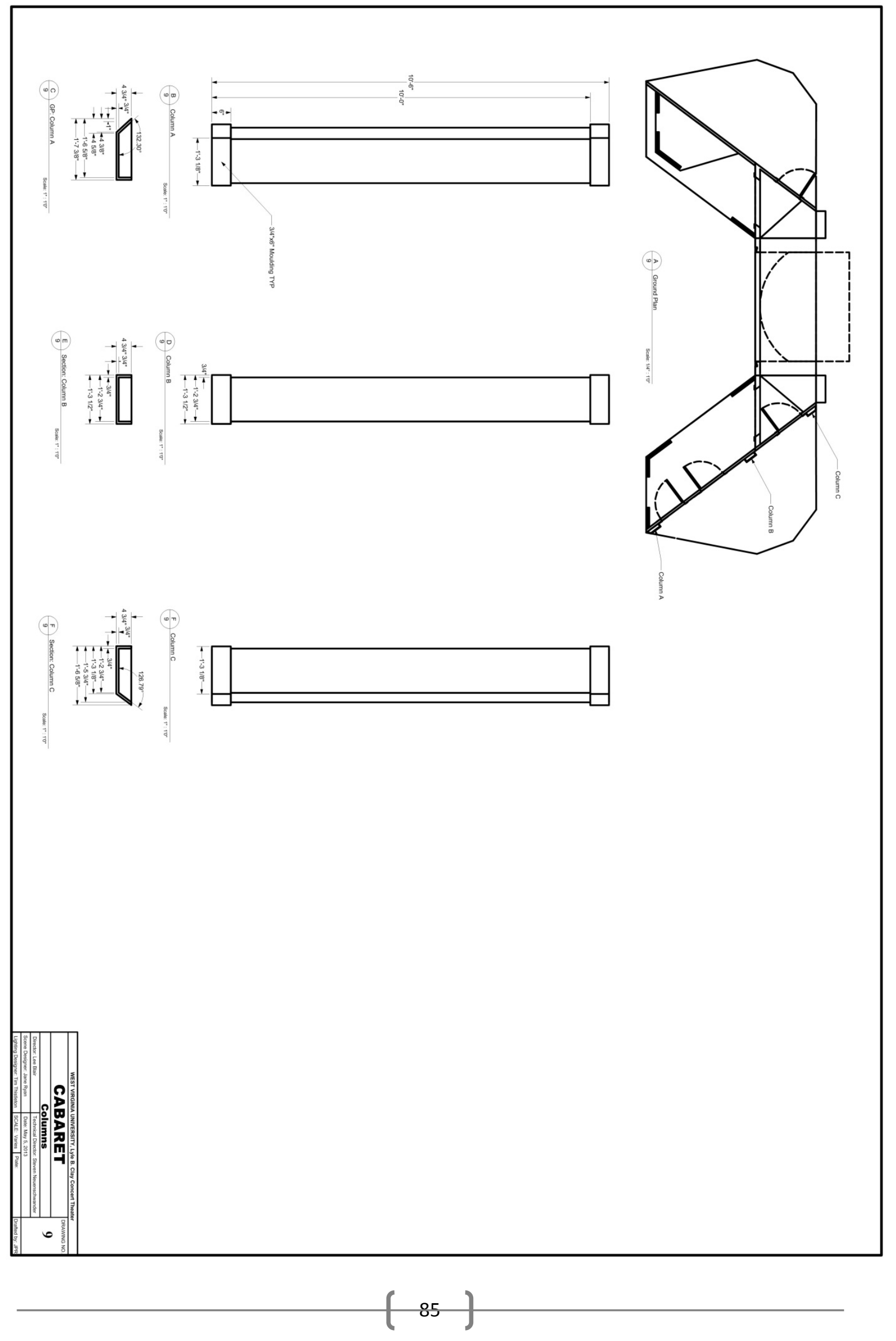



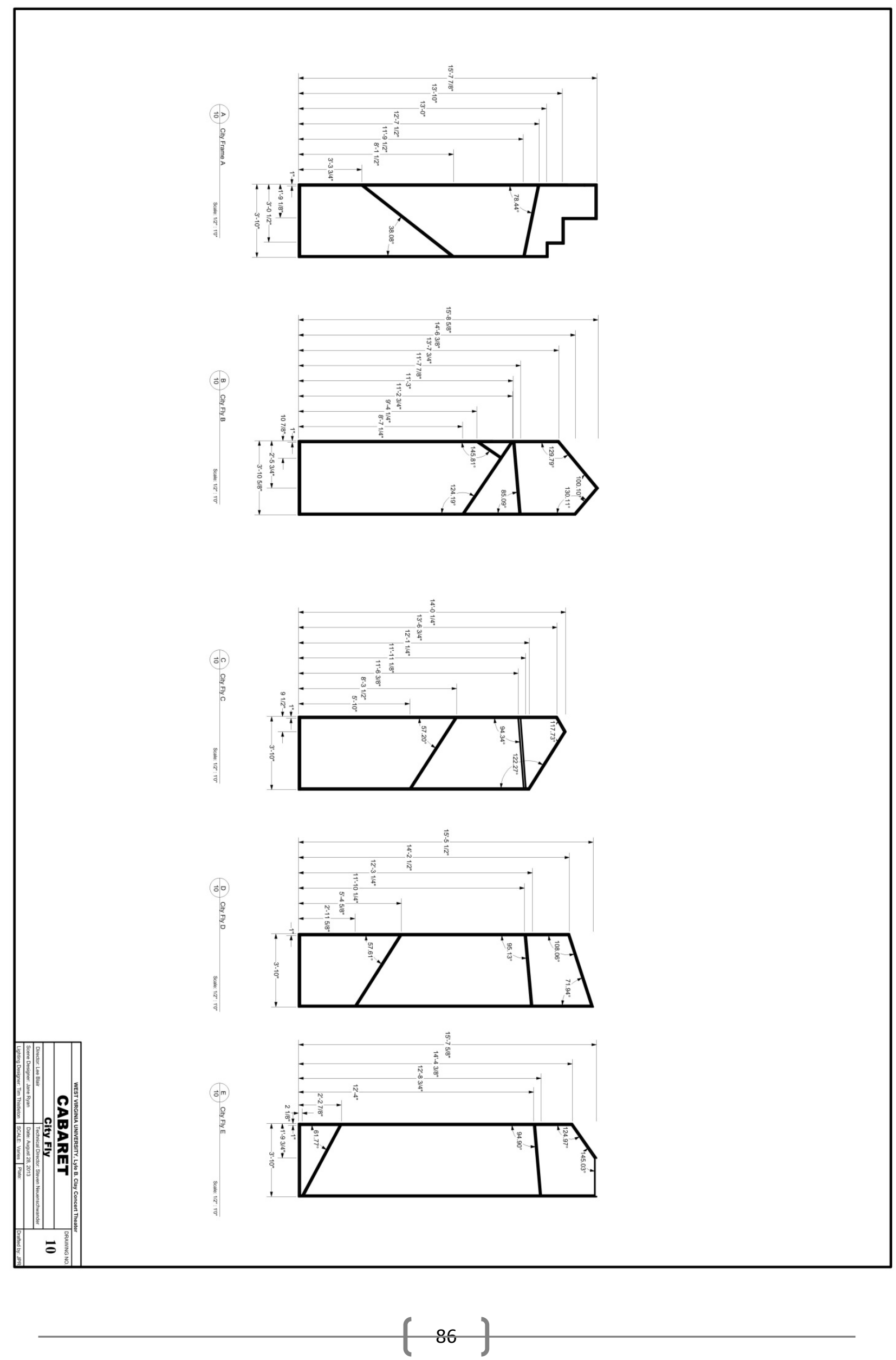


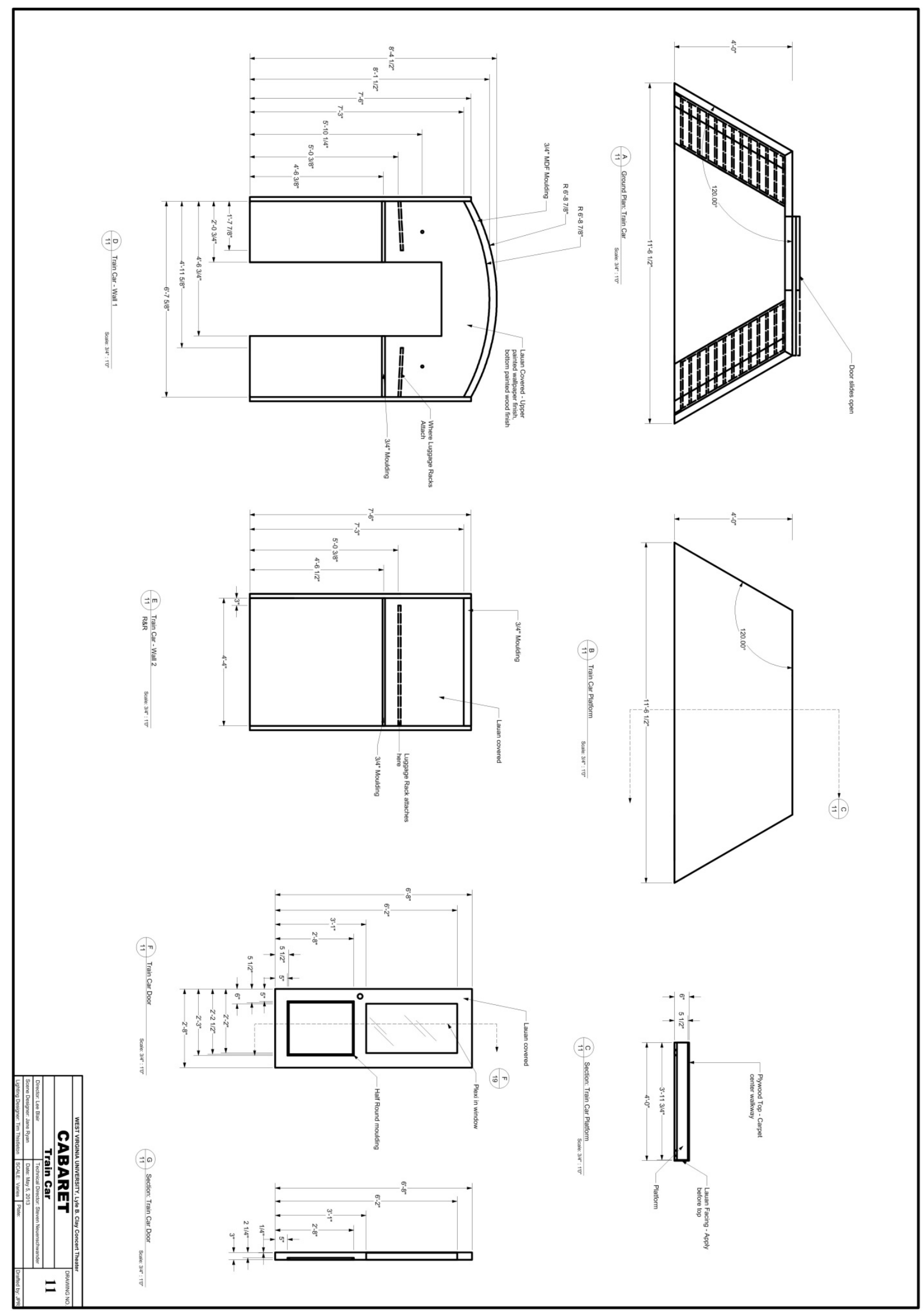




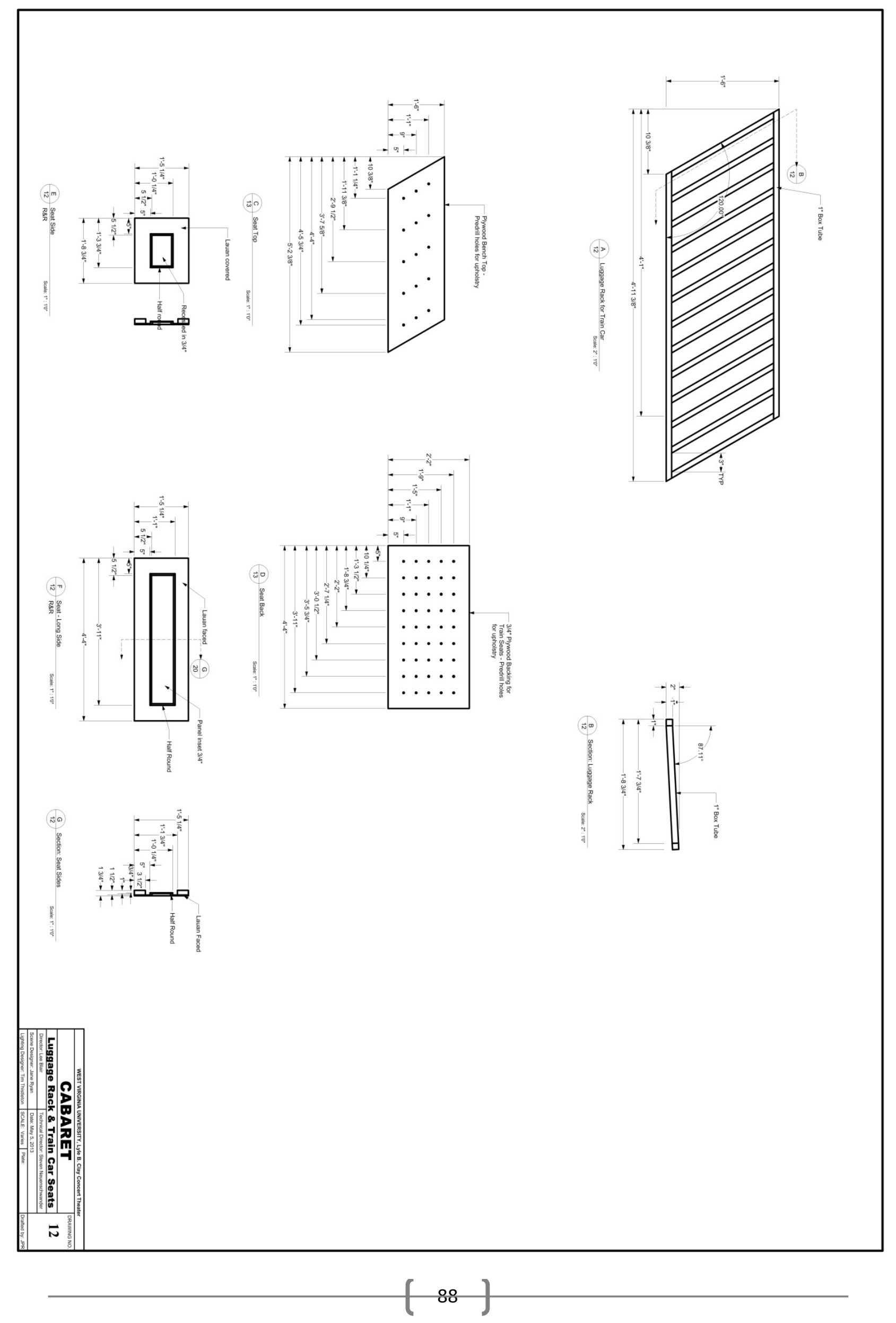




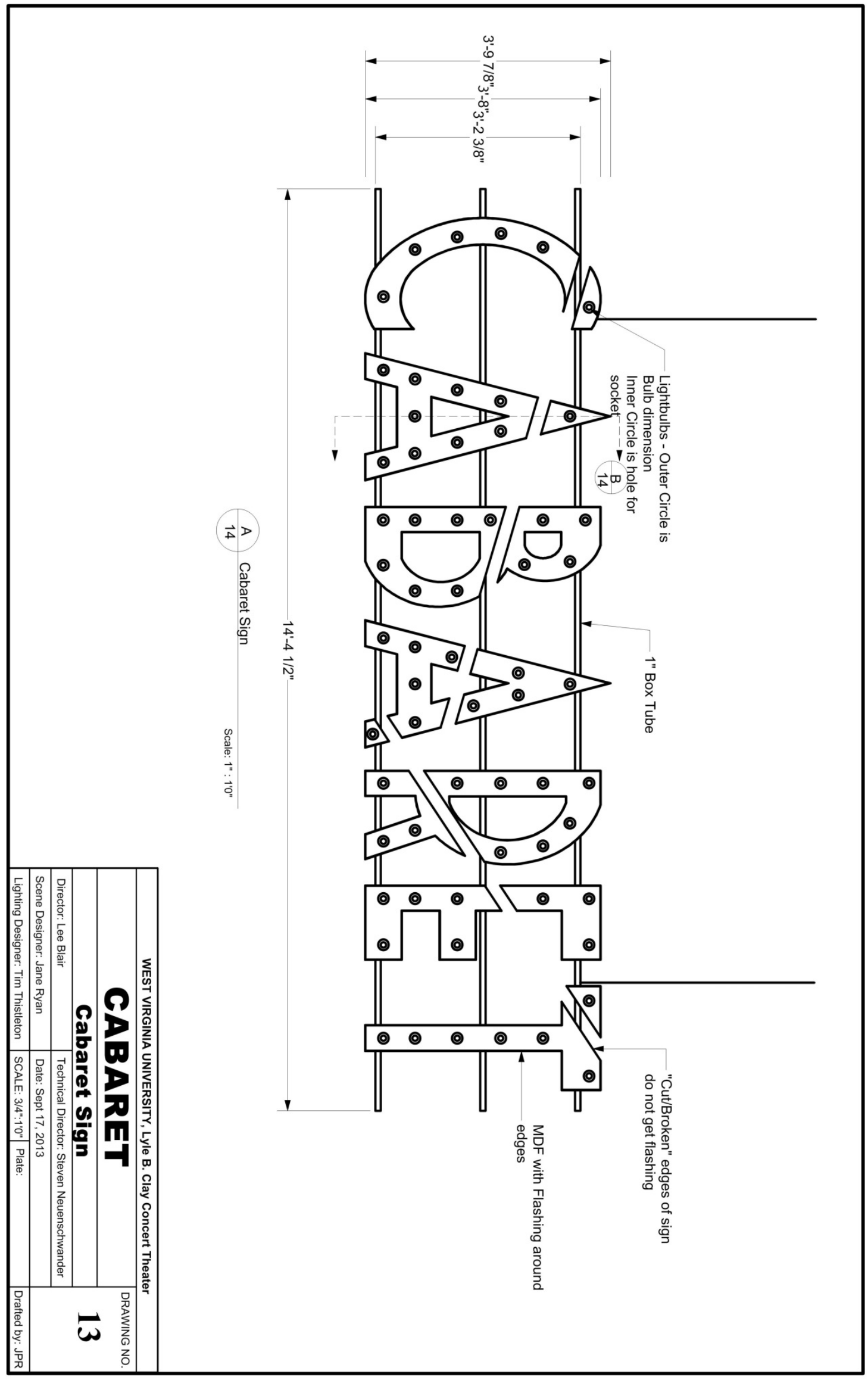




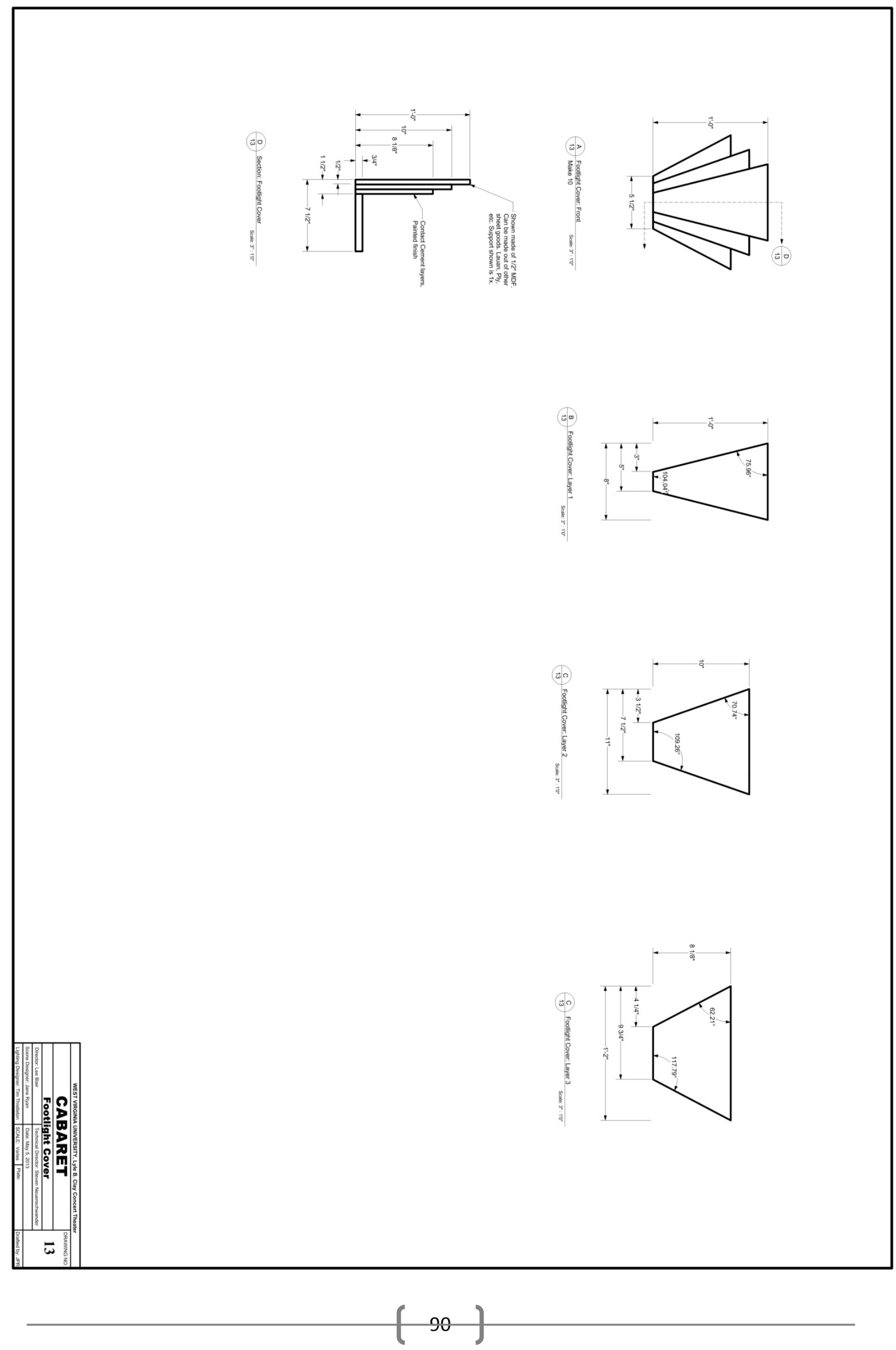



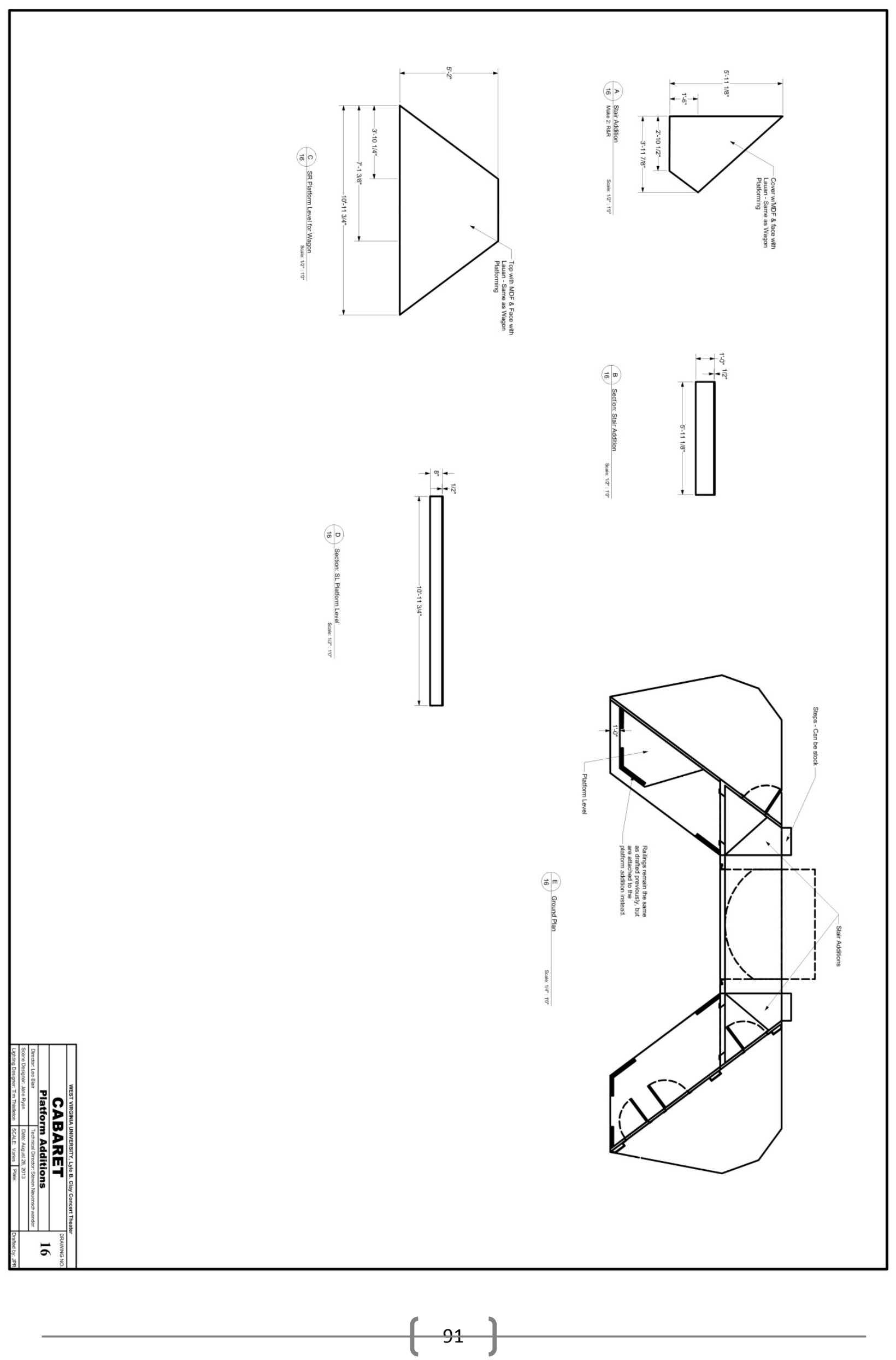


\title{
Appendix B: Final Show Photos
}

\author{
Act I
}

Pre-Show

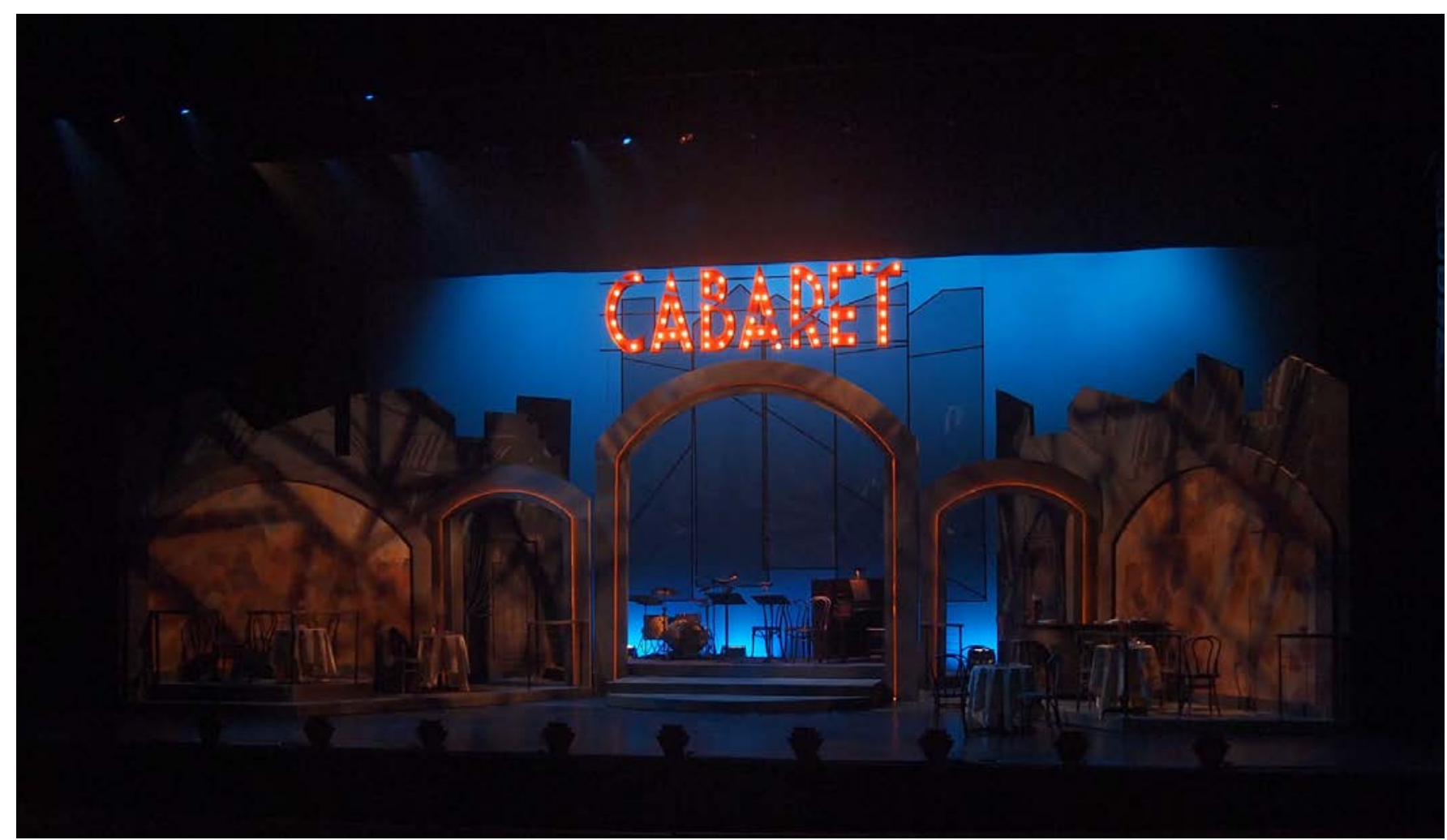


Willkommen - Emcee

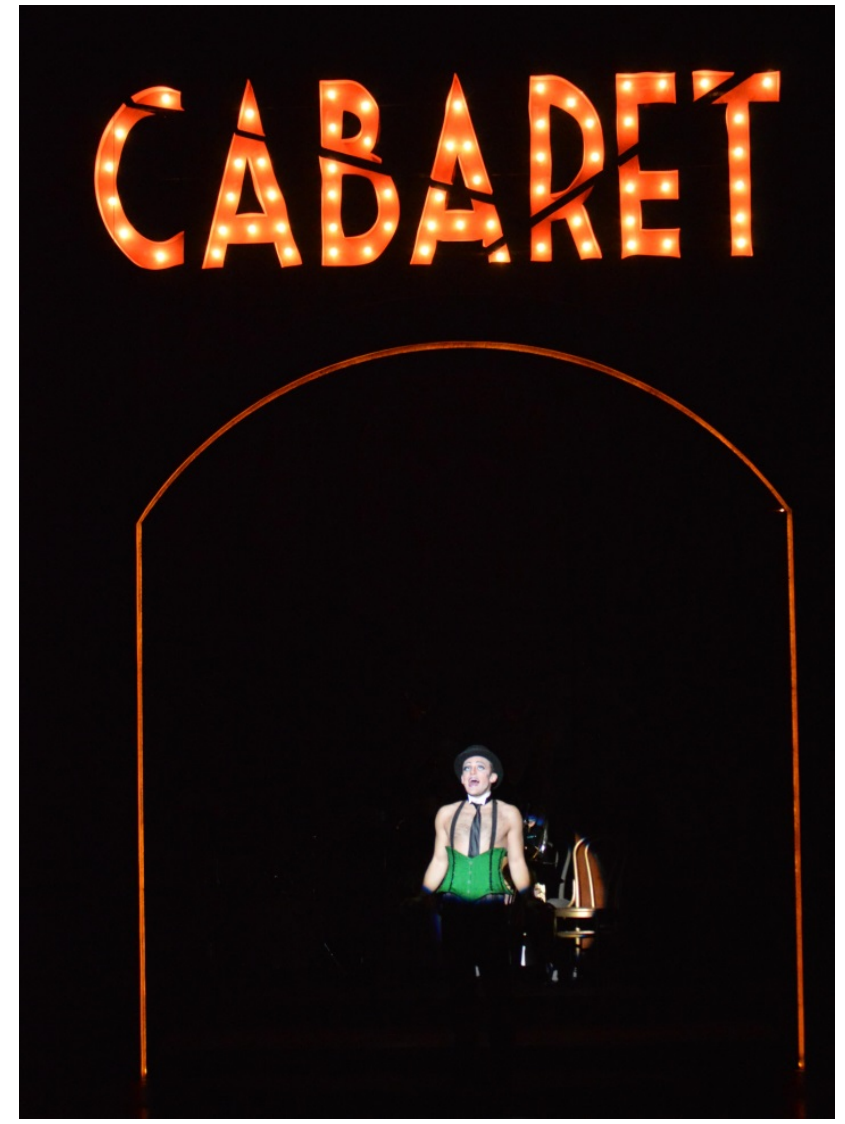

Willkommen - Emcee, Klub Girls, Stage Band

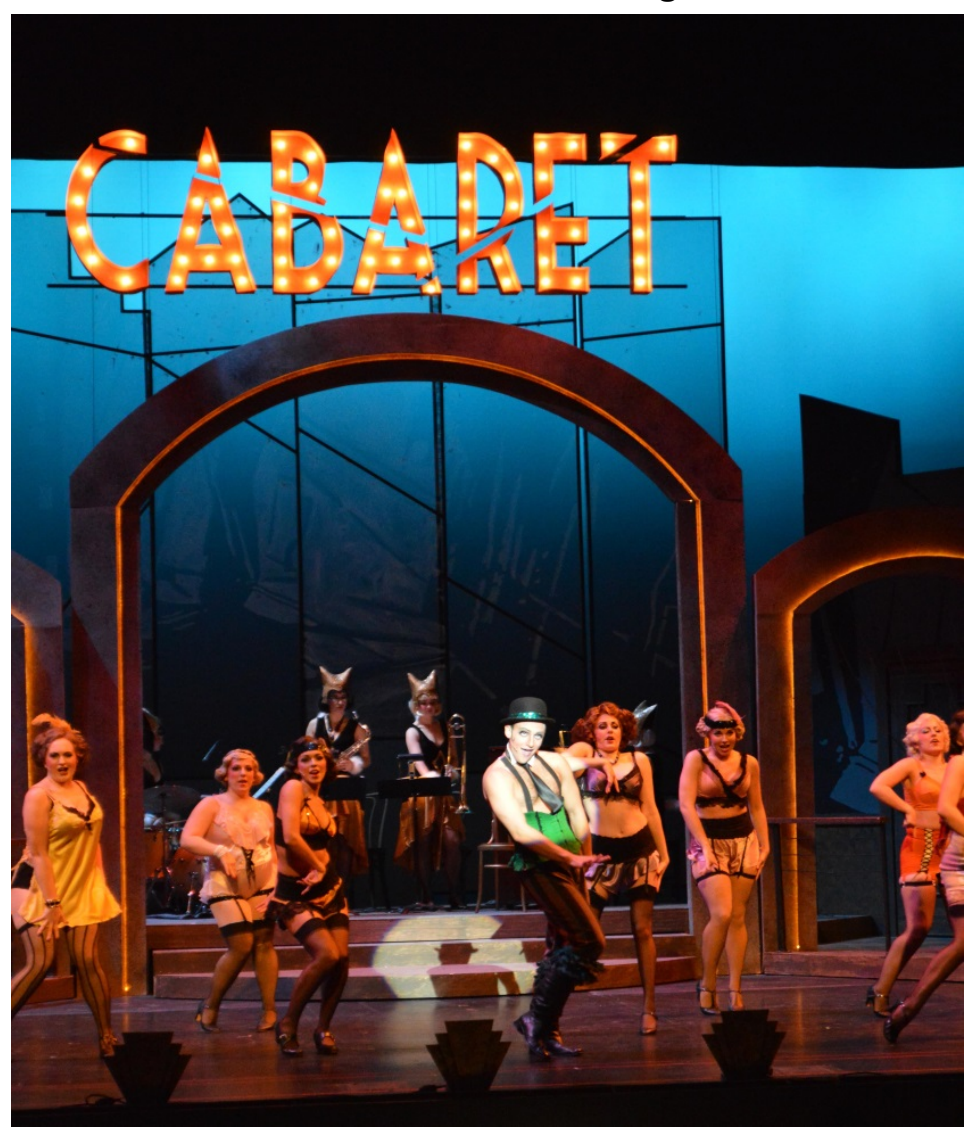

Cliff arrives in Berlin - Cliff, Ernst, Emcee

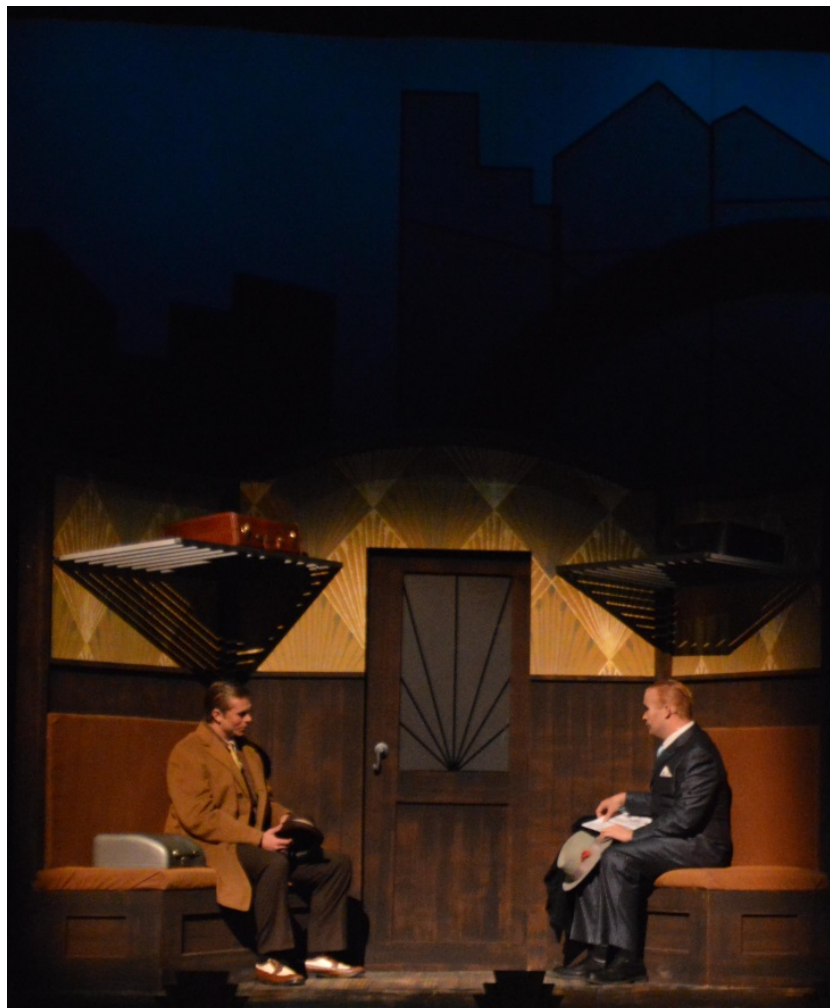


So What? - Cliff, Fraulein Schneider

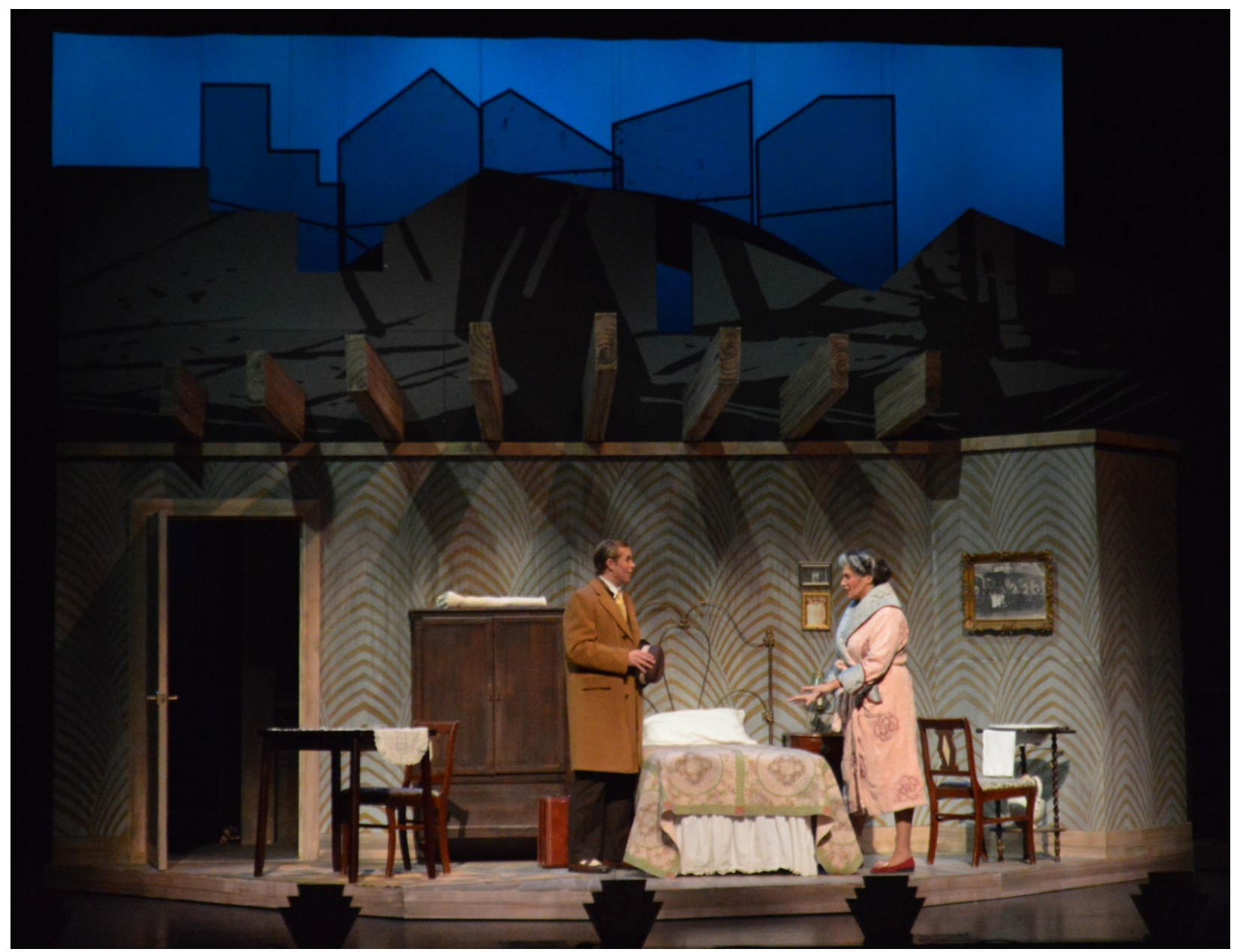

Telephone Song - Cliff, Klub Patron

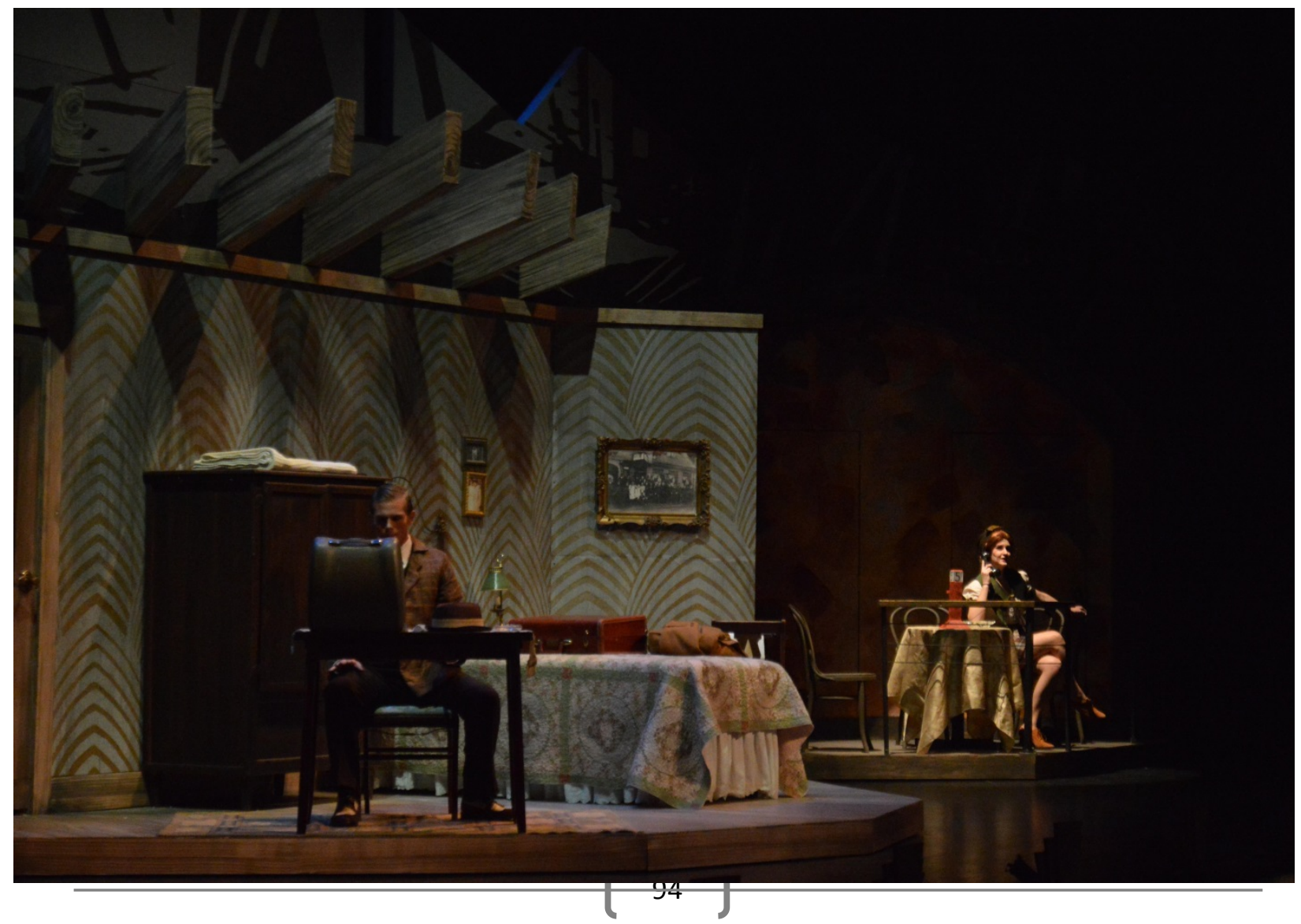


New Year's at the Kit Kat Klub - Emcee, Stage Band

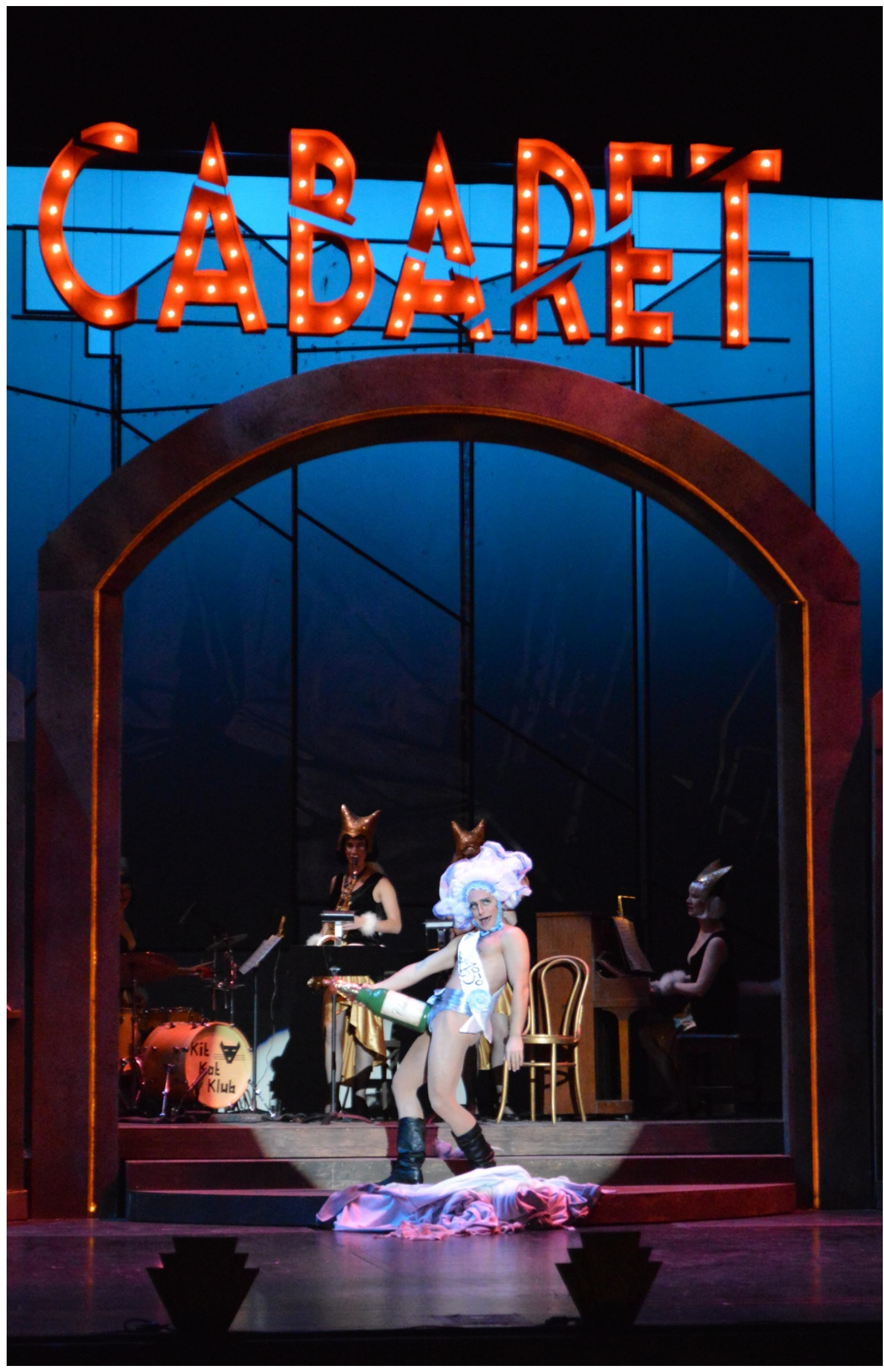


Don't Tell Mama - Sally, Kit Kat Klub Girls, Patrons

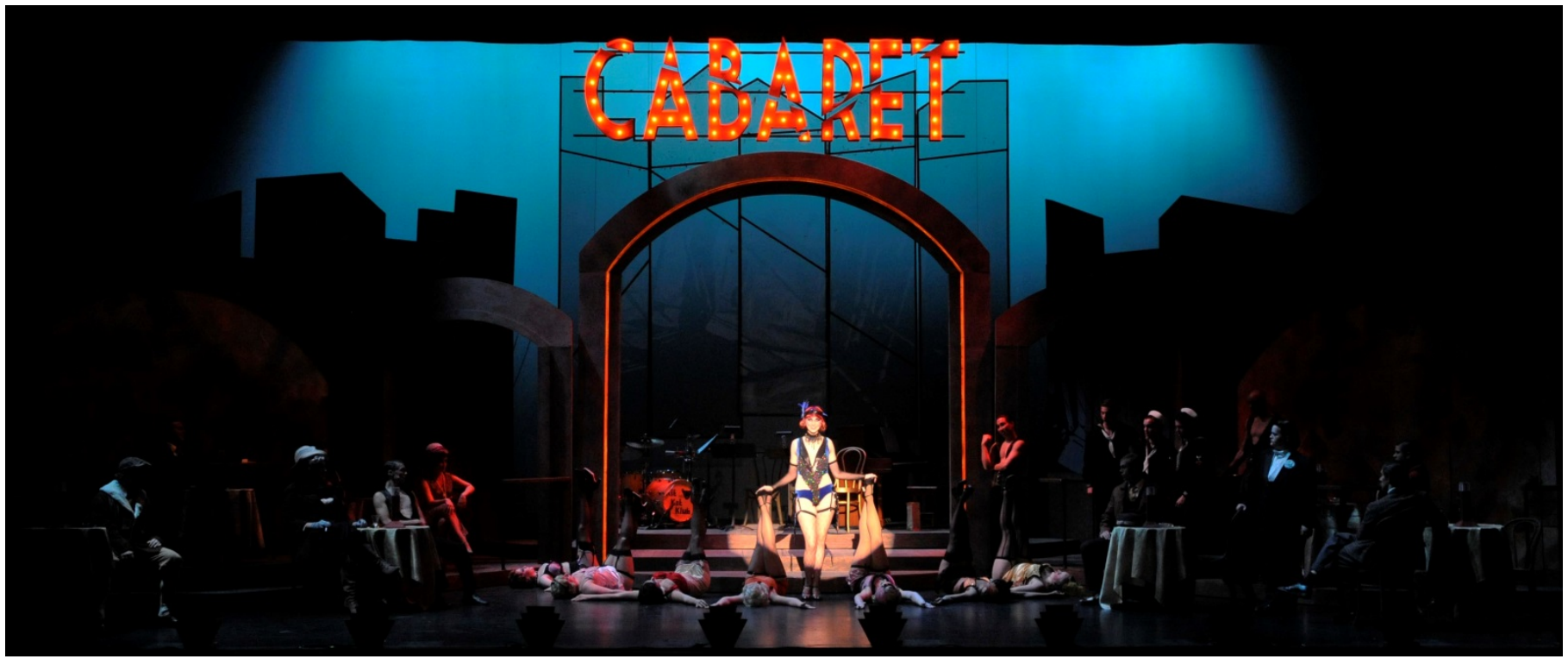

Telephone Dance - Kit Kat Klub Girls, Patrons

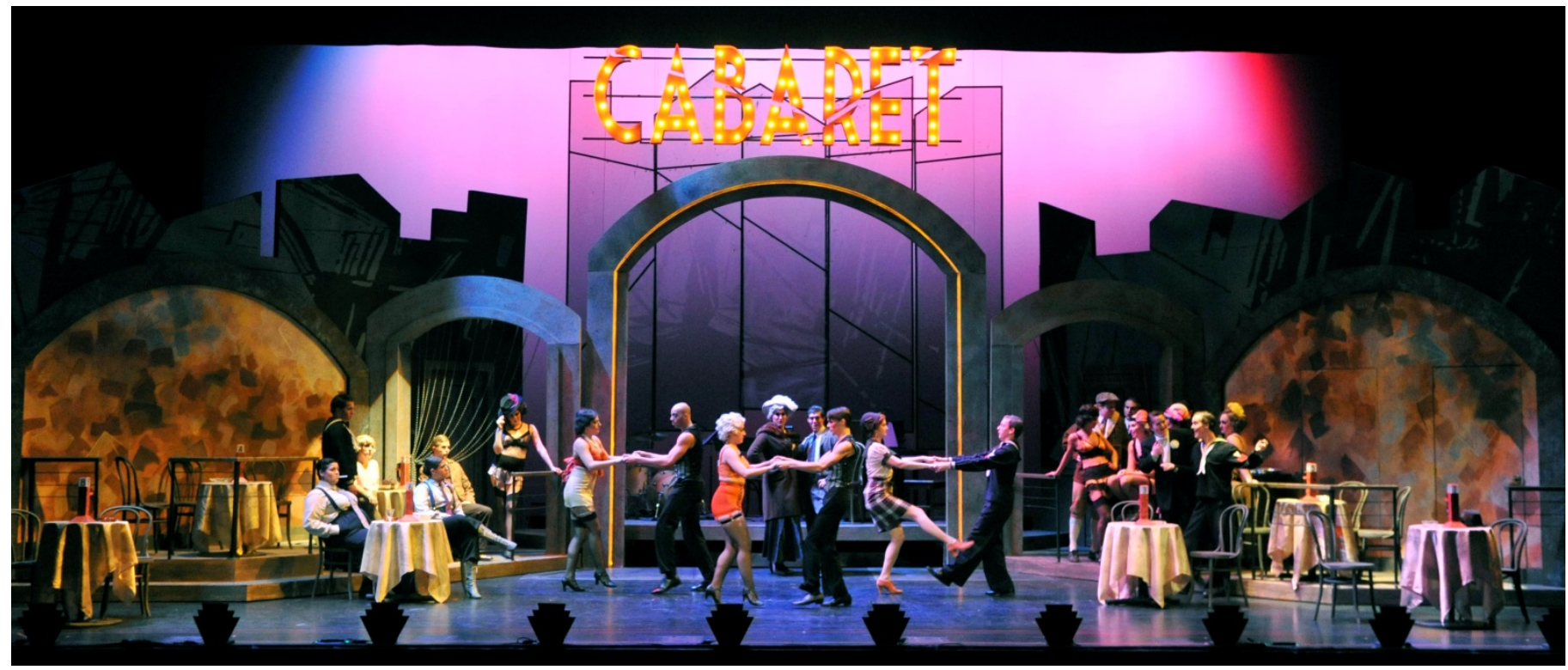


Perfectly Marvelous - Sally, Cliff

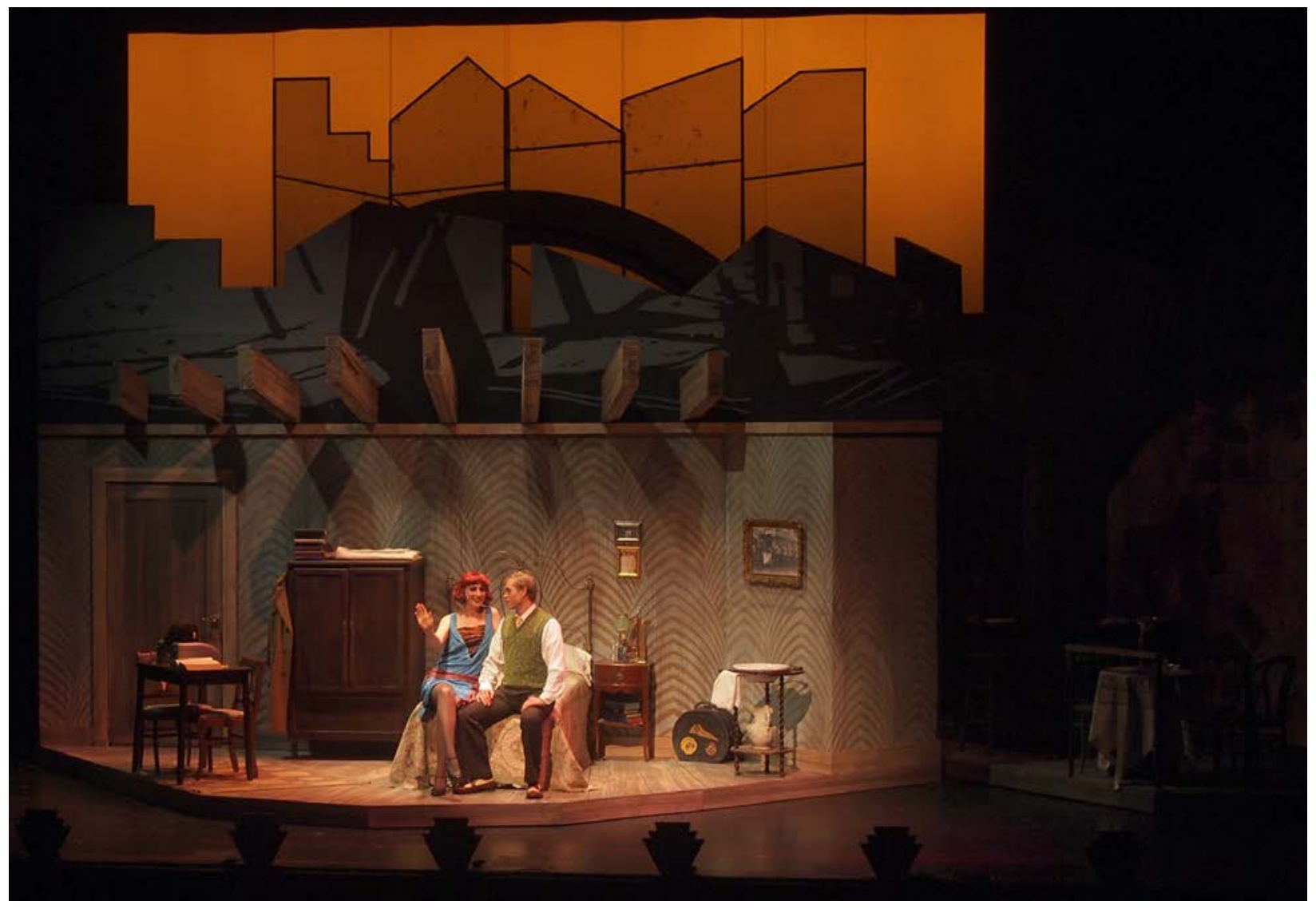

Two Ladies - Emcee, Kit Kat Klub Girls

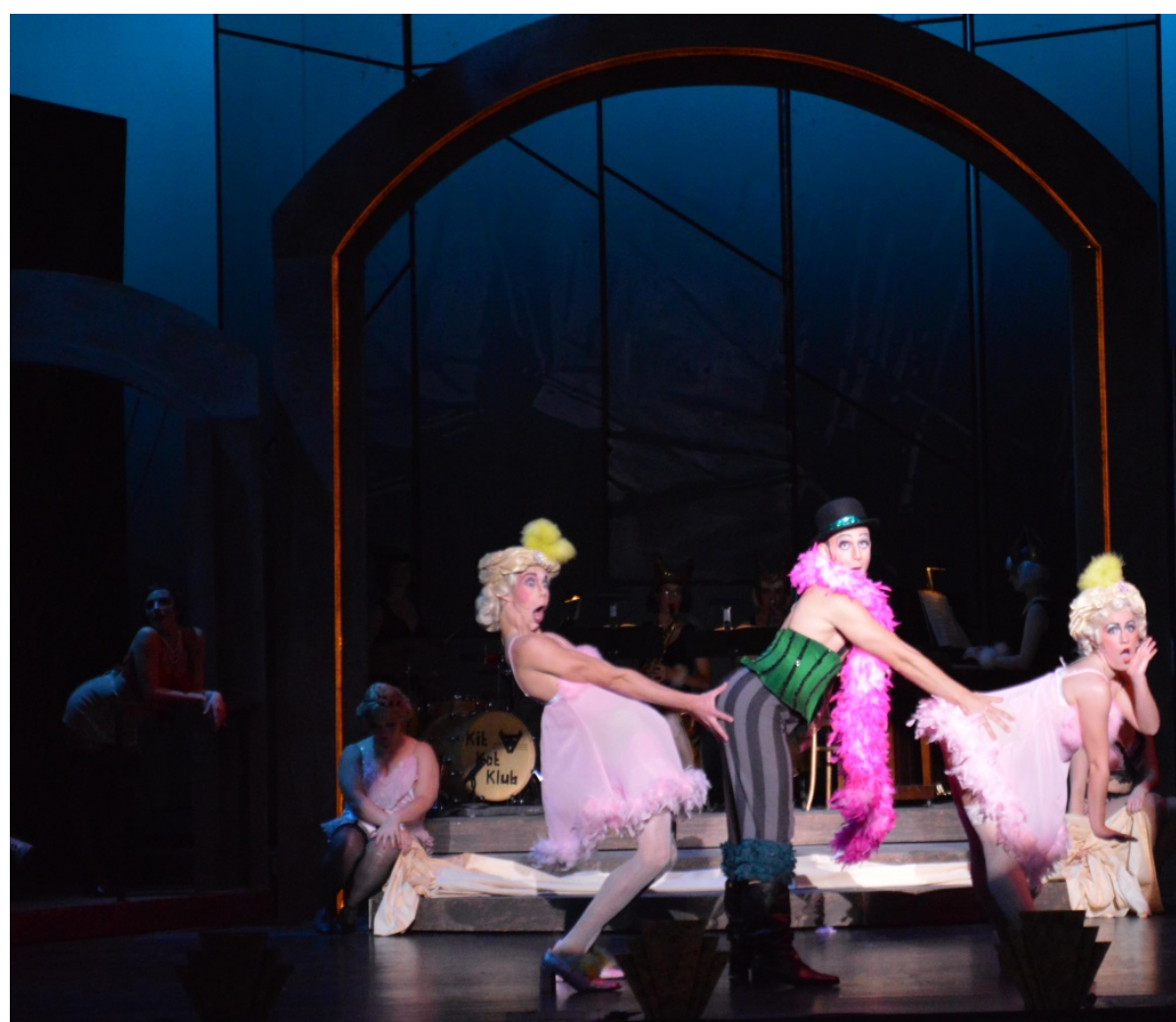


It Couldn't Please Me More - Fraulein Schneider, Herr Schultz

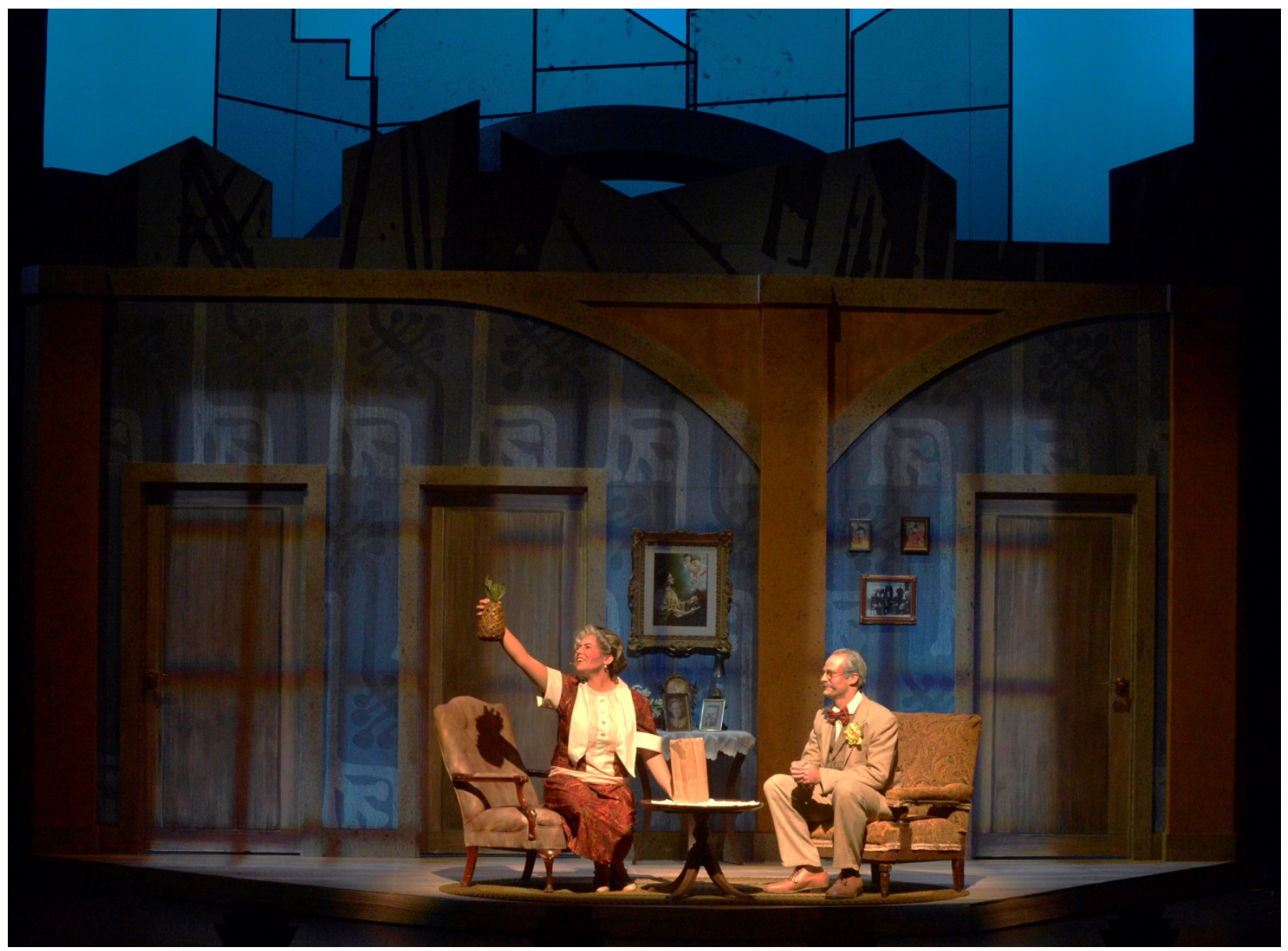

Tomorrow Belongs To Me - Nazi Youth, Emcee, Chorus of Waiters
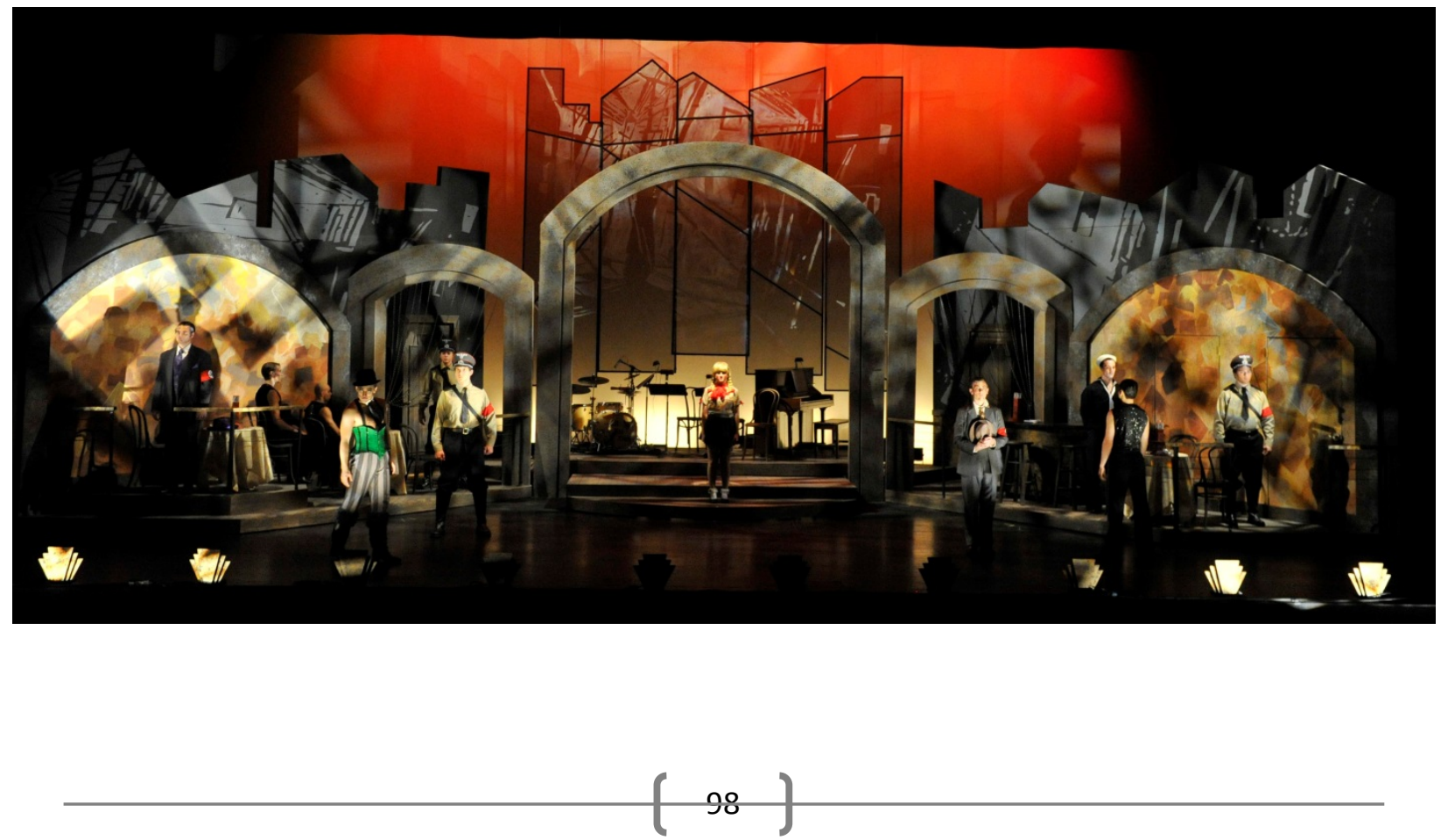
Don't Go - Cliff, Sally

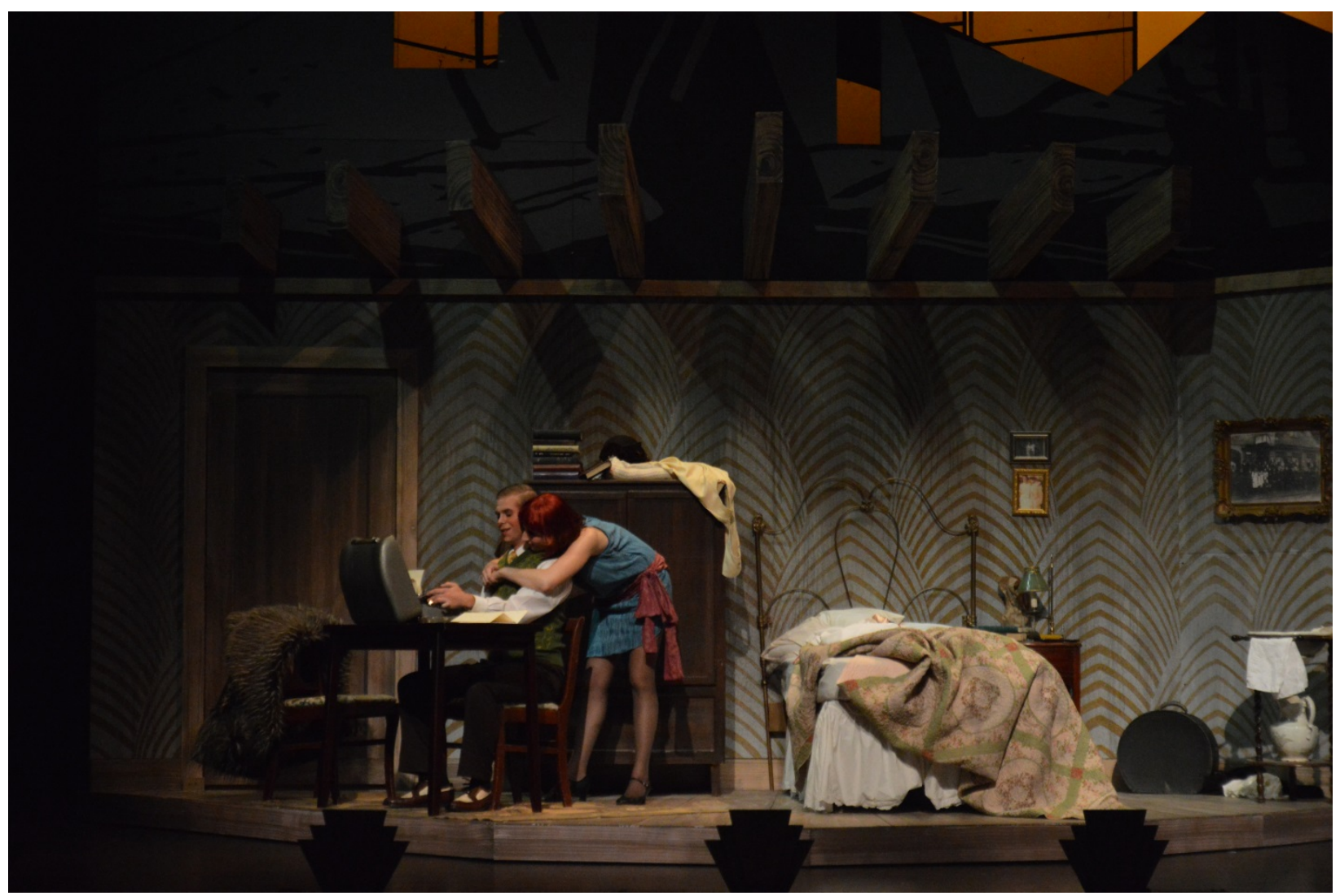

The Money Song - Emcee, Kit Kat Klub Girls, Patrons

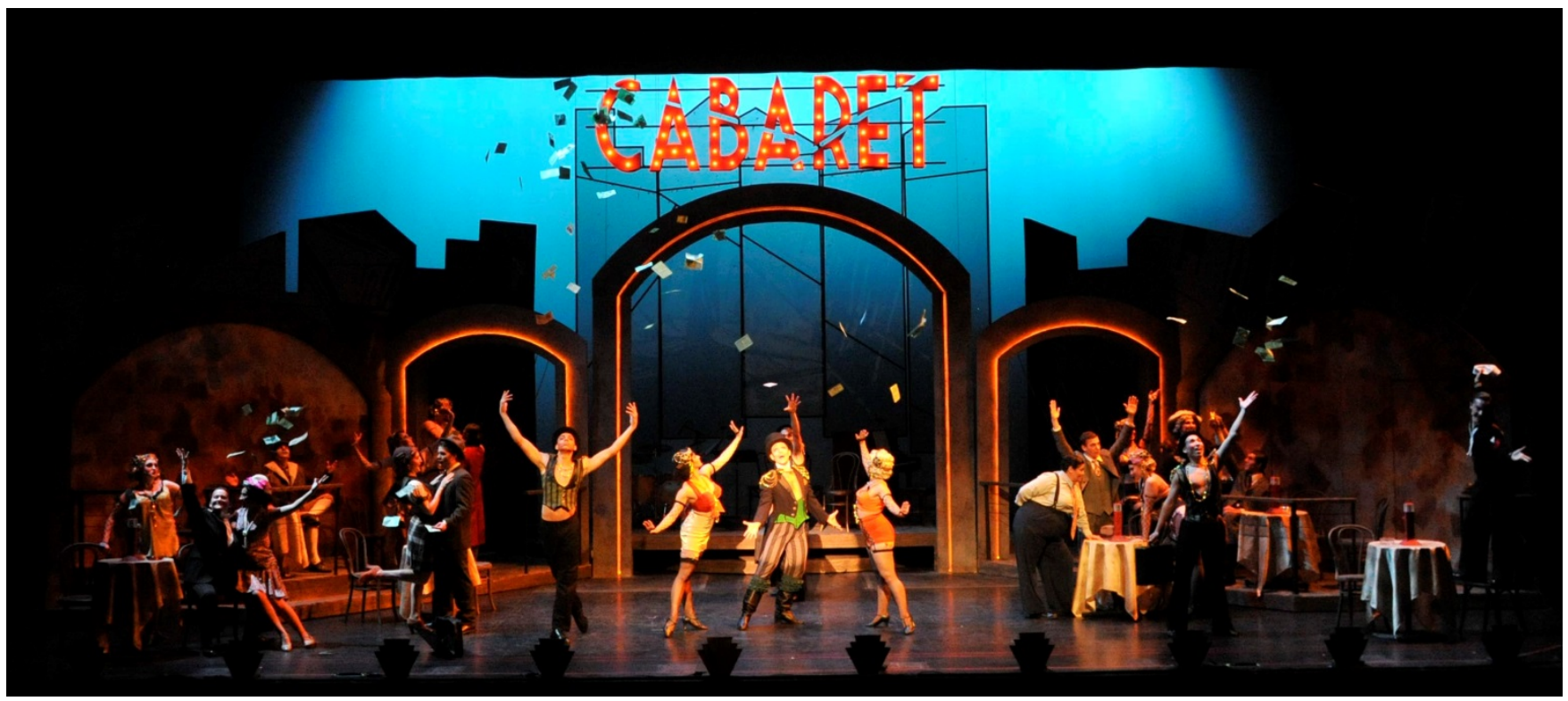


Tomorrow Belongs to Me Reprise - Company

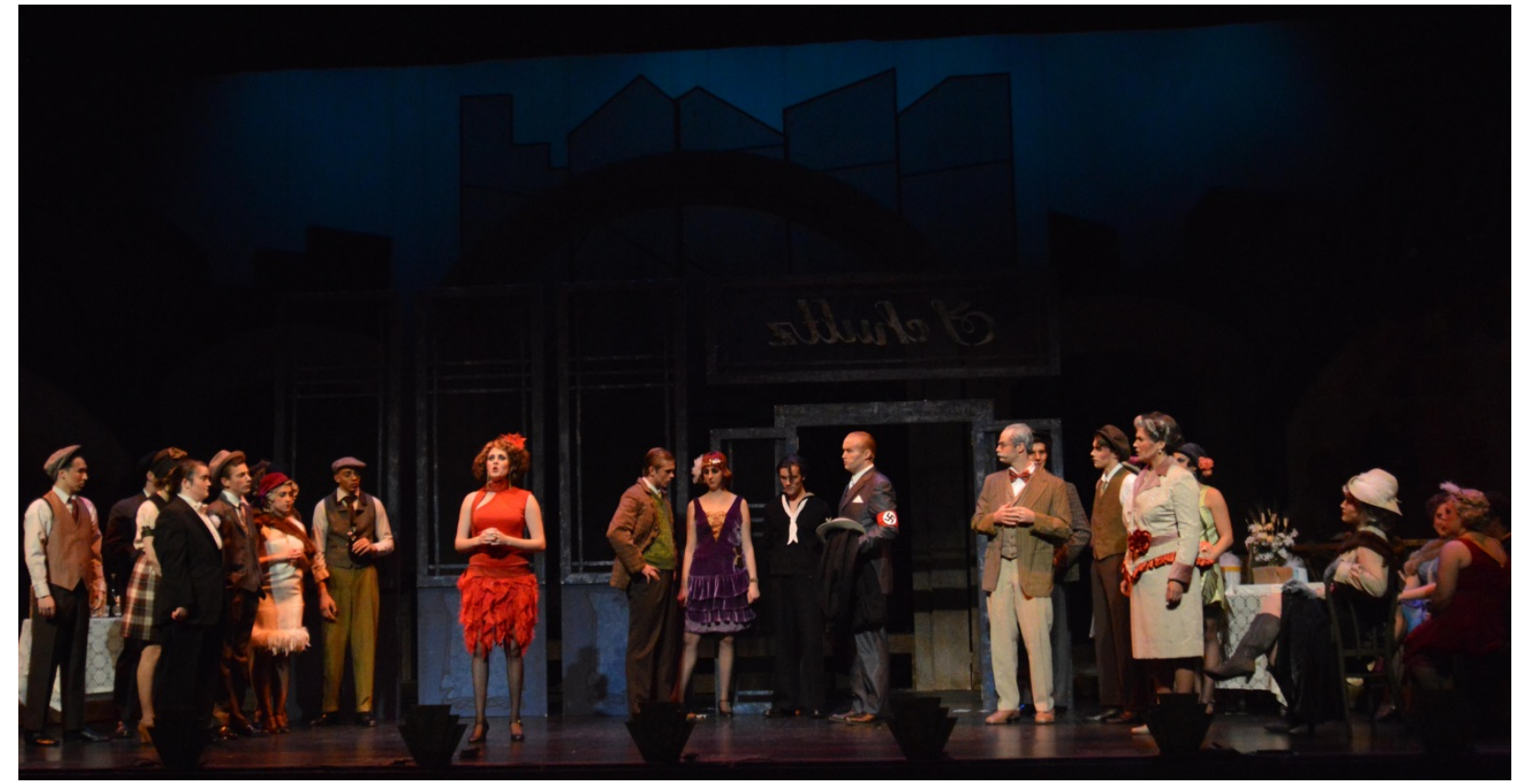


Act 2

Entr'acte - Stage Band

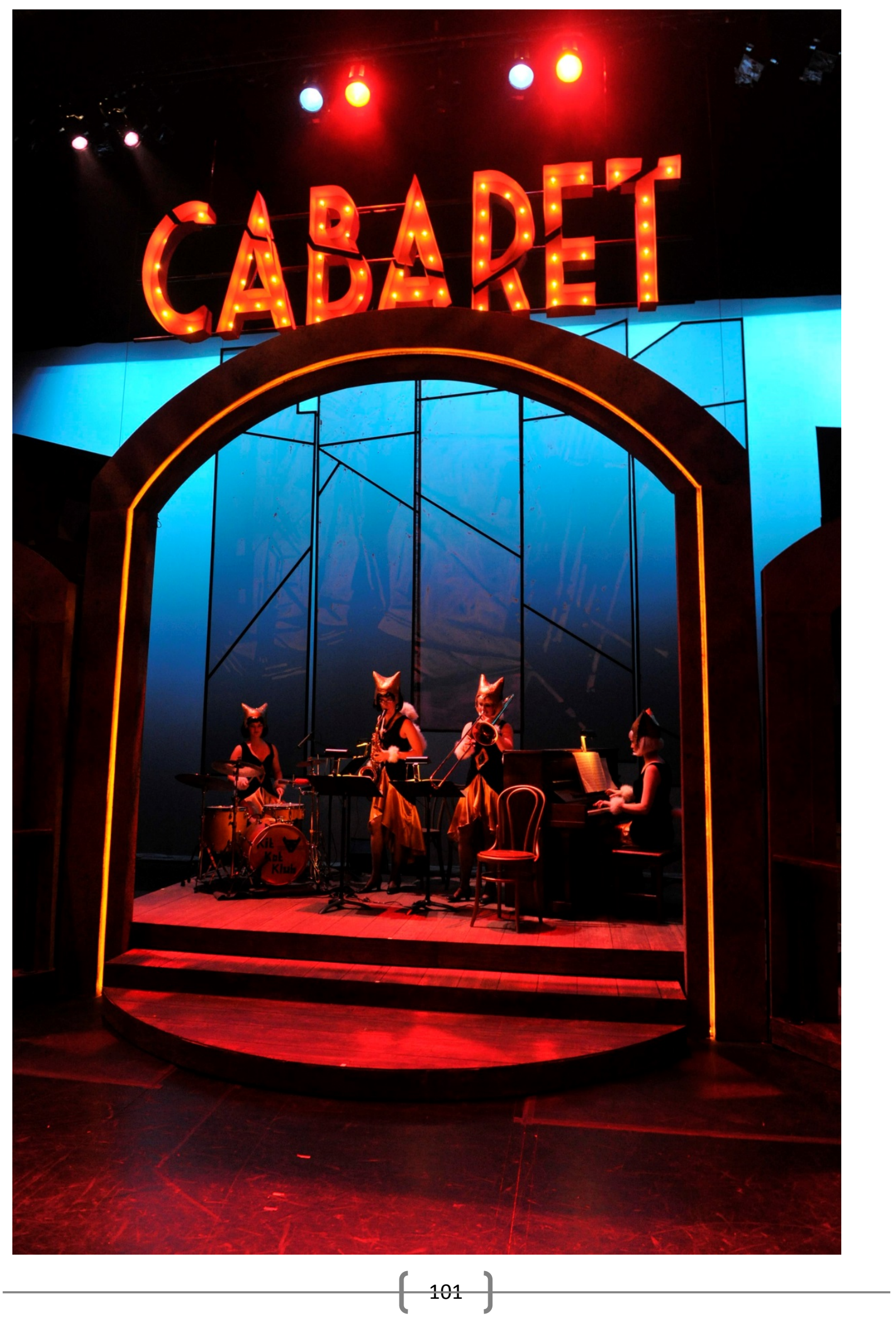


If You Could See Her - Emcee, Gorilla
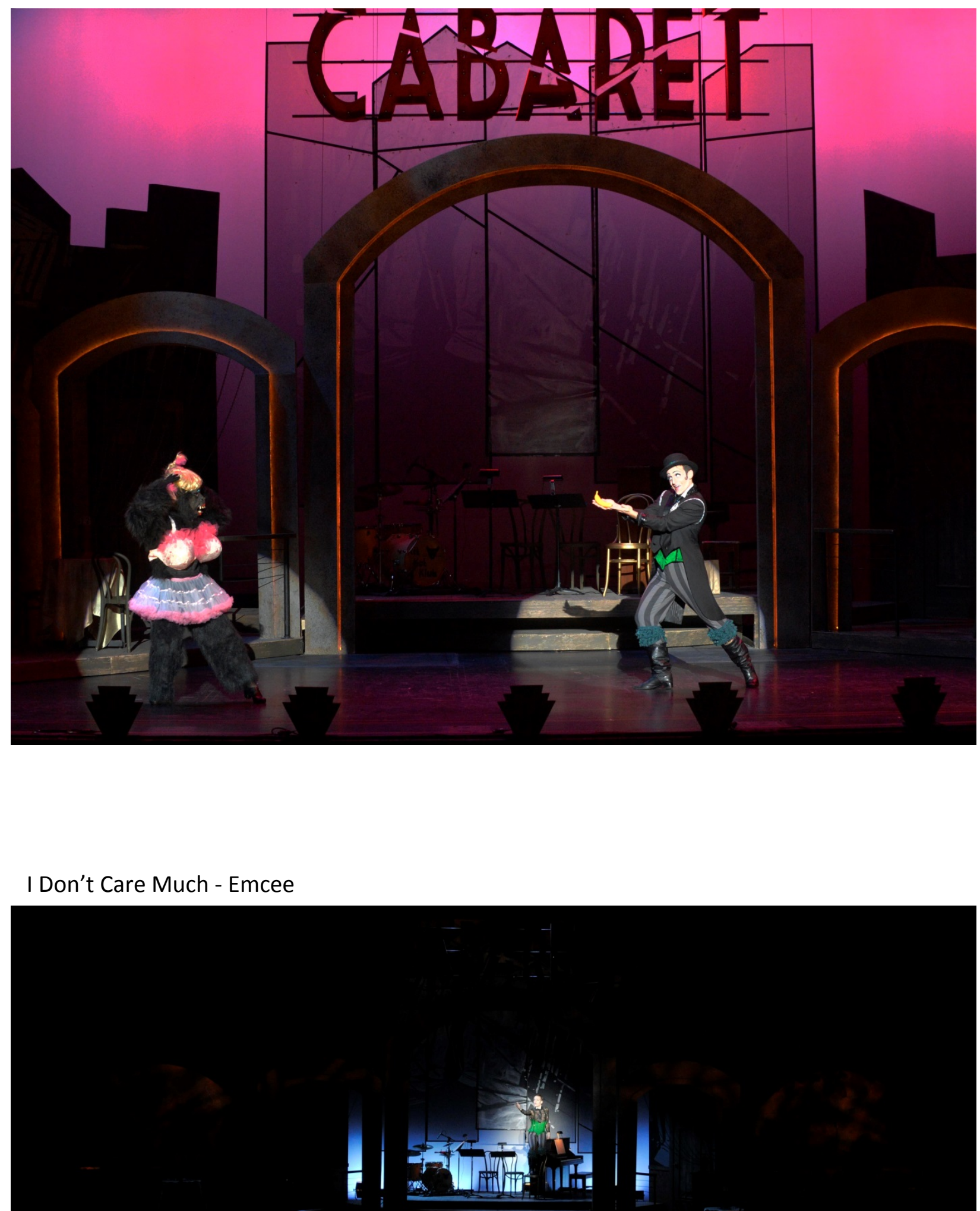

tif 
Cabaret - Sally, Club Patrons

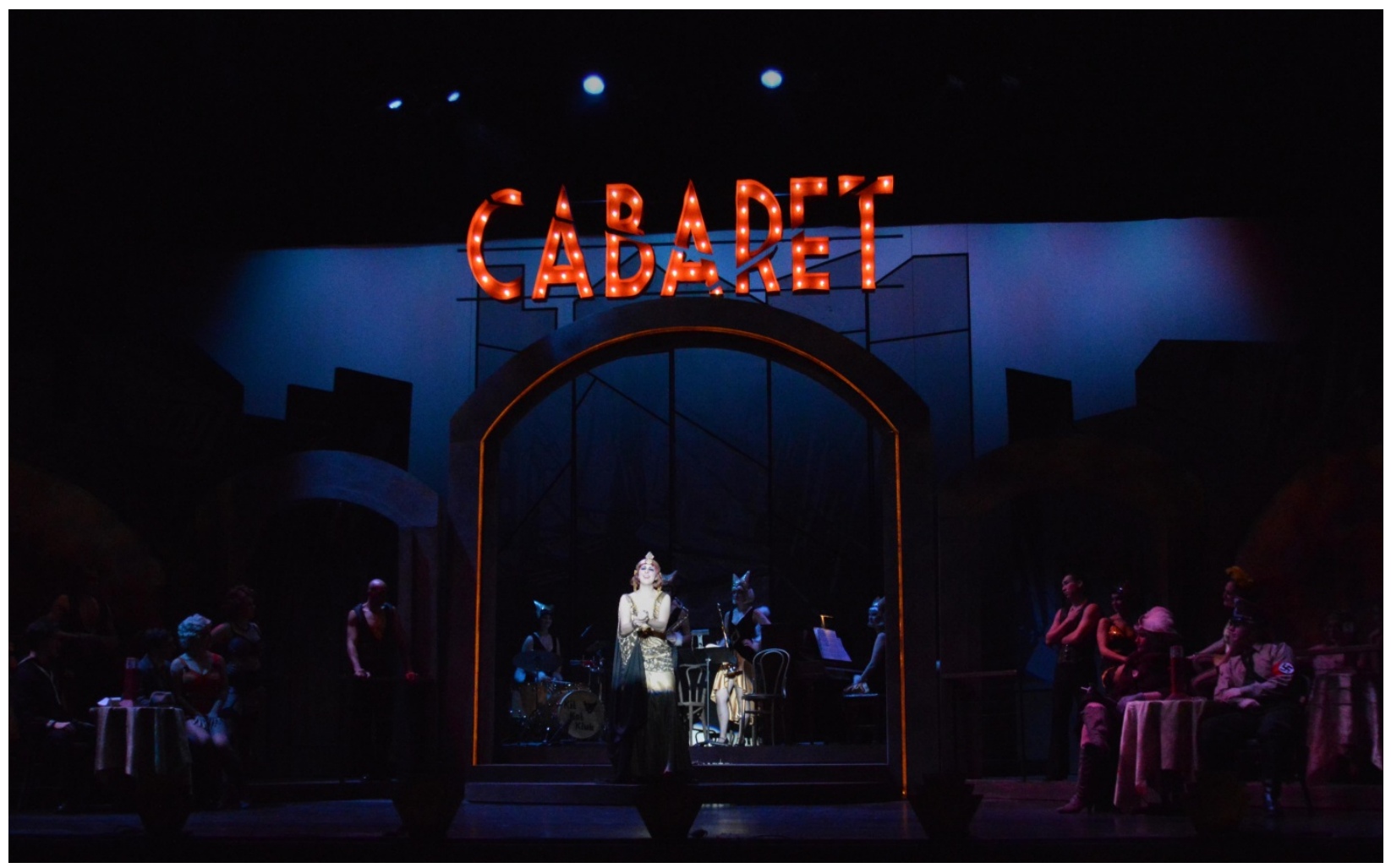

Finale - Company

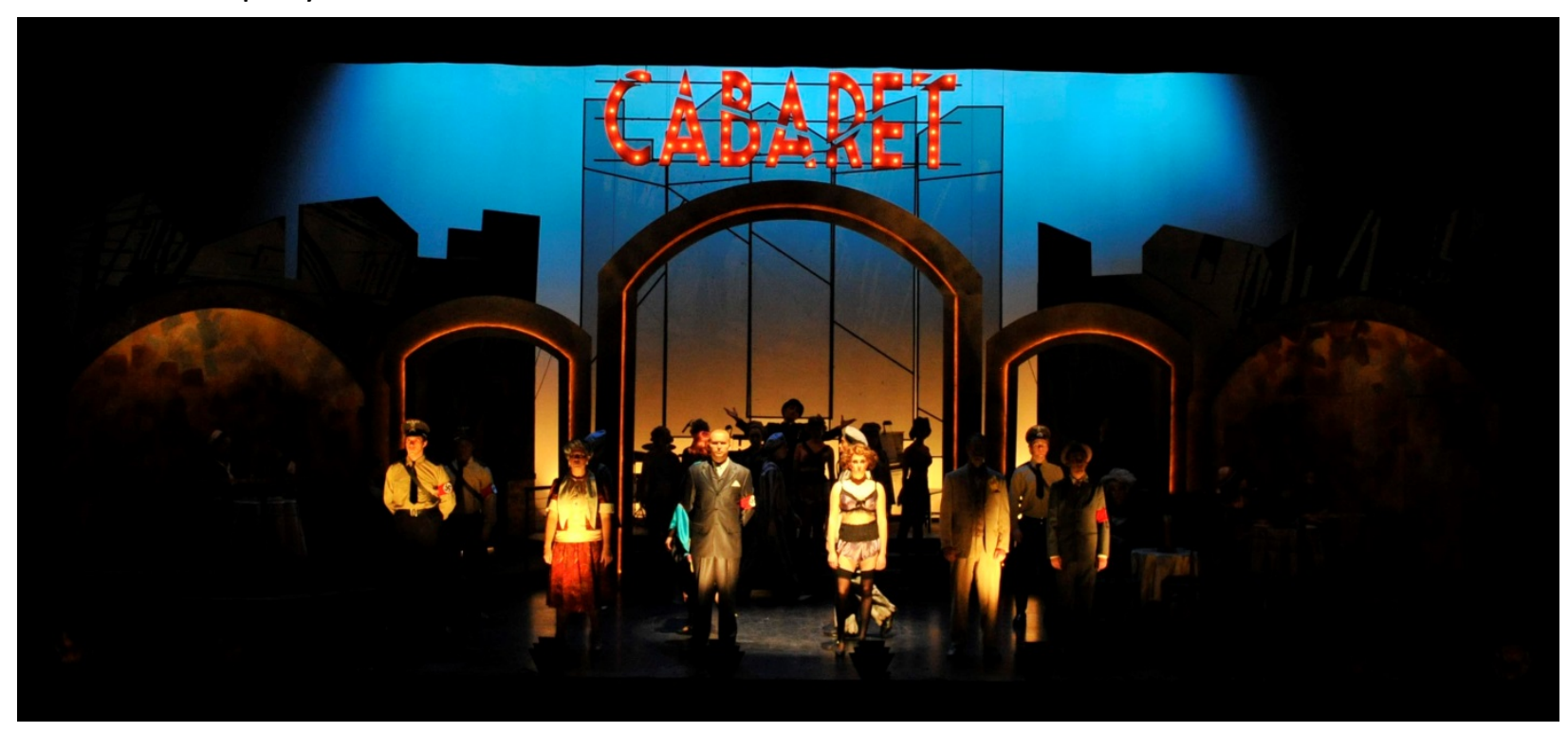




\section{Bibliography}

Robinson, Michael, and Rosalind Ormiston. Art Deco: The Golden Age of Graphic Art \& Illustration. London: Flame Tree Publishing Limited, 2008.

"Secret Garden: An abandoned cabaret theater is discovered in Berlin." WONDERLANCE Digital Magazine. WONDERLANCE Ltd., 1 Jan. 2011. Web. 1 Jan. 2013. <http://www.wonderlance.com/dm_filmentertainment_secretgarden.html>. 